\title{
Review Article \\ Recent Developments in Environmental Photocatalytic Degradation of Organic Pollutants: The Case of Titanium Dioxide Nanoparticles-A Review
}

\author{
Mphilisi M. Mahlambi, ${ }^{1}$ Catherine J. Ngila, ${ }^{1}$ and Bhekie B. Mamba $^{2}$ \\ ${ }^{1}$ Department of Applied Chemistry, University of Johannesburg, P.O. Box 17011, Doornfontein 2028, South Africa \\ ${ }^{2}$ Nanotechnology and Water Sustainable Unit, College of Science, Engineering and Technology, University of South Africa, \\ Florida Campus, Johannesburg 17025, South Africa
}

Correspondence should be addressed to Mphilisi M. Mahlambi; mmahlambi@yahoo.co.uk

Received 29 April 2015; Revised 29 July 2015; Accepted 5 August 2015

Academic Editor: Xin Zhang

Copyright (C) 2015 Mphilisi M. Mahlambi et al. This is an open access article distributed under the Creative Commons Attribution License, which permits unrestricted use, distribution, and reproduction in any medium, provided the original work is properly cited.

\begin{abstract}
The presence of both organic and inorganic pollutants in water due to industrial, agricultural, and domestic activities has led to the global need for the development of new, improved, and advanced but effective technologies to effectively address the challenges of water quality. It is therefore necessary to develop a technology which would completely remove contaminants from contaminated waters. $\mathrm{TiO}_{2}$ (titania) nanocatalysts have a proven potential to treat "difficult-to-remove" contaminants and thus are expected to play an important role in the remediation of environmental and pollution challenges. Titania nanoparticles are intended to be both supplementary and complementary to the present water-treatment technologies through the destruction or transformation of hazardous chemical wastes to innocuous end-products, that is, $\mathrm{CO}_{2}$ and $\mathrm{H}_{2} \mathrm{O}$. This paper therefore explores and summarizes recent efforts in the area of titania nanoparticle synthesis, modifications, and application of titania nanoparticles for water treatment purposes.
\end{abstract}

\section{Introduction}

The South African National Water Act (Act number 36 of 1998) specifically states that water resources must remain fit for use on a sustainable basis and that their quality must be constantly monitored [1]. Therefore the availability of water should be based not only on the quantity but also on the quality of the available water [2]. However, due to agricultural, industrial, and domestic activities the quality of river water or groundwater continues to deteriorate due to pollution by hazardous materials $[3,4]$. Water pollution is defined as the direct or indirect introduction of substances into the water bodies. These pollutants may be harmful to human health or the quality of aquatic ecosystems thus affecting the use of amenities and other legitimate uses of water [1].

The sources of water pollution are categorised as either a point source or nonpoint source (diffuse sources). Point source water pollution occurs when the polluting substance is emitted directly into the water system, for example, a pipe that spews sewage directly into a river, while nonpoint source (NPS) pollution refers to diffuse contamination which occurs when pollutants enter a water system through runoff, for example, when fertiliser is washed into a river by surface runoffs. Water pollutants can be classified as physical (odour, colour, solids, or temperature), biological (pathogens), or chemical (organic or inorganic compounds) [1, 2, 5-9]. Organic pollutants are of more concern than the other types because of their carcinogenic and mutagenic effects even after exposure to minute concentrations $[10,11]$.

1.1. Organic Pollutants. Organic contaminants have become of more concern due to the inability of conventional water-treatment technologies to completely decompose these contaminants in aqueous media $[12,13]$. The ubiquitous appearance of organic contaminants in sewage effluents, groundwater, drinking water, and sludge poses a significant 
threat to humans and aquatic organisms [14]. Volatile organic compounds (VOCs) are known to be toxic and carcinogenic and have been implicated in the depletion of the stratospheric ozone layer while also contributing to global warming [10, 15]. These pollutants have been reported as being mutagenic and hence are responsible for the emergence of antibiotic resistance bacteria and genes [16].

Some organic pollutants are referred to as persistent organic pollutants (POPs) because when they enter the environment, they do not readily break down and may remain there for very long periods of time, for example, polychlorinated biphenyls (PCBs), and may enter the food chains and accumulate to levels detrimental to organisms that are high up in the food chain [17]. Also organic pollutants are a serious threat because they can be transported from the source of contamination through air as vapour or as dust particles by water currents or sediments and released in a new environment [17]. Some of these organic pollutants eventually contaminate groundwater and surface waters; however, groundwater contamination is likely to be the primary source of human contact with these toxic chemicals [18]. Generally, exposure to organic contaminants could be through breathing, through ingestion, through drinking, or by skin contact.

1.2. Natural Organic Matter. Natural organic matter (NOM) is an agglomeration of organic compounds that naturally occur when animal and plant material break down [19-21]. NOM consists of a wide range of compounds with diverse chemical properties (due to geographic origin and age of the decomposing organism) and occurs in all natural water sources $[20,22,23]$. NOM components are a heterogeneous mixture of complex organic materials which consists of both hydrophilic and hydrophobic components. The hydrophilic components are microbial by-products and contain a higher proportion of aliphatic carbon and nitrogenous compounds with relatively high charge density such as amino acids and proteins as well as polysaccharides [22, 24, 25]. Humic substances (HS) constitute the more hydrophobic fraction of NOM and exhibit relatively high specific ultraviolet absorbance (SUVA) values due to the presence of a relatively large proportion of aromatic carbon, phenolic structures, and conjugated double bonds [5, 19, 21, 22, 24, 25].

Due to the complexity of NOM no single tool can give its definitive structural or functional information. Nondestructive spectroscopic techniques appear to be the most useful analytical techniques for NOM characterisation [20]. Treatment options for the removal of NOM include coagulation, the use of magnetic ion-exchange resins, activated carbon, membrane filtration, and advanced oxidation processes [22]. Characterisation of the structure and reactivity of NOM is vital because its presence creates problems in the quality of drinking water as well as in water-treatment processes [20, 26]. The presence of NOM results in an increased coagulant and disinfectant dosage resulting in increased sludge. It also increases biological growth in water-distribution networks and may also result in increased levels of heavy metal complexes and adsorbed organic pollutants [22]. Furthermore, the presence of NOM causes membrane fouling as well as aesthetic and malodour problems in water. The organic acids that result from the oxidation of NOM have the capability to corrode turbines and engineering systems and this affects transportation of contaminants $[19,22,27,28]$. Thus, understanding the impact of NOM in water-treatment processes is vital for human health and water-treatment plants as well as industrial processes where pure water is a prerequisite.

1.3. Disinfection By-Products. In the water-treatment processes, NOM may have adverse effects since it may react with disinfectants (e.g., chlorine or chloramines) resulting in the formation of disinfection by-products (DBPs), many of which are either carcinogenic or mutagenic $[5,25,26$, 29]. For example, haloacetic acids (HAAs) are a component of DBPs that are considered harmful to human health. These have been found to result in impaired reproductive and developmental retardation when tested on laboratory animals [24, 30-33]. Also, trihalomethanes (THMs) have been classified as possible carcinogens to humans $[30,32,34$, 35]. Nitrosamines are another group of DBPs, formed due to the reaction of NOM with disinfectants that have been reported to be a threat to human life due to its carcinogenicity [32, 36-38].

1.4. Industrial Effluents. Industrial development is directly related to the release of various toxic pollutants into the environment, especially to aqueous streams, and these pollutants are harmful and hazardous to the environment [12, 39-41]. Prevention of industrial pollution is currently a major focus of environmentalists and therefore treatment of industrial effluents before disposal into the ecosystem is imperative to protect human life and environmental quality [3, 40, 42]. Thus, a constant effort to protect water resources is being made by various government and nongovernmental organisations (e.g., US EPA, WHO, and DWAF) through the introduction of increasingly strict legislation covering pollutant release into the environment, with particular emphasis on liquid industrial effluents [5, 40,43,44]. There are major types of industries in the industrial complex, for example, pulp and paper mills, food, pharmaceutical, electroplating, textile, photographic, mining, and agriculture, to mention just a few, which do not generate uniform waste streams; industrial effluents are complex mixtures of chemical and biological compositions that have various environmental impacts depending on the source of the toxicant $[45,46]$.

1.4.1. Textile Industry Effluents. Textile-processing industries form the economic backbone of most developing countries. Effluents from textile industries are characterised by a variety of chemicals generated from the dyeing, bleaching, and washing processes $[47,48]$. Wastewaters discharged from textile industries are a serious environmental threat due to their characteristic high colour, fluctuating $\mathrm{pH}$, malodour, high biological oxygen demand (BOD) and chemical oxygen demand (COD), acids, and alkalis as well as various heavy metals that breach environmental standards [48-50]. Dyes are soluble in water and even a small amount of dye is highly visible and reduces the transparency of water bodies $[49,51]$. 
TABLE 1: Molecular structure and chemical properties of Rhodamine B [6, 52-54].

Molecular structure

Also, dyes can be mutagens and carcinogens $[49,50]$, and thus they need to be removed from industrial effluents.

It is estimated that about $1 \%$ to $20 \%$ of the total world production of dyes is lost to the environment during synthesis and dyeing processes. These textile effluents are an environmental burden as they contain a large amount of azoic, anthraquinonic, and heteropolyaromatic dyes $[6,50]$. The discharge of these highly pigmented synthetic dyes to the ecosystem causes aesthetic pollution, eutrophication, and perturbations in aquatic life as they hinder light penetration resulting in decreased photosynthesis [48, 49, 51]. Therefore textile wastewaters need to be treated to acceptable levels to meet the national discharge standard before being discharged to the environmental ecosystem.

1.4.2. Rhodamine B. Rhodamine $\mathrm{B}$ ( $\mathrm{Rh} \mathrm{B})$ is a type of triphenylmethane dyes. Triphenylmethane (TPM) dyes are extensively used in textile, printing, food, photographic, and cosmetic industries [52]. TPM dyes can persist for long periods in the aquatic environment because they are resistant to chemical and biological (bacterial) attacks. Rh B is a common dye in the TPM family, which contains four (4) $N$-ethyl groups at either side of the xanthene rings (Table 1). It has achieved its prominent use due to its good stability as a laser material and is one of the major sources of pollution in the textile and photographic industry effluent streams [53]. Also, although Rhodamine B is a highly phosphorescent (fluorescent) dye, its toxicity is not dependent on the synergic effect of visible light $[52,54]$. As a dye in the TPM family (i.e., azoic, anthraquinonic, and heteropolyaromatic dyes), the presence of $\mathrm{Rh} \mathrm{B}$ in the ecosystem causes aesthetic pollution, eutrophication, and perturbations in aquatic life $[6,50,52,53]$.

1.4.3. Other Industrial Effluents. Other sources of industrial pollution are from surface treatment (mechanical and chemical surface-finishing processes), thermal power stations, and agricultural activities, to name but a few. Effluents originating from surface-treatment processes contain both organic and metal pollution from the washing and rinsing of process baths [43]. Fly ash is the by-product of combustion in thermal power plants using coal and lignite and is mainly used as landfills [39]. However, studies to characterise leachate originating from these landfills have indicated that leachates contain hazardous pollutants like arsenides, PCBs, and sulfanilamides [14, 16, 55, 56]. Commonly used pesticides from agricultural activities (either domestic or large commercial scale) have high recalcitrant organic groups and hence are extremely difficult to break down through normal degradation $[2,38,42,57]$. Also, the use of nitrogencontaining fertilisers causes acidification and eutrophication of ecosystems due to leaching $[44,58,59]$. These nitrogencontaining pollutants from agricultural activities are usually intermediates to the formation of refractory organic pollutants [44].

\section{Refractory Organic Pollutants}

Degradation of refractory organic pollutants is a challenge because these pollutants cannot be degraded using the current water-treatment technologies. They are resistant to aerobic microbial degradation in conventional biological treatment processes and the natural environment $[44,60,61]$. High-molecular-weight organics are the typical refractory pollutants. The presence of refractory pollutants in industrial wastewaters causes problems in the water-treatment system [46]. These pollutants cause biomass poisoning and die-off in conventional biological water-treatment systems. Other techniques such as flocculation, precipitation, or reverse osmosis require posttreatment to dispose of the pollutants while the use of chemical techniques either fails to adequately remove these organic pollutants or results in the formation of DBPs [28, 33, 36, 44, 62].

Current water-treatment technologies are designed to deal with either organic or inorganic pollutants in an aqueous medium, but not both. In addition, due to the diversity and varying chemical properties of organic pollutants these technologies fail to remove pollutants to the required levels. Furthermore, the presence of NOM in water-treatment processes may have adverse effects since it may react with disinfectants (e.g., chlorine or chloramines) and result in the formation of DBPs. Therefore the development of techniques that can remove both contaminants simultaneously without the production of DBPs would be ideal. Nanocatalysts have shown the ability to cost-effectively mineralise recalcitrant organic pollutants and reduce metal ions in aqueous media producing innocuous products, that is, $\mathrm{H}_{2} \mathrm{O}$ and $\mathrm{CO}_{2}$, and 
zero-valent metals, respectively. The approaches that we have undertaken in our laboratories in an attempt to address these problems are also described in this review.

\section{Advanced Oxidation Processes (AOPs)}

Due to the aforementioned limitations of the conventional water-treatment methods, there is an ongoing research interest to develop more efficient and environmentally friendly systems for the treatment of recalcitrant organic pollutants. Advanced oxidation processes (AOPs) have demonstrated the capability to develop such a green system. AOPs provide an effective remediation for the treatment of water since they have the ability to completely degrade a variety of organic pollutants, oxidise heavy metals, and destroy microbial substances. Advanced oxidation processes exploit the high reactivity of hydroxyl radicals as the oxidation driving force resulting in the formation of benign by-products (i.e., $\mathrm{H}_{2} \mathrm{O}$ and $\mathrm{CO}_{2}$ ); hence they are environmentally friendly [41, 6367].

3.1. Supercritical Water Oxidation. Supercritical water oxidation (SCWO) is a technique that has been proven to destroy highly persistent organic pollutants without the production of harmful products. SCWO reactions are carried out above the critical point of water $\left(374^{\circ} \mathrm{C}\right.$ and $\left.22.1 \mathrm{MPa}\right)$ and at this point the volume of water is three times higher than at room temperature, with a density of $0.322 \mathrm{~g} \cdot \mathrm{mL}^{-1}$ and a dielectric constant of 5.3 [68-71]. A homogeneous single phase results when oxygen and organic compounds are dissolved in supercritical water $[69,71,72]$. SCWO has been studied in the degradation of nitrogenated compounds (e.g., pyridine, aniline, nitrobenzene, and ammonia), phenolic compounds, and radioactive wastes [70].

SCWO is regarded as an environmentally friendly process, because not only does it produce $\mathrm{CO}_{2}$ and $\mathrm{H}_{2} \mathrm{O}$ during oxidation, but also none of the $\mathrm{NO}_{x}$ and $\mathrm{SO}_{x}$ compounds are produced due to the relatively mild operating conditions $\left(340^{\circ} \mathrm{C}\right.$ to $400^{\circ} \mathrm{C}$ and $22.29 \mathrm{MPa}$ to $\left.25.33 \mathrm{MPa}\right)[69,71]$. However, during the degradation of halogenated hydrocarbons, the SCWO process is subject to corrosion problems due to the formation of acidic conditions as well as fouling problems due to the utilisation of neutralising processes and these are the major obstacles that have led to the noncommercialisation of SCWO [71, 73].

3.2. Wet Oxidation. Wet oxidation, also referred to as wet air oxidation (WAO), is used to oxidise organic and inorganic substances, in either suspension or solution forms, in the presence of an oxidant (water or air) at elevated temperature and pressure $[44,61,74]$. WAO technology has a high potential for the treatment of effluents containing a high content of organic matter and/or hazardous materials for which biological treatment is not feasible [44]. In WAO technology the organic pollutants are either partially oxidised into biodegradable intermediate products with low molecular weights or completely mineralised to water, carbon dioxide, and innocuous end-products at temperatures ranging between $125^{\circ} \mathrm{C}$ and $320^{\circ} \mathrm{C}$ and at pressures of between $0.5 \mathrm{MPa}$ and 20.0 MPa in the aqueous phase $[44,59]$. The mechanism of wet oxidation seems to take place by means of a free radical. However, WAO is only effective for aliphatic and aromatic compounds that do not have halogenated groups. Moreover, investment and operation costs of WAO plants are not feasible due to excessive temperatures and pressures, while treatment of effluents containing refractory organic pollutants would further escalate the operating costs $[75,76]$.

3.3. Electrochemical Oxidation. Electrochemical oxidation processes employ an electrochemical cell to generate oxidising species which are used to destroy organic pollutants at ambient temperatures $[60,77-79]$. The mechanism of electrochemical oxidation involves three stages which are electrocoagulation, electroflotation, and electrooxidation [79]:

$$
\begin{gathered}
\mathrm{RH} \stackrel{-\mathrm{e}^{-}}{\longrightarrow} \mathrm{RH}^{+} \\
\mathrm{RH}^{+} \stackrel{-\mathrm{H}^{+}}{\longrightarrow} \mathrm{R}^{\bullet} \\
\mathrm{R}^{\bullet}+\mathrm{R}^{\bullet} \longrightarrow \mathrm{R}-\mathrm{R}
\end{gathered}
$$

Electrochemically, organic pollutants can be oxidised either directly or indirectly. In direct anodic oxidation, the pollutants are adsorbed on the anode before being destroyed by the oxidising species (mediator ions) produced at the anode while indirect electrochemical oxidation makes use of strong oxidising agents and the pollutants are oxidised in the bulk solution [77-79]. Although electrochemical oxidation processes offer an environmentally friendly prospect, the process is economically not viable due to high energy consumption. Furthermore, fouling of the electrodes has been observed due to either the deposition of oligomers formed during phenol oxidation or radical combination as an effect of $\mathrm{pH}[60,80]$.

3.4. Photolysis. In photolysis, a chemical compound absorbs radiation energy, is elevated to a state of higher energy and an excited state, and produces radicals that carry out the photochemical reactions. The source of radiation is either solar energy or low and medium-pressure mercury lamps $[27,33,81,82]$. In photolysis, the hydroxyl compounds are generated by water splitting:

$$
\mathrm{H}_{2} \mathrm{O} \stackrel{h v}{\longrightarrow} \mathrm{H}^{\bullet}+\mathrm{OH}^{\bullet}
$$

These radicals then react with the organic pollutant, splitting it to smaller and more bioavailable compounds [27]. However, photolysis is a poor source of radicals and the radicals produced are not efficient enough to fully degrade refractory pollutants due to slow reaction kinetics observed in photolysis [8]. To accelerate these photochemical processes, metallic salts called semiconductors which act as catalysts to speed up the photochemical processes need to be added, giving rise to the so-called advanced oxidation processes [8,83-85].

\section{Semiconductor Photocatalysis}

4.1. Introduction. Interest in semiconductor photocatalysis has recently risen exponentially because of the potential and 
TABLE 2: Band gap energies of some semiconductor photocatalysts $[8,52,89]$.

\begin{tabular}{lccc}
\hline Photocatalyst & $\begin{array}{c}\text { Band gap } \\
\text { energy } \\
(\mathrm{eV})\end{array}$ & Photocatalyst & $\begin{array}{c}\text { Band gap } \\
\text { energy } \\
(\mathrm{eV})\end{array}$ \\
\hline $\mathrm{Si}$ & 1.1 & $\mathrm{SiC}$ & 3.0 \\
$\mathrm{WSe}_{2}$ & 1.2 & $\mathrm{TiO}_{2}$ rutile & 3.02 \\
$\alpha-\mathrm{Fe}_{2} \mathrm{O}_{3}$ & 2.2 & $\mathrm{Fe}_{2} \mathrm{O}_{3}$ & 3.1 \\
$\mathrm{CdS}$ & 2.4 & $\mathrm{TiO}_{2}$ anatase & 3.2 \\
$\mathrm{NaBiO}_{3}$ & 2.62 & $\mathrm{ZnO}$ & 3.2 \\
$\mathrm{~V}_{2} \mathrm{O}_{5}$ & 2.7 & $\mathrm{SrTiO}_{3}$ & 3.4 \\
$\mathrm{~B}_{2} \mathrm{WO}_{6}$ & 2.78 & $\mathrm{SnO}_{2}$ & 3.5 \\
$\mathrm{WO}_{3}$ & 2.8 & $\mathrm{ZnS}$ & 3.7 \\
\hline
\end{tabular}

opportunities it offers in a variety of fields. These include treatment of environmental pollution, biotissue generation and biosensors, medicine (destruction of cancer and viruses), and pharmaceutical industries [7, 18, 86-90]. The major advantages of semiconductor photocatalysis are that it offers a good substitute for the energy-intensive treatment methods and has the capacity to use renewable and pollution-free solar energy. Also, unlike the conventional treatment methods, which not only transfer pollutants from one medium to another but also transform those to more refractory pollutants, semiconductor photocatalysis converts contaminants to innocuous products, such as $\mathrm{CO}_{2}$ and $\mathrm{H}_{2} \mathrm{O}$. Furthermore, the reaction conditions are mild, and the reaction time is modest and can be applied to aqueous, gaseous, and solidphase treatments with the possibility of being both supplementary and complementary to the present technologies $[8,18,52,83,87,88]$. Semiconductor photocatalysts therefore have the advantage of not only minimising running costs but also generating the desired product in the most efficient and effective way.

4.2. Properties of Semiconductor Photocatalysts. The defining property of a good semiconductor photocatalyst material is that the core element making up the material can reversibly change its valence state to accommodate a hole without decomposing the semiconductor (e.g., $\mathrm{Ti}^{3+} \rightarrow \mathrm{Ti}^{4+}$ in nonstoichiometric $\mathrm{TiO}_{2}$ ) $[8,18,91]$. The photogenerated holes should be highly oxidizing to produce hydroxyl radicals $\left({ }^{\circ} \mathrm{OH}\right)$ and the photogenerated electrons should be reducing enough to produce superoxides from the oxygen [92]. Also, the element should have more than one stable valence in the semiconductor so that it is not decomposed (photocorrosion) by the formation of holes (e.g., $\mathrm{Zn}^{2+}$ in $\mathrm{ZnO}$ and $\mathrm{Cd}^{2+}$ in $\mathrm{CdS}$ are photocorroded by the formation of holes) [8, 18, 93-95]. Furthermore, the semiconductor must have a suitable band gap, which is highly stable to chemical corrosion, nontoxic, and generally of low cost $[8,18,92,93,96,97]$. The band gap energies of some semiconductor photocatalysts are shown in Table 2 .

4.3. Mechanism of Photocatalysis. Semiconductor photocatalysts do not have a continuum of electronic states like metals, but they have a void region that extends from the top of the highest occupied molecular orbital (HOMO), that is, the valence band (VB), to the bottom of the lowest unoccupied molecular orbital (LUMO) which is also referred to as the conduction band (CB). This void region is called the band gap $\left(E_{g}\right)[8,18,98-100]$. When the semiconductor is illuminated with light, it absorbs a photon $(h v)$ and when the energy of the photon is equal to or exceeds the band gap energy, an electron $\left(\mathrm{e}_{\mathrm{cb}}{ }^{-}\right)$is promoted from the VB to the CB leaving a hole $\left(\mathrm{h}_{\mathrm{vb}}{ }^{+}\right)$in the VB (Figure 1) [2, 18, 99-101]. The electron-hole pair then migrates to the surface of the photocatalyst where it can recombine and dissipate the energy as heat, get trapped in metastable surface states, or react with electron donors or acceptors adsorbed on the surface of the semiconductor [18]. Generally, the hole oxidises water to form hydroxyl radicals and initiates a chain reaction that then proceeds to oxidise organics while the electron can be donated to an electron acceptor, for example, $\mathrm{O}_{2}$, leading to the formation of superoxides or a metal ion that is reduced to its lower valence state and deposited on the catalyst surface $[8,18,98,102,103]$.

The mechanism for semiconductor photocatalysis (of a $\mathrm{M}(\mathrm{IV})$ lattice metal, e.g., $\mathrm{TiO}_{2}$ ) can be summarised in the following reaction steps $[8,18]$ :

(i) Excitation of photon greater than band gap resulting in the formation of electrons $\left(\mathrm{e}_{\mathrm{cb}}{ }^{-}\right)$and holes $\left(\mathrm{h}_{\mathrm{vb}}{ }^{+}\right)$, that is, charge-carrier generation:

$$
\mathrm{TiO}_{2}+h v \longrightarrow \mathrm{h}_{\mathrm{vb}}^{+}+\mathrm{e}_{\mathrm{cb}}^{-}
$$

(ii) Charge-carrier trapping:

$$
\begin{aligned}
& \mathrm{h}_{\mathrm{vb}}{ }^{+}+\mathrm{Ti}^{\mathrm{IV}} \mathrm{OH} \longrightarrow\left\{\mathrm{Ti}^{\mathrm{IV}} \mathrm{OH}^{\bullet}\right\}^{+} \\
& \mathrm{e}_{\mathrm{cb}}{ }^{-}+\mathrm{Ti}^{\mathrm{IV}} \mathrm{OH} \longrightarrow\left\{\mathrm{Ti}^{\mathrm{III}} \mathrm{OH}\right\}
\end{aligned}
$$

(iii) Charge-carrier recombination producing thermal energy:

$$
\begin{array}{r}
\mathrm{h}_{\mathrm{vb}}{ }^{+}+\left\{\mathrm{Ti}^{\mathrm{III}} \mathrm{OH}\right\} \rightarrow \mathrm{Ti}^{\mathrm{IV}} \mathrm{OH}+\text { heat } \\
\mathrm{e}_{\mathrm{cb}}{ }^{-}+\left\{\mathrm{Ti}^{\mathrm{IV}} \mathrm{OH}^{\bullet}\right\}^{+} \longrightarrow \mathrm{Ti}^{\mathrm{IV}} \mathrm{OH}+\text { heat }
\end{array}
$$

(iv) Interfacial charge transfer:

$$
\begin{array}{r}
\left\{\mathrm{Ti}^{\mathrm{IV}} \mathrm{OH}^{\bullet}\right\}^{+}+\mathrm{Red} \longrightarrow \mathrm{Ti}^{\mathrm{IV}} \mathrm{OH}+\mathrm{Red}^{\bullet+} \\
\mathrm{e}_{\mathrm{cb}}{ }^{-}+\mathrm{Ox} \longrightarrow \mathrm{Ti}^{\mathrm{IV}} \mathrm{OH}+\mathrm{Ox}^{\bullet-}
\end{array}
$$

where Red is an electron donor (reductant) and Ox is an electron acceptor (oxidant).

(v) Reduction of metal ions by $\mathrm{e}_{\mathrm{cb}}{ }^{-}$, if present:

$$
n \mathrm{e}_{\mathrm{cb}}{ }^{-}+\mathrm{M}^{n+} \longrightarrow \mathrm{M}^{0}
$$

This fundamental phenomenon observed in semiconductor photocatalysts to oxidise (degrade) organic compounds and reduce metal ions is a promising technique in the treatment of refractory organic pollutants and heavy metals present in wastewater treatment plants. 


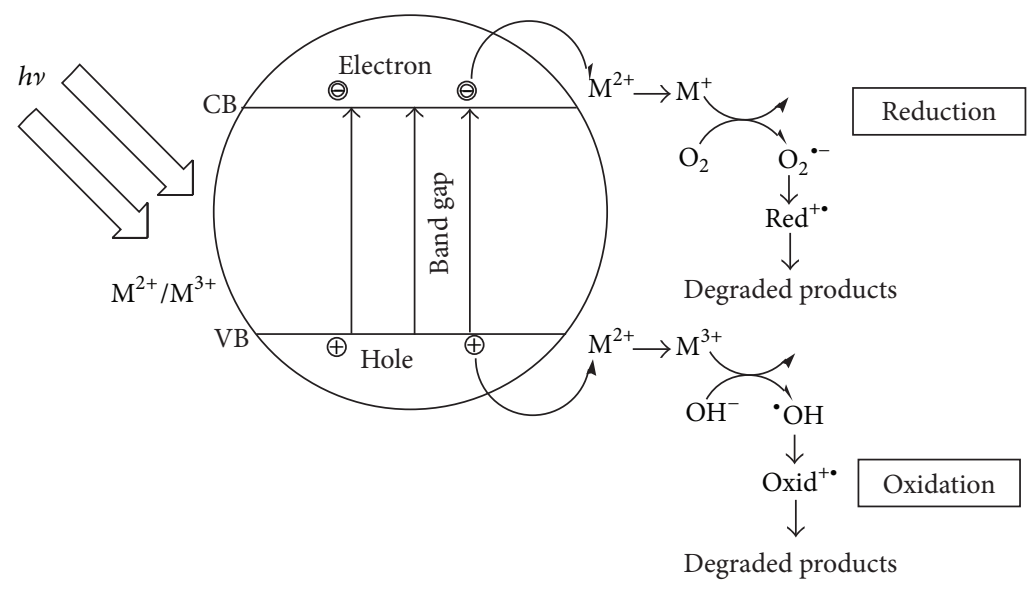

FIGURE 1: Mechanism for semiconductor photocatalysis [18].

\section{Nanophotocatalysts in Water Treatment}

Due to industrial and geographical reasons there is always a difference in the quality of water across the world. It is therefore acceptable that there is no possibility of one solution that can solve all the problems of water contamination. Thus, in the design for water-treatment technologies, nanotechnology will always play a key role. The intrigue of nanotechnology is the ability to control the manipulation of nanoscale (approximately $1 \mathrm{~nm}$ to $100 \mathrm{~nm}$ ) structured materials and integrate them into large material components, systems, and architecture that have novel properties and functions $[2,86,113,114]$. The merits of using semiconductor photocatalysts in their nanorange far outweigh their use in their bulk form [115]. For example, in the case of adsorption where surface sites of the adsorbent are utilised, diffusion is usually hindered due to the lack of a porous structure in the bulk materials. This is because the surface-to-volume ratio increases drastically with the decrease of the adsorbent from bulk to nanodimensions $[2,7,11,87,113]$.

Also, new physical and chemical properties emerge when the size of a material is reduced to the nanoscale level. The surface energy per nanoparticle increases significantly in the nanorange. This increase in surface energy directly results in an increase in contaminant removal even at low concentrations. The use of nanocatalysts also results in less waste generation, especially in posttreatment, since less quantity of nanomaterial will be required compared to its bulk form. Furthermore, with the use of nanomaterials, novel reactions can be accomplished at nanoscale due to an increase in the number of surface atoms which is not possible with its analogous bulk material, for example, the degradation of pesticides by nanoparticles which cannot be done by the metals in their bulk form $[2,7,93,94,113]$.

\section{Titanium Dioxide/ $/ \mathrm{TiO}_{2} /$ Titania Photocatalysts}

6.1. Introduction. Among the nanophotocatalysts used in the treatment of environmental wastewater, titanium dioxide, also known as titania or $\mathrm{TiO}_{2}$, has been extensively studied
[88, 116-119]. Since the discovery of the phenomenon of photocatalytic splitting of water on $\mathrm{TiO}_{2}$ electrode under UV light, enormous efforts devoted to titania research have led to promising applications in the fields of photovoltaics, photocatalysis, photoelectrochromics, ceramics, and sensors [120-126]. As the most promising semiconductor photocatalyst, $\mathrm{TiO}_{2}$-based materials are therefore expected to play a major role to curb serious environmental and pollution challenges and ease the energy crisis through the use of renewable solar energy [93, 127-134].

6.2. Synthetic Methods for $\mathrm{TiO}_{2}$ Nanoparticles. There are a number of available techniques for the synthesis of titania nanoparticles and these include sol-gel, sol, hydrothermal, solvothermal, and chemical vapour deposition, to name just a few $[88,135,136]$. These synthetic methods are highlighted in the following subsections. The method used plays a significant role in the shape, size, and photochemical properties of $\mathrm{TiO}_{2}$.

6.2.1. Sol-Gel Method. The sol-gel method is the most commonly used technique for the synthesis of $\mathrm{TiO}_{2}$ nanoparticles [137-140]. In a typical sol-gel process, a colloidal suspension (a sol) is formed from the hydrolysis of the precursors, usually inorganic metal salts or metal inorganic salts such as metal alkoxides $[16,88]$. For titania synthesis, the sol-gel process usually proceeds via an acid-catalysed hydrolysis of titanium (IV) alkoxides followed by condensation [88, 138]. The sol-gel process has found more extensive use in the synthesis of titania because the reaction takes place at low temperatures, does not use complicated equipment, results in the formation of highly homogeneous and pure products, and allows for modification to produce specific desired products [138, 141-143].

Also, the sol-gel method results in the synthesis of high surface-area nanomaterials. It also allows for easy control of shape, size, and distribution, as well as the easy introduction of foreign materials into the catalyst lattice and at low temperatures [135, 141, 144-147]. Moreover, nanomaterials prepared by this method have a well-crystalline phase and a small crystalline size, which benefit thermal stability and photocatalytic activity. Hence, in this study, the sol-gel 
process was used for the synthesis of $\mathrm{TiO}_{2}$ nanoparticles as well as the introduction of metal ions into the crystal lattice of the $\mathrm{TiO}_{2}$ nanoparticles.

6.2.2. Sol Method. This method is also referred to as the nonhydrolytic sol-gel process and usually involves the reaction of titanium chloride with oxygen donating materials, for example, metal alkoxides or organic ethers [88, 148-152]. The reaction between $\mathrm{Ti}-\mathrm{Cl}$ and $\mathrm{Ti}-\mathrm{OR}$ leads to the formation of $\mathrm{Ti}-\mathrm{O}-\mathrm{Ti}$ bridges. The alkoxide groups are formed in situ by the reaction of titanium chloride with alcohols or ethers. The length of the alkyl substituent of the alcohols affects the reaction speed (the longer the chain, the faster the reaction) but not the average particle size. However, the variation of the halogen (e.g., $\mathrm{TiF}_{4}$ and $\mathrm{TiI}_{4}$ ) affects the average particle size $[88,153]$. Also, the shape and size of the titania nanoparticles can be controlled by the addition of a surfactant. For example, $\mathrm{TiCl}_{3}$ was added to a solution of trioctylphosphine oxide (TOPO) and lauric acid and the reaction conditions controlled to produce either diamondshaped, bullet-shaped nanocrystals or a mixture of branched and unbranched $\mathrm{TiO}_{2}$ nanorods $[88,153-155]$.

6.2.3. Hydrothermal Method. Hydrothermal synthesis of nanoparticles takes place under controlled temperature and/or pressure in an autoclave $[88,127]$. The reaction takes place in an aqueous medium. The hydrothermal process is effective for selective crystallisation of anatase titania from the amorphous phase. However, the presence of the $\mathrm{Cl}^{-}$ion (from the precursor, $\mathrm{TiCl}_{3}$ ) results in the formation of a mixture of anatase and the brookite phases. Thermal treatment of the amorphous phase below $300^{\circ} \mathrm{C}$ results in a mixture of the anatase and the brookite phases due to a solid-state epitaxial growth mechanism. At temperatures above $300^{\circ} \mathrm{C}$ the formation of only the anatase phase is achieved because the dissolution/precipitation mechanism dominates [88, 127].

The hydrothermal process is thought to be environmentally friendly since the reactions are carried out in a closed system and the contents can be recovered and reused after cooling down to room temperature [53]. Moreover, proper and careful control of the hydrothermal processing conditions allows for the control over the physical properties of titania such as crystallite size and form, surface area, contamination, morphology and phase, uniform distribution and high-dispersion, and stronger interfacial adsorption properties [53, 88, 127].

6.2.4. Solvothermal Method. The solvothermal method is almost identical to the hydrothermal method except that it uses nonaqueous solvents $[88,156,157]$. However, in the solvothermal method the temperature can be elevated much higher than in the hydrothermal method and a variety of organic solvents with high boiling points can be used. With the solvothermal method there is a better control of the size, shape, and the crystallinity of the $\mathrm{TiO}_{2}$ nanoparticle distributions than hydrothermal methods [158]. Thus the solvothermal method has been found to be a versatile method for the synthesis of a variety of nanoparticles with controlled particle size, narrow size distribution, and dispersity [159162]. Also the versatility of this method is seen in that it can be employed to synthesise $\mathrm{TiO}_{2}$ nanoparticles and nanorods with or without the aid of surfactants.

6.2.5. Chemical Vapour Deposition (CVD) Method. Chemical vapour deposition (CVD) is a process in which materials in a vapour state are condensed to form a solid-phase material $[88,163]$. This process alters the mechanical, electrical, thermal, optical, corrosion resistance, and wear-resistance properties of various substrates [163]. CVD has been used to form free-standing bodies, films, and fibres and to infiltrate fabric to form composite materials and, recently, in the fabrication of various nanomaterials [164, 165]. Chemical vapour deposition of titanium dioxide is usually carried out through the reaction of titanium tetrachloride $\left(\mathrm{TiCl}_{4}\right)$ with oxygen or through the thermal reaction of a titanium alkoxide such as $\mathrm{Ti}(\mathrm{OPri})_{4}$, which already displays the $\mathrm{Ti}-$ $\mathrm{O}_{4}$ tetrahedral motif of the titanium dioxide lattice in its chemical structure [165-167].

CVD processes usually take place within a vacuum chamber. If no chemical reaction occurs within the reaction chamber, the process is called physical vapour deposition (PVD). In CVD processes, the gaseous precursor compounds chemically react on a heated substrate surface and the deposition reaction is driven by thermal energy. The reactions usually happen in an inert atmosphere in the presence of a gas, for example, $\mathrm{N}_{2}$, Ar, or He [163-165, 167]. Moreover, the reaction conditions in a CVD process can be tuned to determine the phase, size, and morphology of the $\mathrm{TiO}_{2}$ nanostructures.

6.3. Properties of $\mathrm{TiO}_{2}$ Nanoparticles. Titanium dioxide has gained prominence for use as an environmental remediation catalyst to completely mineralise organic and inorganic contaminants because of its outstanding characteristics. These include high thermal stability, high photocatalytic activity, high resistance to chemical and photocorrosion, nontoxicity, and dielectric properties as well as being inexpensive [168172]. The photocatalytic activity of $\mathrm{TiO}_{2}$ depends on its crystal phase, crystallinity, particle size, lattice impurities, density of surface hydroxyl groups, and the surface area. Titania has three (3) phases, namely, anatase (tetragonal), rutile (tetragonal), and brookite (orthorhombic), and the anatase phase of titania is the most photoreactive of the phases $[121,172-174]$. Of the three phases, the anatase phase has the smallest particle sizes $(<50 \mathrm{~nm})$, high concentrations of surface hydroxyl $(\mathrm{OH})$ groups, and a high surface area, hence the high photocatalytic activity [169].

However, the band gap of anatase $\mathrm{TiO}_{2}$ is $3.2 \mathrm{eV}$ and can only be activated under UV light irradiation with wavelength of $387 \mathrm{~nm}$ [117, 175-177]. This high-energy band gap rules out the use of solar energy as the photoactivity source. The UV source requires large quantities of electrical energy which would result in high costs in practical applications [52]. Moreover, titania is characterised by low quantum yields (i.e., low electron transfer rate) resulting in high electron-hole pair recombination which results in the termination of the photocatalytic reactions $[41,104,168,178-180]$. As a result, a 
number of reformative initiatives have been investigated as a means of overcoming these drawbacks.

6.4. $\mathrm{TiO}_{2}$ Modifications. The main aim for titania modifications is to reduce the band gap of titania thus shifting its optical response to the visible-light region and to reduce the rate of electron-hole pair recombination to increase its photoreactivity $[105,132,180] . \mathrm{TiO}_{2}$ modifications result in the "decrease" of the band gap by means of introducing a donor level on the valence band (Figure 2). The paramount condition for titania modification is to ensure that the anatase phase is maintained. The most common techniques used for $\mathrm{TiO}_{2}$ modifications include anion doping, dye sensitizers, the use of binary oxides, and metal-ion doping. These are discussed in the following subsections.

6.4.1. Metal-Ion Doping. Doping of titanium dioxide nanoparticles with transition and noble metal ions for the degradation of organic pollutants is the most studied phenomenon and has been found to enhance both the photoresponse and photoresponse and photocatalytic activity of $\mathrm{TiO}_{2}$ nanoparticles under visible-light irradiation [47, 96, 105, 142, 181-191]. The electronic states of titania can be decomposed into three parts: $\delta$ bonding of $\mathrm{O} \mathrm{p}$ and $\mathrm{Ti} e_{g}$ orbitals or states that are located in the lower region, $\pi$ bonding of $\mathrm{O} \mathrm{p}_{\pi}$ and Ti $e_{g}$ states in the middle energy region, and $\mathrm{O} \mathrm{p}_{\pi}$ states in the higher energy region (Figure 3). The bottom of the lower CB has the $\mathrm{Ti}_{x y}$ orbital and contributes to the metal-metal interactions due to $\delta$ bonding of the Ti $\mathrm{t}_{2 g}-\mathrm{Ti}_{2 g}$ states. The top of the lower $\mathrm{CB}$ consists of the $\mathrm{Ti}_{2 g}$ states that are antibonding with the $\mathrm{O} \mathrm{p}_{\pi}$ states. The upper $\mathrm{CB}$ is characterised by the $\delta$ antibonding orbitals between the $\mathrm{O} \mathrm{p}_{\delta}$ and $\mathrm{Ti} e_{g}$ states [88].

During metal-ion doping, the energy due to the metalion dopant either lies at the top of the valence band or produces midgap states. When the atomic number of the dopants is increased, the localised level shifts to lower energy thus significantly contributing to the formation of the valence band with the $\mathrm{O} \mathrm{p}$ and $\mathrm{Ti} 3 \mathrm{~d}$ electrons. This results in the band gap narrowing due to the introduction of electron states into the band gap of $\mathrm{TiO}_{2}$ resulting in the formation of a new lowest unoccupied molecular orbital (LUMO) [88]. Basically, metal ions provide a "cushion" on the valence band (the donor level) which results in the "decrease" in the band gap.

Metal doping should be differentiated from metal ions codissolved in a photodegraded solution and noble metals deposited on the semiconductor surface $[88,105]$. Metal ions (dopants) are therefore incorporated into the $\mathrm{TiO}_{2}$ lattice resulting in a "decrease" between the valence band and the conduction band hence altering the band gap energy thereby shifting the absorption band to the visible-light region [47]. Metal-ion dopants are nanoscale metal semiconductor contacts that act as electron scavengers hence resulting in increased photocatalysis $[192,193]$.

It is worth noting that although the introduction of metalion dopants on the titania lattice drastically shifts the absorption edge to the visible-light region, it can also result in reduced photocatalytic activities. Metal doping can increase the rate of electron-hole pair recombination and the photocatalyst can also cause thermal instability $[57,176]$. It is therefore imperative to avoid this by taking into consideration the adequate amount of the dopant (metal) when preparing doped titania $[105,194]$. This is because when the dopant level passes the optimal limit, which usually lies at a very low dopant concentration, the metal ions act as recombination centres resulting in reduced photoactivity. The presence of adequate amounts of metal doping (optimal limit) also ensures that the metal particles only act as electron traps hence aiding electron-hole separation $[105,195]$.

6.4.2. Anion Doping. Anion doping of titania has increased recently and has been reported to shift the absorption edge towards the visible-light region and increase the photocatalytic activity $[16,102,119,176,196-199]$. The narrowing of the band gap is as a result of the mixing of either the $\mathrm{p}$ or the $2 \mathrm{p}$ states of the halogen $(\mathrm{X})$ with the $2 \mathrm{p}$ states of the oxygen $(\mathrm{O})$ atom in the valence band of the $\mathrm{TiO}_{2}$ nanoparticles $[88,196$, 197]. However, the mixing of the p states of the halogen and the $2 \mathrm{p}$ states of the $\mathrm{O}$ atom has the most positive effect on the band gap narrowing as it induces some states which act as shallow donors on the valence band [88]. The anion therefore traps holes resulting in less recombination of the electronhole pair and displaces the surface $\mathrm{OH}$ groups increasing the rate of electron scavenging by $\mathrm{O}_{2}$ resulting in the formation of an increased yield of superoxide radicals [103]. Anions therefore undergo innersphere ligand substitution reactions with surface hydroxyl groups.

6.4.3. Dye Sensitizers. Organic dyes have been widely employed as sensitizers for titanium dioxide nanomaterial to improve its optical properties as they are light absorbing chromophores $[6,84,88,125,193,200]$. Organic dyes are usually transition-metal complexes with low-lying excited states, for example, polypyridine, phthalocyanine, and metalloporphyrin complexes. The metal centres for the dyes include $\mathrm{Ru}(\mathrm{II}), \mathrm{Zn}(\mathrm{II}), \mathrm{Mg}(\mathrm{II}), \mathrm{Fe}(\mathrm{II})$, and $\mathrm{Al}(\mathrm{III})$, while the ligands include nitrogen heterocycles with delocalised $\pi$ or aromatic ring systems. The conduction band usually acts as a mediator for transferring the electrons from the excited sensitizer to the substrate on the titania surface [84, $125,187]$.

These organic dyes act as both sensitizers and substrates and are normally linked to the $\mathrm{TiO}_{2}$ nanoparticle surfaces via functional groups. The various interactions between the dyes and the $\mathrm{TiO}_{2}$ nanoparticle substrates include covalent attachment by directly linking groups of interest or via linking agents, electrostatic interactions via ion-exchange, ionpairing, or donor-acceptor interactions, hydrogen bonding, van der Waals forces, or hydroxyl groups [84, 88, 95]. Most dyes of interest link via direct covalent bonding with the functional groups that are on the $\mathrm{TiO}_{2}$ surface. Carboxylic and phosphonic acid derivatives react with the hydroxyl groups to form esters, while amide linkages are obtained via the reaction of amine derivatives on $\mathrm{TiO}_{2}[88,95]$. However, dye sensitizers are not stable and are usually prone to thermal instabilities which result in increased recombination centres. Furthermore, they are susceptible to damage from 


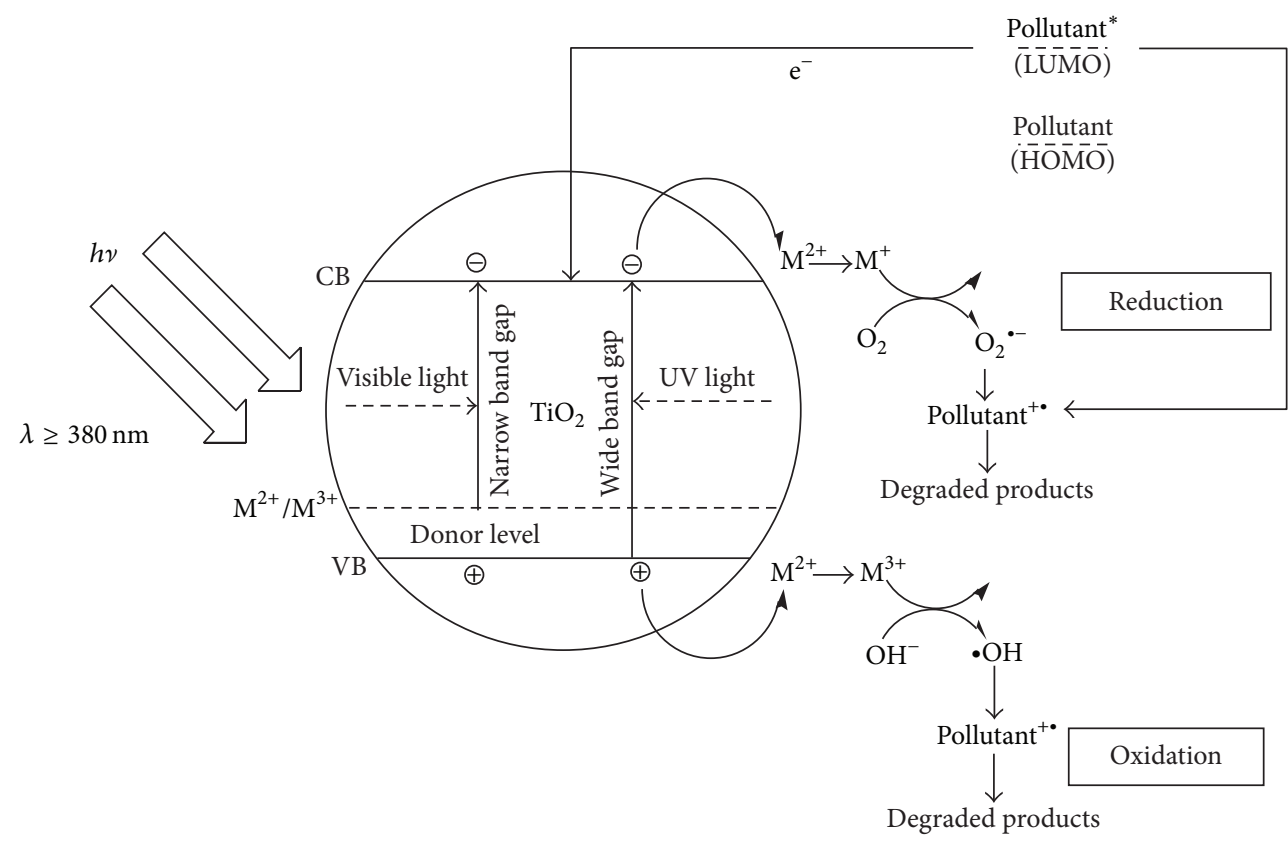

FIgURE 2: Band gap (effect of doping) and photocatalysis mechanism of $\mathrm{TiO}_{2}[18,104,105]$.

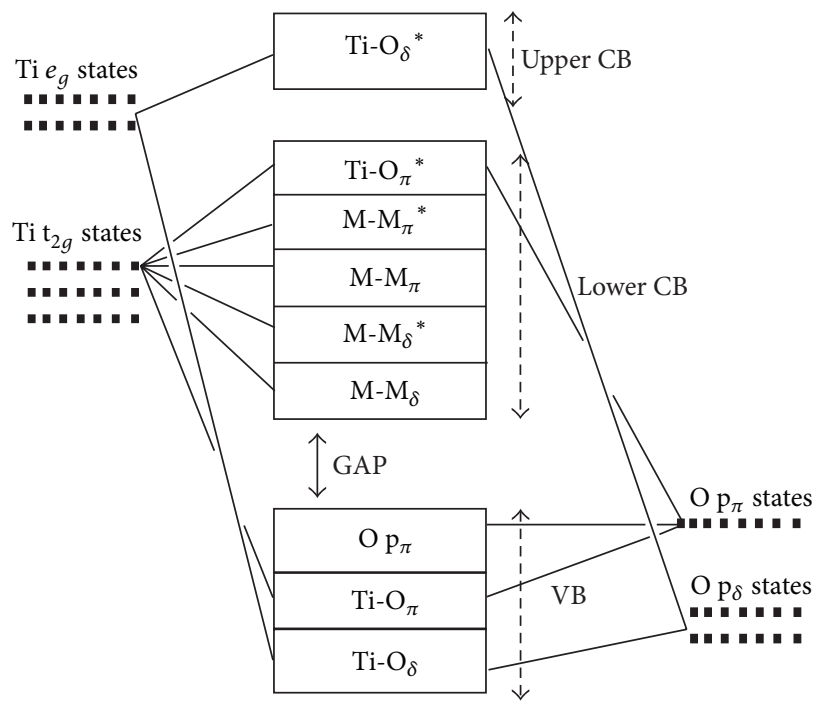

FIGURE 3: Bonding diagram of $\mathrm{TiO}_{2}[18]$.

reactive oxygen species (ROS) which destroy the catalyst $[92,176]$.

6.4.4. Binary Oxides. Binary metal oxides like $\mathrm{TiO}_{2} / \mathrm{SiO}_{2}$, $\mathrm{TiO}_{2} / \mathrm{ZrO}_{2}, \mathrm{TiO}_{2} / \mathrm{WO}_{3}, \mathrm{TiO}_{2} / \mathrm{Fe}_{2} \mathrm{O}_{3}, \mathrm{TiO}_{2} / \mathrm{SnO}_{2}, \mathrm{TiO}_{2} /$ $\mathrm{Ln}_{2} \mathrm{O}_{3}$, and $\mathrm{TiO}_{2} / \mathrm{RuO}_{2}$ systems have been applied in the photocatalytic degradation of environmental pollutants under visible light $[3,95,118,124,140,201-207]$. The photoactivity of these binary oxides was found to be enhanced because the metal oxides increased the acidity of the titania surface. The surface acidity takes the form of surface hydroxyls and accepts holes generated by illumination of the catalyst and oxidises the adsorbed molecules [118, 204]. Basically, since the coupling oxide is activated under visible light, it is believed that the metal oxide will absorb visible light and the photocatalytic activity of the titanium dioxide will be used to mineralise organic pollutants. The metal oxides also enhance the separation properties of titania suspended particles from solution and thus decrease the effect of beam splitting by agglomerated particles [118]. Moreover, the metal oxides act as supports of the catalysts [10]. However, some of the metal oxides are thermodynamically unstable, for example, $\mathrm{RuO}_{2} /$ $\mathrm{TiO}_{2}$, thus resulting in electron-hole pair recombination and significantly decreasing the photocatalytic activity [95].

Other techniques that have been used to shift the absorption edge of titania towards the visible-light region and 
reduce the rate of electron-hole pair recombination include carbon nanotube-titania composites, metal-anion codoping, mounting $\mathrm{TiO}_{2}$ on activated carbon exfoliated graphite, and polymeric substrates, for example, chitosan [116, 130, 208213]. For the purposes of this research metal-ion-doped titania will be synthesised and investigated for its photocatalytic properties under visible-light irradiation.

\section{5. $\mathrm{TiO}_{2}$ Applications}

6.5.1. Industrial Applications. The existing and potential applications of titanium dioxide nanomaterials include toothpaste, paint, UV protection, photovoltaics, photocatalysis, sensing, electrochromics, and photochromics. The photocatalytic properties of $\mathrm{TiO}_{2}$ have found application, as well as potential application, in the manufacture of self-cleaning surfaces, air cleaning devices, and self-sterilising devices [88, 92, 194, 214, 215]. Photochromic and electrochromic compounds (with a redox potential above the conduction band edge of titania) exhibit different colours in different oxidation states, and $\mathrm{TiO}_{2}$ acts as an electron conductor between the conduction band and the photo/electrochromic material. Electrochromic devices like electrochromic windows, displays, contact lenses, catheters, and spectacles with $\mathrm{TiO}_{2}$ as the electron conductors have been synthesised and commercialised [131, 216-218]. Also, biomedically, $\mathrm{TiO}_{2}$ has shown much potential in cancer therapy (endoscopic-like instruments) due to its antitumor activity [92].

6.5.2. Environmental Applications. The photocatalytic properties of $\mathrm{TiO}_{2}$ make it an important semiconductor in applications in environmental remediation. Titanium dioxide has shown tremendous ability not only as a sensor for chemical, biological, and various gases $\left(\mathrm{H}_{2}, \mathrm{NO}_{x}, \mathrm{CO}\right.$, etc.) even at low concentrations, but also to photocatalytically degrade and self-clean the contaminated environment [88, 200, 219222]. Moreover, the degradation of organic pollutants and reduction of metals to their zero oxidation states have been earmarked as one of the peak applications of $\mathrm{TiO}_{2}$ for the treatment of river water, groundwater, the drainage water from fish-feeding tanks, and industrial wastewater $[57,65,91$, $92,117,223,224]$. Furthermore, photodegradation of organic pollutants by titanium dioxide results in the formation of innocuous products and therefore eliminates the problems associated with the recalcitrant DBPs [18, 83, 174, 175, 225]. Although titania has the ability to completely degrade organic refractory pollutants and to be coused with the existing watertreatment technologies, its large-scale industrial application in drinking-water treatment is still considered to be miles away.

6.6. Problems Associated with $\mathrm{TiO}_{2}$ Applications. The use of $\mathrm{TiO}_{2}$ in suspension form is efficient due to its large surface area but there are four major technical challenges that restrict its large-scale application and its use in water-treatment technologies. Firstly, it has a relatively wide band gap $(\sim 3.2 \mathrm{eV}$, which falls in the UV range of the solar spectrum), and therefore it is unable to harness visible light thus ruling out sunlight as the energy source of its photoactivation $[9,16$,
211, 226-229]. Secondly, it has low quantum efficiency due to the low rate of electron transfer to oxygen resulting in a high recombination of the photogenerated electron-hole pairs [226, 227, 230]. Thirdly, when used in a suspension, titanium dioxide aggregates rapidly due to its small size ( $4 \mathrm{~nm}$ to $30 \mathrm{~nm}$ ) and its aggregates may cause scattering of the light beam resulting in loss of catalytic efficiency [66, 211, 231]. And lastly, the application of powdered $\mathrm{TiO}_{2}$ catalysts requires posttreatment separation to recover the catalyst from water. This is normally difficult, is energy consuming, and is economically not viable for use in water-treatment plants $[12,66,156,211,230]$. Therefore new research initiatives need to be explored to counter these challenges.

One of the major challenges facing scientists and government bodies is the development of materials using "clean" energy applications, the so-called Green Science, to relieve the environmental burden due to pollution. $\mathrm{TiO}_{2}$ has the potential to be that green material and hence so much research has been ongoing to try and harness its potential applications. To achieve this, doping metals into the $\mathrm{TiO}_{2}$ lattice is an effective strategy to reduce the band gap and shift the absorption edge towards the visible-light range [57, 84, $105,107,191,227,232,233]$. However, the amount of the metalion dopant when preparing doped titania is important. This is because when the dopant level passes the optimal limit, $(\sim 0.4 \%)$, the metal ions then act as recombination centres resulting in reduced photoactivity $[105,194]$.

Also, $\mathrm{TiO}_{2}$ nanoparticles can be supported on catalyst supports. This would help improve the photocatalytic activity and potential application of the titania nanoparticles. Furthermore, to avoid the aggregation and posttreatment challenges, $\mathrm{TiO}_{2}$ can also be assembled onto different substrates and fabricated into different types of titania thin films $[150,211,214,234-237]$. The advantage of using thin films is that they are known to be chemically stable and possess a high dielectric constant, a high refractive index, and excellent transmittance; therefore they have the ability to retain the photocatalytic activity of the assembled catalysts [236].

\section{Catalyst Supports}

7.1. Introduction. A support material is very important in catalysis because it determines the catalytic activity of a catalyst [238, 239]. Catalyst supports are porous and have high surface areas $[44,240,241]$. The electronic interactions between the support and the catalyst bring about slightly acidic conditions which increases the rate of electron transfer thus reducing the rate of electron-hole combination. Also, supports result in an increased adsorption ability and stability of the catalyst and hence increase the rate of oxidation of organic pollutants [44, 76, 242, 243]. Moreover, catalyst support materials do not only shift the band edge towards the visible-light energy region but also have the ability to disperse the supported catalysts thus preventing them from agglomerating and also helping to improve catalyst separation from posttreatment wastes [130, 238, 243-247]. These conditions are therefore important since they enhance the photocatalytic activity and the application of the supported $\mathrm{TiO}_{2}$ catalysts. The common types of supports used for catalysts include 
alumina $\left(\gamma-\mathrm{Al}_{2} \mathrm{O}_{3}\right)$ supports, carbon supports, and carboncovered alumina (CCA) supports.

7.1.1. Alumina Supports. $\gamma$-Alumina as a catalyst support has a high surface area, good mechanical properties, and numerous pores as well as the ability to disperse the active metal phase [238, 239, 247, 248]. However, its exclusive use as a support has been found to have some disadvantages. For example, its acidity results in low catalytic activity of the supported catalysts. Furthermore, its reactive surfaces form unwanted metal oxides upon calcination. The reactive surfaces of alumina react with the promoter ions resulting in the formation of oxides which lower the catalytic activity of the catalysts [238, 247-249]. The strong interactions of the alumina support with the metal atoms are therefore undesirable since it is detrimental to the catalyst activity.

7.1.2. Carbon Supports. Carbon has also been used to support catalysts. Carbon supports have mild interactions with the supported metals and have a neutral surface, good thermal conductivity, and high surface area with controlled pore volume. Carbon is also resistant to nitrogen poisoning and contains variable surface functional groups [246, 248-251]. However, it also has some undesirable properties that limit its use as a catalyst support. It has poor mechanical properties and a low surface area. Moreover, it is also microporous and has poor adsorption properties and hence catalysts may be deposited on the micropores thus making their photocatalytic effect trivial $[238,246,248-251]$. These properties therefore make the sole use of carbon as a support material inapplicable.

7.2. Carbon-Covered Alumina (CCA) Supports. As described before, the sole use of either carbon or alumina as support materials has some shortcomings. A support system that exploits the merits of both carbon and alumina can provide an ideal support system. This is because it overcomes their shortcomings while improving their advantages. In this system, the alumina is coated with a thin layer of carbon prior to catalyst impregnation which results in a support material that possesses both the textural and mechanical properties of alumina and the favourable surface properties of carbon $[238,250,252-255]$. The properties of this carbon-covered alumina (CCA) support include reduction of the alumina acidity ( by $90 \%$ ) due to the presence of carbon; increased electron-charge transfer and reduced metal-support interactions resulting in increased catalytic activity; and increased mechanical strength and increased surface area [238, 239, $247,252-254,256,257]$. CCA supports are therefore superior catalyst supports due to the integration of the properties of both the carbon and alumina.

7.3. Synthesis of CCA Supports. The most common approach to the synthesis of CCA supports is based on the "pyrolyzability" of organic compounds, such as cyclohexene, acetylene, or ethane, on the surface of alumina at elevated temperatures $\left(600^{\circ} \mathrm{C}\right.$ to $\left.700^{\circ} \mathrm{C}\right)$ in the flow of nitrogen, that is, chemical vapour deposition (CVD) of organic compounds [247, 249, 254, 258-260]. However, it has been found that the materials synthesised by this method have some drawbacks. For example, their textural properties are dependent on the amount of carbon deposited and the type of the hydrocarbon used; hence the carbon coating is nonuniform [254]. Furthermore, increasing the degree of surface coverage of the alumina by carbon through CVD results in the aggregation of carbon on the alumina surface and this decreases the apparent surface area and pore volume which are key to catalytic activity of the supported catalysts.

Another method used to synthesise CCA involves the impregnation of alumina with sucrose solutions [198, 238, $250,253,257]$. In this method the sucrose-impregnated alumina is dried in an oven and the pyrolysis of the sucrose takes place in an inert atmosphere at elevated temperatures $\left(600^{\circ} \mathrm{C}\right.$ to $\left.700^{\circ} \mathrm{C}\right)$ to produce CCA supports. The CCA supports produced by the impregnation of sucrose have a uniform carbon layer; hence this is regarded as a better method than CVD of organic compounds. Lately, Sharanda et al. have synthesised CCA supports using an adsorptionequilibrium method [254, 261]. In this method highly reactive compounds like acetylacetone and isocyanates form surface complexes with the $\mathrm{OH}$ groups of the alumina via the $\mathrm{C}=\mathrm{O}$ and $\mathrm{N}=\mathrm{C}=\mathrm{O}$ bond openings, respectively. Upon pyrolysis, a carbon coating is expected to form on the surface of the alumina. The equilibrium adsorption method has the advantage of forming better CCA supports since the interaction between the $\mathrm{C}$ and alumina is a chemical process and not a physical or mechanical one like in the case of CVD and sucrose impregnation. Hence, for the purposes of this study, the adsorption-equilibrium method was adopted for the synthesis of CCA supports.

7.4. Applications of CCA Supports. CCA supports have found utilisation as supports for hydrotreating catalysts in the Fischer-Tropsch conversion of heavy crude oil into light fractions $[252,258]$. Also, CCA supports have a high surface area and high adsorption affinity for both organic and inorganic compounds $\left(\mathrm{Al}_{2} \mathrm{O}_{3}\right.$ is a polar adsorbent and $\mathrm{C}$ is a nonpolar adsorbent). These properties have been exploited and CCA supports have been used as packing material for high-performance chromatography [249, 260, 261]. Recently, Jana and Ganesan [255] have synthesised CCA in the form of foams and increased its surface area and also enhanced its adsorptive properties. Due to their high catalytic activity and stability, CCA supports have been used to support $\mathrm{Ru}$ catalysts in the synthesis of $\mathrm{NH}_{3}$ [262]. Ag nanoparticles have been used in CCA supports and used to remove bacteria in drinking water [239]. Since not much work has been done on the environmental application of CCA-supported catalysts, this research therefore seeks, for the first time, to support anatase $\mathrm{TiO}_{2}$ nanoparticles on CCA supports and apply them in the degradation of organic pollutants.

\section{CCA-Supported $\mathrm{TiO}_{2}$ Nanoparticles}

Titania nanoparticles have been recently attached on CCA supports and used for the photocatalytic degradation of Rhodamine B under visible-light irradiation [263]. Metal-doped titania has also been supported on these CCA supports. Ag, 
$\mathrm{Co}, \mathrm{Ni}$, and Pd were used as the metal dopants [106]. The CCA supports were synthesised from glucose and an impregnation method was used to attach the nanoparticles on the supports. According to the results obtained, attaching the titania nanoparticles on the CCA supports greatly enhanced their photocatalytic activity. Both these $\mathrm{CCA} / \mathrm{TiO}_{2}$ and $\mathrm{CCA} / \mathrm{m}$ $\mathrm{TiO}_{2}$ nanoparticles had a large surface area due to the porous nature of the CCA supports, and they were highly active under visible-light irradiation and exhibited less electronhole combination due to the presence of $\mathrm{C}$ (which acts as electron traps) on the supports. Also, the band gap of the CCA-supported titania nanoparticles was highly reduced. The decrease in the band gap of the CCA-supported catalysts was found to be much higher than the decrease of $0.14 \mathrm{eV}$ which is usually observed for carbon doped titania. The SEM images (Figure 4) revealed that the carbon formed a layer on top of the alumina and that the nanoparticles were successfully impregnated on the highly porous CCA supports.

Figure 5 showed that the catalysts were successfully impregnated onto the CCA supports. The authors also revealed that the catalysts were evenly distributed on the CCA supports. Uniform distribution is a distinguishing feature of CCA supports due to their high adsorption and porous nature. The CCA-supported catalysts were found not to have lost their crystallinity which would have inversely affected the photocatalytic activity of the catalysts.

\section{Thin Films}

As mentioned earlier, the tendency of titanium dioxide nanoparticles to aggregate and scatter incident light as well as the need for posttreatment recovery has made its largescale application economically impractical $[91,211,264]$. This had led to the exploration of a number of techniques to try and immobilise $\mathrm{TiO}_{2}$ nanoparticles on solid supports not only to solve posttreatment problems but also to facilitate the renewable use of the catalyst [66]. Also, $\mathrm{TiO}_{2}$ thin films retain the photocatalytic properties of its powder form. $\mathrm{TIO}_{2}$ thin films can still be applicable in gas sensors, electrodes for solar cells, electrochromic applications, as gate oxides of metaloxide-semiconductor field transitions, laser applications, and photocatalytic degradation of pollutants [150, 264-267].

Although immobilised titania is less photocatalytically active than suspended titania particles due to reduced surface area and less porosity, the merits of using immobilised titania still far outweigh the disadvantages as it provides new avenues in the practical utilisation of titania. The techniques used for synthesis of $\mathrm{TiO}_{2}$ thin films include CVD, dip coating, sol-gel, spin coating, spray pyrolysis, sputtering, liquid-phase deposition, and layer-by-layer (LbL) self-assembly. The substrates used include glass, single-crystal silicon, or polymeric substrates. Some of these thin-film synthesis techniques are discussed in the following subsections.

9.1. Chemical Vapour Deposition. Chemical vapour deposition (CVD) is a versatile method that can be used for the synthesis of a number of materials. To synthesise $\mathrm{TiO}_{2}$ thin films by CVD, either a titanium alkoxide such as titanium isopropoxide (TTIP) is used, which already has the $\mathrm{Ti}-\mathrm{O}_{4}$ tetrahedral motif of the $\mathrm{TiO}_{2}$ in its chemical structure, or $\mathrm{TiCl}_{4}$ is reacted with oxygen to form the $\mathrm{T}-\mathrm{O}_{4}$ tetrahedral motif. These are thereafter deposited on a substrate at elevated temperatures in a vacuum to form the titania thin films [165, $236,268,269]$. CVD offers good control of film structure and composition, excellent uniformity even on highly irregular substrates (conformal deposition), and a sufficiently high growth rate thus applicable for synthesis of multilayer structures [268, 270-272]. To realise the desired physicochemical properties of a material, a suitable substrate surface must be exposed to a suitable growth environment (temperature, pressure, and chemical composition) especially in the gas phase conditions close to the substrate surface [270].

The factors that affect the physicochemical properties of the thin films are the choice of precursors, carrier gas, and their respective flow rates, the total pressure in the reactor, the substrate temperature, the distance between the substrate and the nozzle head, and the water-vapour content in the whole reaction chamber [270,273]. However, CVD is not a straightforward process and is complicated to control. The deposition rates, uniformity, and film properties change when one inert gas is replaced by another, a different-sized substrate is used, a different reactor loading is applied, or an identical process is applied in a different reactor setup [270]. Moreover, the vacuum equipment is expensive and due to the complicated nature of the reaction kinetics in the CVD reactors CVD processes developed in the laboratory are difficult to scale up to industrial scales $[166,235,270]$.

9.2. Liquid-Phase Deposition. Liquid-phase deposition (LPD), unlike CVD, is referred to as a unique soft process in which a metal oxide or hydroxide forms thin films through ligand-exchange (hydrolysis) equilibrium deposition at low temperatures $[232,274]$. The substrate is immersed in the precursor solution (soft-solution deposition) and thereafter the substrate is calcined at high temperatures to obtain crystalline thin films [232, 275]. LPD is a cost-effective method, is regarded as environmentally friendly, and produces smooth, uniform, and dense thin films with good adherence $[235,275]$. However, the thermal treatment of the thin films has been reported to affect the adhesion properties of the nanoparticles on the substrate [235].

9.3. Dip Coating. In dip coating the substrate is slowly immersed in a titanium dioxide precursor solution, for example, TTIP, $\mathrm{TiCl}_{4}$, or $\mathrm{TiCl}_{3}$ and then slowly pulled out at a fixed rate. The coated substrate is then immediately dried in furnace before calcination at elevated temperatures $\left(400^{\circ} \mathrm{C}\right.$ to $\left.500^{\circ} \mathrm{C}\right)[65,276-278]$. Sometimes a complexing agent and a wetting additive are added to stabilise the solution and enhance film adherence [279]. Dip coating is also regarded as a simple, cost-effective technique and it produces uniform coatings with controllable film thickness [277, 280]. However, just like in LPD, the thermal treatment of the thin films affects the adhesion properties of the nanoparticles on the substrate [235].

9.4. Spray Pyrolysis. Spray pyrolysis (SP) is a simple technique that requires a precursor solution (e.g., $\mathrm{TiCl}_{3}, \mathrm{TiCl}_{4}$, 


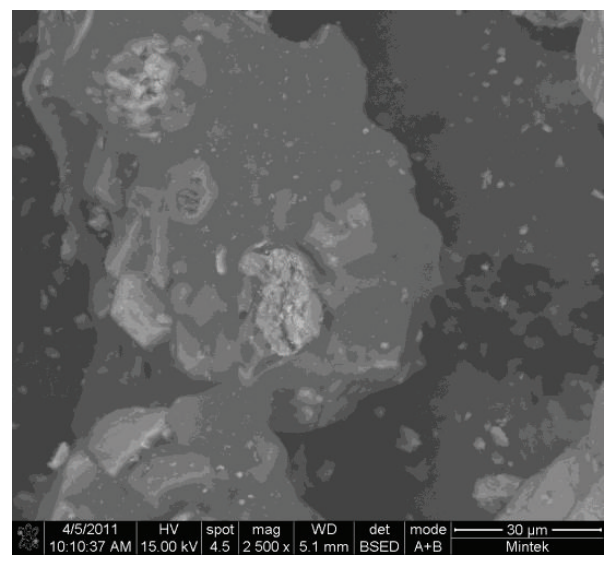

(a)

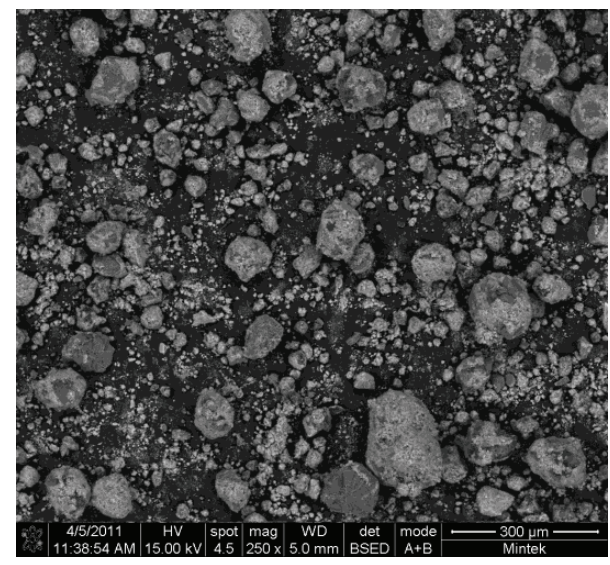

(b)

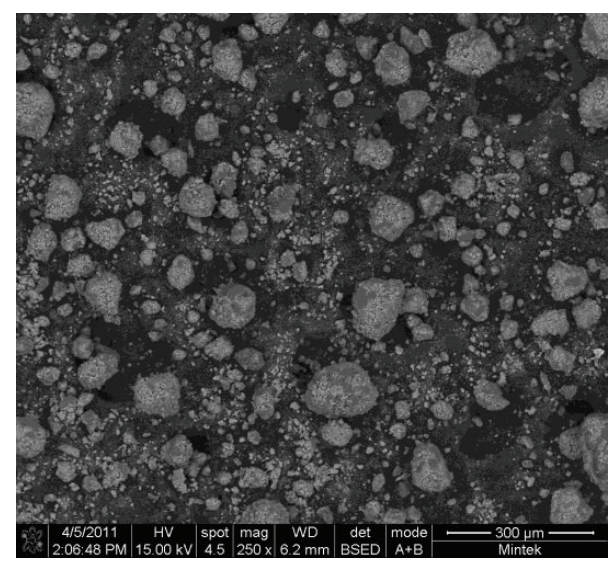

(d)

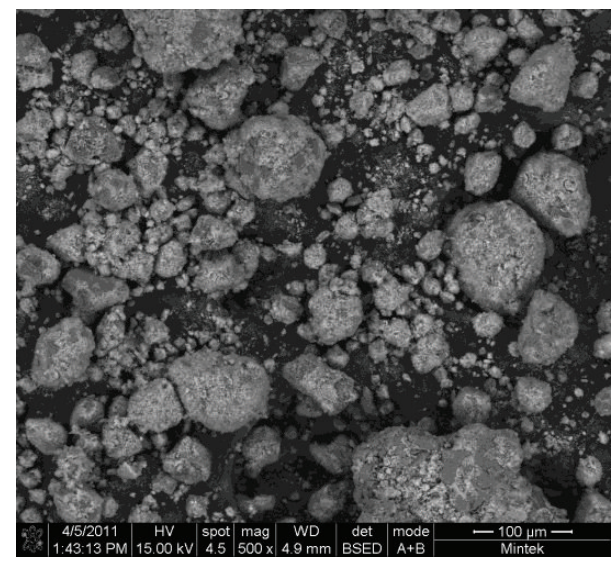

(c)

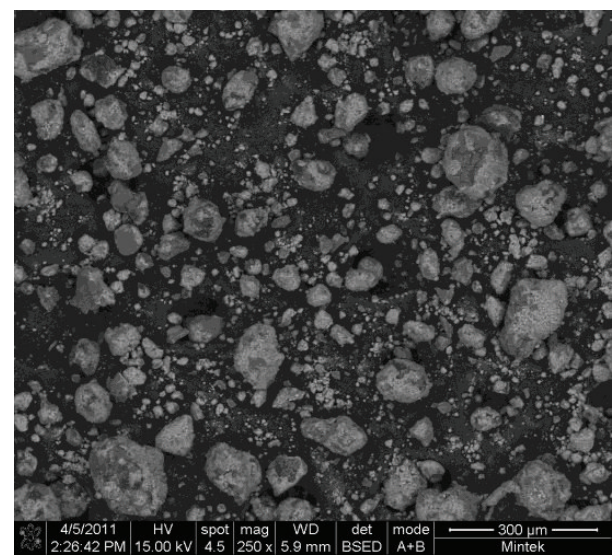

(e)

Figure 4: SEM images of CCA and CCA/ $\mathrm{TiO}_{2}$ nanoparticles [106].

$\mathrm{Ti}(\mathrm{OEt})_{4}$, or TTIP dissolved in water, ethanol, or other solvents), an atomiser, and a heated substrate [156, 281]. In an SP process the solution is atomised into small droplets and the droplets are transported by a gas to the heated substrate where they form thin films upon immediate approach or impingement on the substrate (Figure 6). The source of the atomic mist (aerosol which produces large droplets or ultrasonic spraying which produces smaller droplets) determines the surface morphology of the deposited films [281-283]. The SP method is attractive because it is inexpensive and uses simple facilities, results in rapid film growth, large surface-area substrate coverage, and homogeneity, and has the potential for mass production [156, 283-286].

However, SP has some drawbacks. Poor film quality is observed due to vapour convection in the hot zone because the vapour formed on the heated substrate may hinder the 


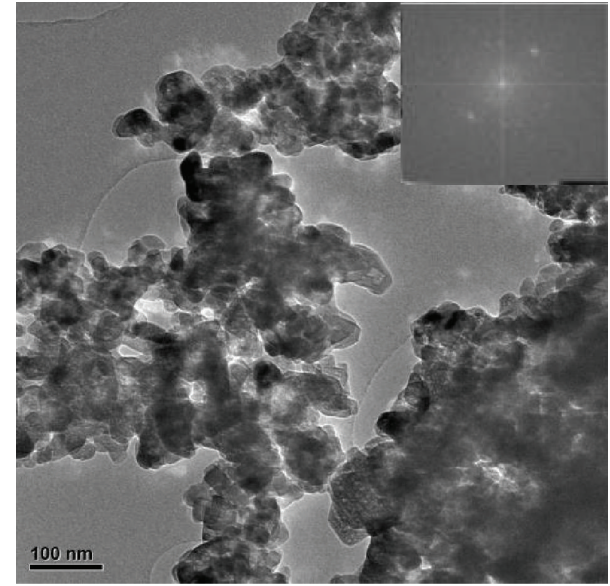

(a)

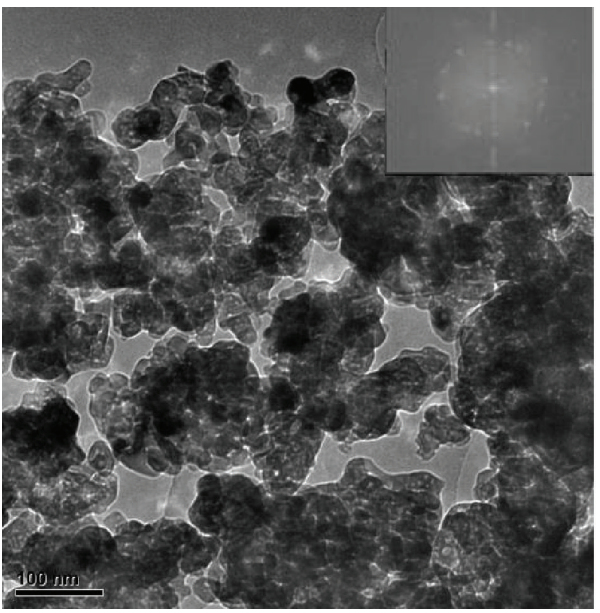

(c)

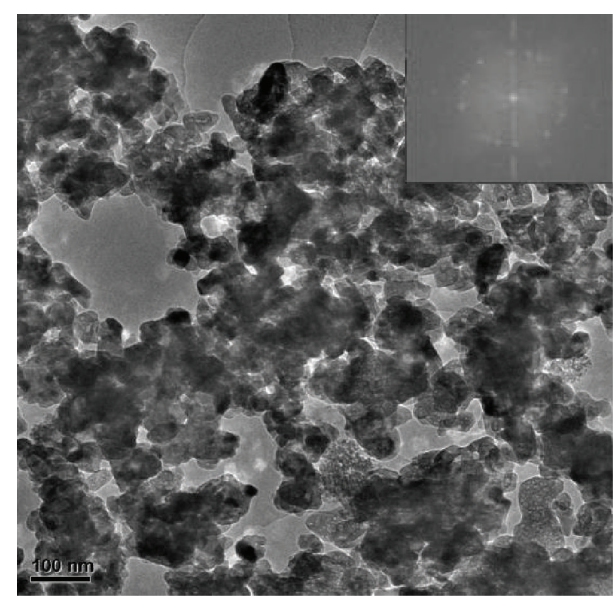

(b)

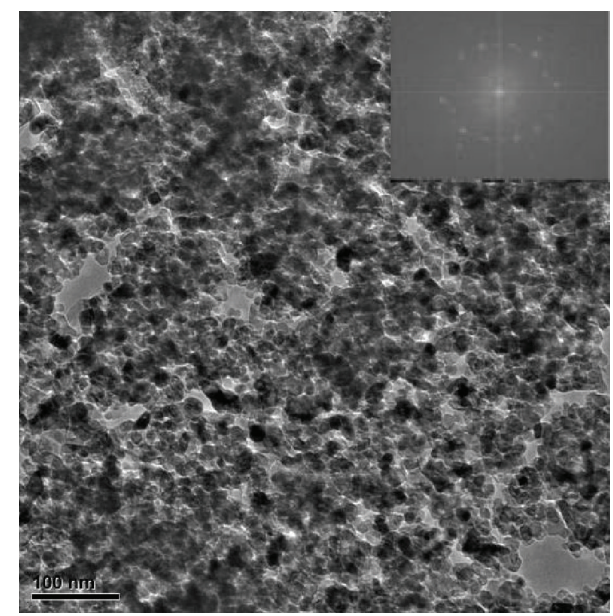

(d)

FIGURE 5: TEM images of the CCA-supported titania nanocatalysts [106].

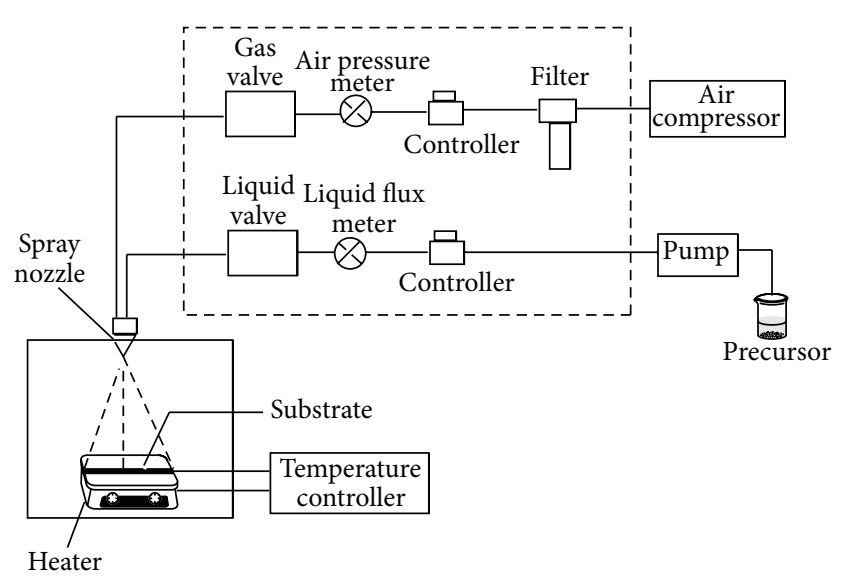

FIGURE 6: Schematic representation of the spray pyrolysis method [107].

source vapour from attaching to the substrate due to the temperature difference. Also, as the source liquid vaporises on the substrate due to thermal decomposition it may result in the formation of thin films with many cracks due to precipitate shrinkage [284]. Also, SP can result in the deposition of powder on the substrate.

9.5. Sol-Gel Technique. The sol-gel technique is the most widely used method for the synthesis of $\mathrm{TiO}_{2}$ thin films. The solution precursors are used to make the sol, and the substrate is immersed in the sol and substrate gelation occurs. These substrates are then aged and calcined at elevated temperatures to produce the thin films [185, 287]. The solgel method has been widely used in the synthesis of titania thin films because it is a simple and cost-effective method that results in the formation of high porosity, low density and low refractive index, high nanoparticle homogeneity, tunable particle size, and high substrate coating [185, 227, 234, 288290]. The $\mathrm{pH}$ of the sol, the ageing time, amount of surfactant template, amount of hydrolysis retardant, and calcination temperature play an important role in the quality of the thin films produced [288]. However, the sol-gel method has some drawbacks. For example, during the ageing of gels and drying of films, the sols produce vapours which cause environmental pollution [287]. Also, the thermal treatment of the thin films 

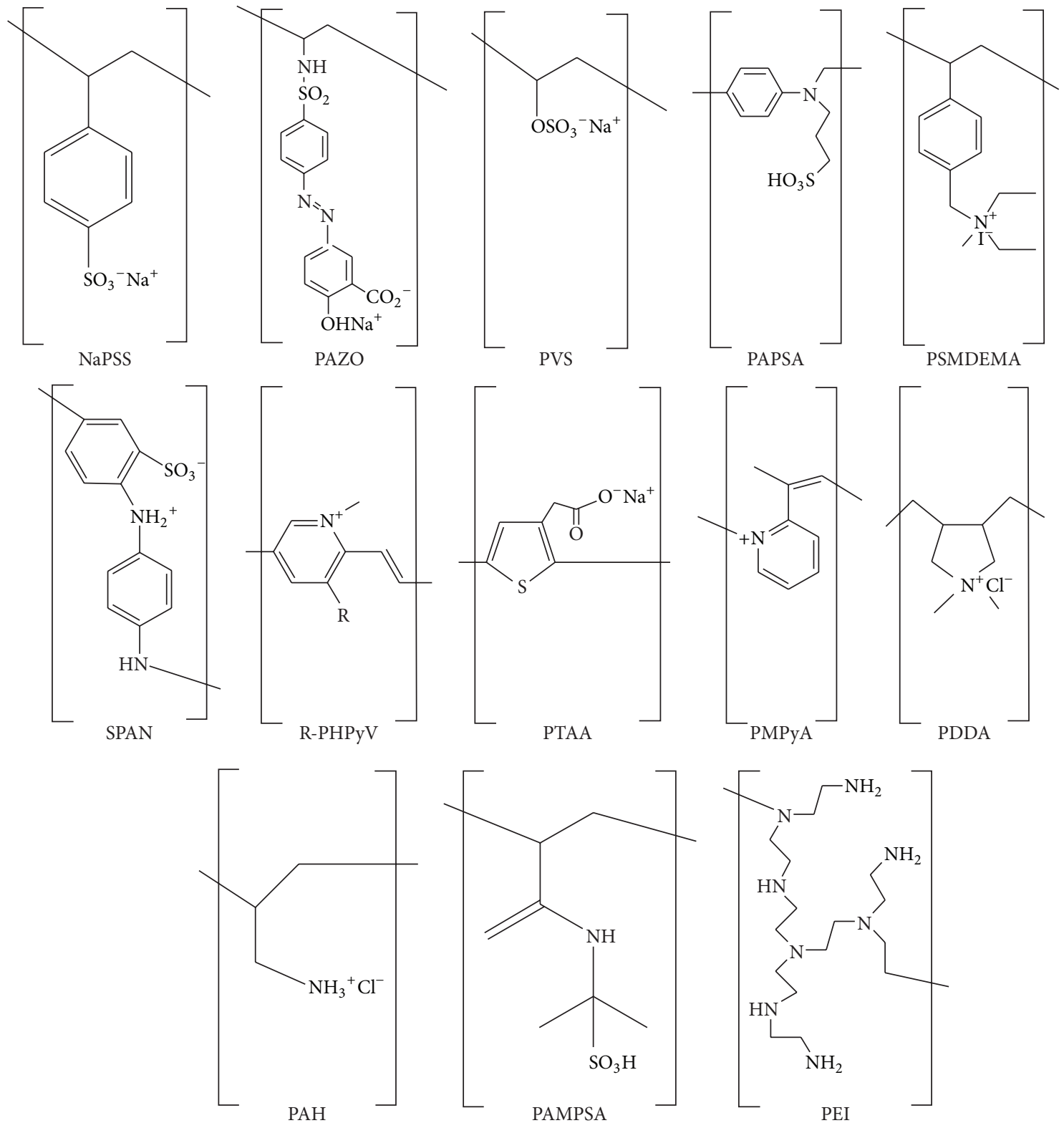

FIGURE 7: Examples of polyelectrolytes used in LbL thin-film synthesis.

affects the adhesion properties of the nanoparticles on the substrate [235].

\subsection{Layer-by-Layer (LbL) Self-Assembly}

9.6.1. Introduction. The layer-by-layer (LbL) self-assembly technique is a technology that enables the nanoconstruction of multifunctional films on solvent-accessible surfaces. It also allows for the design of functional surfaces and surfacebased nanodevices in a "build-to-order" fashion, that is, the capacity to build standard or mass-customised products upon receipt of spontaneous orders without forecasts [109]. Furthermore, the LbL technique exceeds simple selforganisation under equilibrium conditions by making it possible to arrange many different materials at will with nanoscale precision [12, 109, 291-294]. The LbL technique can thus provide solutions for surface modifications and fabrication of thin films; that is, it permits multifunctional assemblies of materials since it allows deposition on surfaces of almost any shape and kind $[109,295]$.

9.6.2. Fabrication of LbL Thin Films. Sequential deposition of polyelectrolytes (polyanions and polycations) on solid surfaces leads to the build-up of multilayer LbL thin films [108, 296, 297]. The LbL self-assembly technique is a physisorption process independent of size and topology of the substrate; however, parameters like solution concentration, ionic strength, solvent composition, and temperature play an important role in the multilayer build-up [292, 295, 298]. Examples of polyelectrolytes used for LbL thin-film fabrication are shown in Figure 7. 


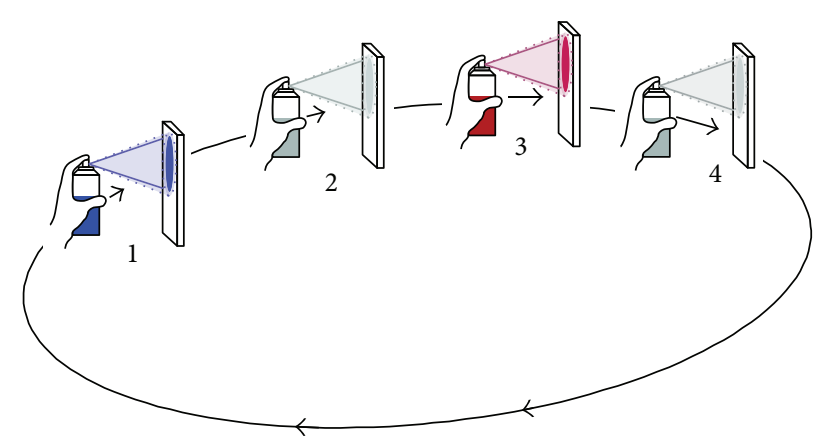

FIGURE 8: Schematic of the LbL electrolyte spraying deposition process [108].
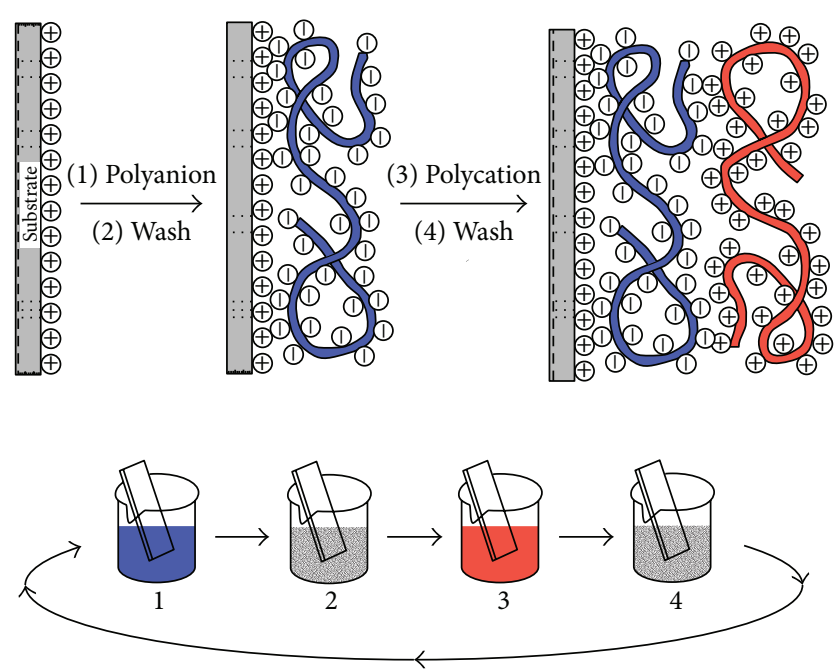

FIGURE 9: Schematic of the LbL electrolyte dipping deposition process [109].

To synthesise LbL thin films, a substrate is either dipped in or sprayed with oppositely charged polyelectrolytes. Also, solutions can be allowed to flow over the substrate. During spraying (Figure 8 ) the electrolyte sprayed on the substrate should not accumulate on the surface but flow away quickly, driven by gravity, and only a thin film of liquid which typically dries within minutes should initially remain on the surface. Because the thickness of the adhering solution is very thin, any spray droplet arriving at the surface immediately fuses with the liquid film and will replace liquid draining off. Spray coating is a fast and convenient application for large surface areas. Thus, this setup provides for mild but permanent agitation as driven by the draining solution [108].

During the dipping method (Figure 9), the substrate is dipped alternately in oppositely charged polyelectrolytes. Each dipping step is followed by a rinsing step to remove excess polyelectrolyte in contact with the surface. The washing is important because it avoids the formation of polyelectrolyte clusters in solution and hence it ensures homogeneity and uniformity of LbL films. Also, the dipping method forms thicker films than the spraying method $[108,109]$. Thus for the purposes of this study the dipping deposition process was preferred.

9.6.3. Applications of LbL Thin Films. There are a number of unprecedented "reagents" or materials for LbL film deposition and these include polymers (linear or branched), colloids (polymeric, metallic, or oxidic), biomacromolecules (DNA/proteins, polynucleotides, bioaggregates, and contact lenses), and nanoparticles (for environmental application) $[293,296,297,299]$. Due to the variety of materials used for LbL thin-film fabrication, its application is therefore spread across a variety of disciplines which include electric and electronic devices (rectifiers, transistors, and switches), film coating, micropatterning, nanobioreactors, photocatalysis, and drug-delivery systems [300-302]. Biomedically, thinfilm coating on medical devices can improve biocompatibility, reduce immunological response, and enhance targeted drug delivery [294]. The LbL self-assembly technique has also been applied in the synthesis of thin-film microcapsules that disintegrate on the target site hence improving drug or DNA delivery to their active site $[298,299,303-307]$. Also, LbL thin films have been applied to assemble semiconductor catalysts (especially $\mathrm{TiO}_{2}$ ) and applied in the degradation of organic pollutants for environmental remediation [12, 293, 308]. LbL self-assembly of $\mathrm{TiO}_{2}$ on thin films can therefore go a long way to overcome the problems associated with the practical application of suspended $\mathrm{TiO}_{2}$ nanoparticles.

9.7. Layer-by-Layer $\mathrm{TiO}_{2}$ Thin Films. The use of titania in powder form has the tendency to aggregate and scatter incident light and there are difficulties associated with the recovery of powdered titania after treatment; hence its largescale application is economically not viable. $\mathrm{TiO}_{2}$ has been assembled on substrates using different methods and applied in catalytic environmental remediation processes. However, since the other $\mathrm{TiO}_{2}$ thin-film fabrication methods have some drawbacks like film cracking, poor adhesion to substrate, the use of high temperatures, expensive equipment, and a high level of expertise required, the LbL self-assembly provides a better alternative. LbL thin films are synthesised at low temperature (room temperature), simple equipment is used, the films require no thermal treatment, and strong adhesion between nanoparticles, electrolyte, and substrate is ensured due to the strong electrostatic interactions [12].

The $\mathrm{TiO}_{2}$ nanoparticles assembled by the LbL selfassembly technique were found to be well separated and highly accessible for the photocatalytic processes. Also, the amount of the nanoparticles deposited was easily controllable $[12,293]$. When compared to other methods like drop-casting and spin-coating, the $\mathrm{LbL}$ assembled $\mathrm{TiO}_{2}$ show superiority in terms of film stability and catalyst reusability (thin film can be used a number of times with the same efficiency). Also, the LbL method has no limit to the number of $\mathrm{TiO}_{2}$ layers that can be assembled and the higher the number of the layers the more the catalytic activity [12]. The use of LbL synthesised thin films therefore overcomes the problems associated with the use of powdered $\mathrm{TiO}_{2}$ as well as the other thin-film assembly techniques and is attractive for practical application in continuous water-treatment and 


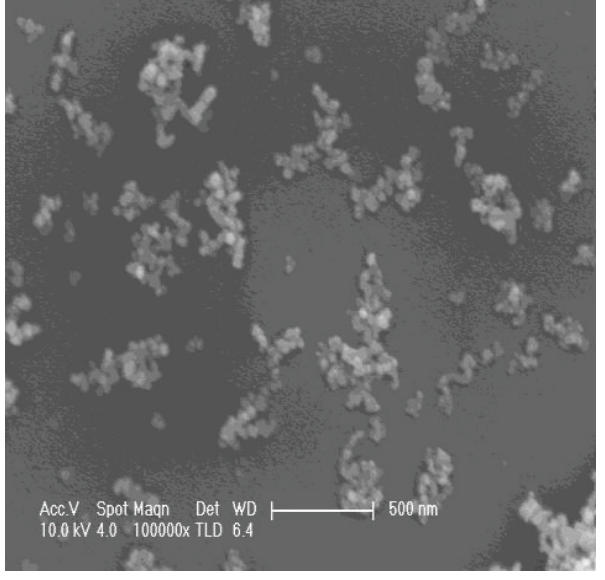

(a)

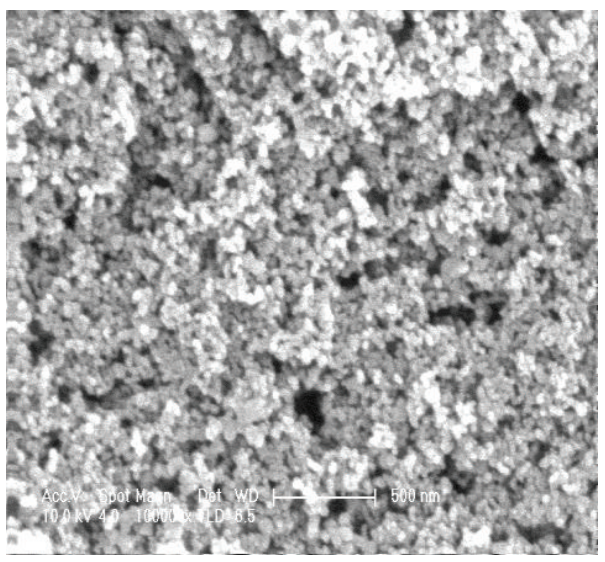

(c)

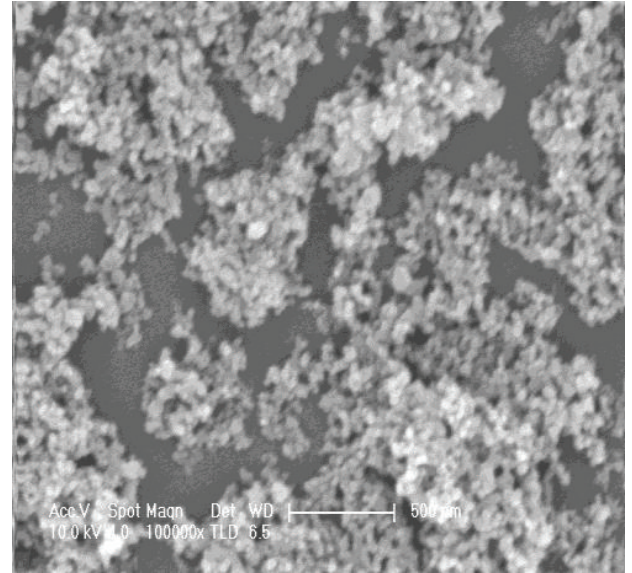

(b)

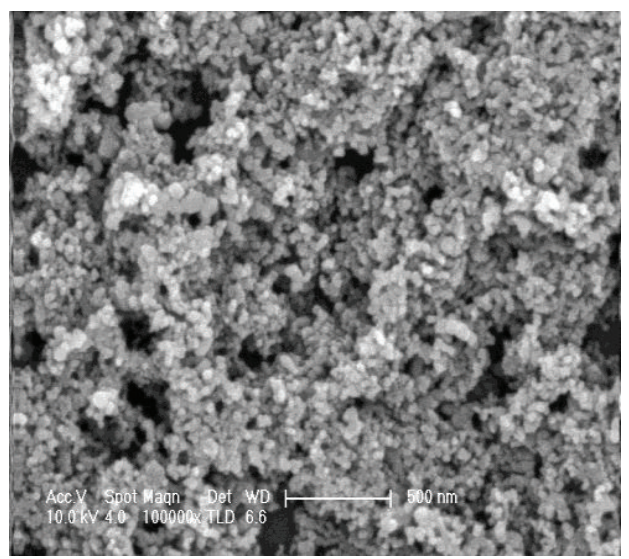

(d)

Figure 10: SEM images of $1,3,5$, and 10 bilayers of the $\mathrm{m}-\mathrm{TiO}_{2}$ nanoparticles thin films [110].

environmental remediation processes. However, little have been reported in recent literature on the assembly and use of metal-doped titania by the LbL method.

\section{Metal-Ion-Doped $\mathrm{TiO}_{2}$ LbL Thin Films}

The immobilization of metal-ion-doped titania on glass slides by the LbL method has been reported recently [110]. This study reveals that the metal-ion-doped titanium dioxide nanoparticles were successfully attached on glass slides and there was an increase in the number of particles and thin-film thickness with increase in the number of bilayers (Figure 10). PAH and PSS electrolytes were used to immobilise these m$\mathrm{TiO}_{2}$ nanoparticles on the glass slides as thin films. The photocatalytic efficiency of the PAH (PSS/ $\left.\mathrm{mTiO}_{2}\right)$ thin films was studied using Rhodamine $\mathrm{B}$ under visible-light illumination. These thin films were highly active towards the photocatalytic degradation of Rhodamine B under visible-light illumination and did not lose their photocatalytic activity and strength even after five cycles. This study shows a great stride in the use of metal-doped titania nanoparticles as it eliminates the problems associated with aggregation and posttreatment and thus increases the chances for easy use in water treatment.

\section{Titania Mixed-Matrix Membranes}

Recently, membrane separation technologies have been found to be cheap and fast, chemically stable, and highly selective. They can also be easily integrated with other watertreatment strategies [309-311]. Because of these properties, they have been found more favourable to be used for watertreatment processes. Membrane techniques do not require addition of chemical substances and therefore it is easy to increase their capacity (modular system). The separation process is in a continuous mode and therefore applicable in mild environmental conditions [312]. Membrane processes can therefore be used in diverse industrial sectors such as pharmaceutical, water treatment, chemical, food processing, electronics (fuel cells), metallurgy, and biotechnology [311, 313-317].

Although using polymeric membranes has major benefits over the conventional water-treatment technologies, their susceptibility to fouling is a major drawback [309, 318]. Foulants may be either crystalline, particulate, thermal, colloidal, microbial (biofouling), or organic fouling [309, 314, 318]. Polysulfone (PS) has been widely used to synthesise membranes. PS membranes are relatively cheap, have a 


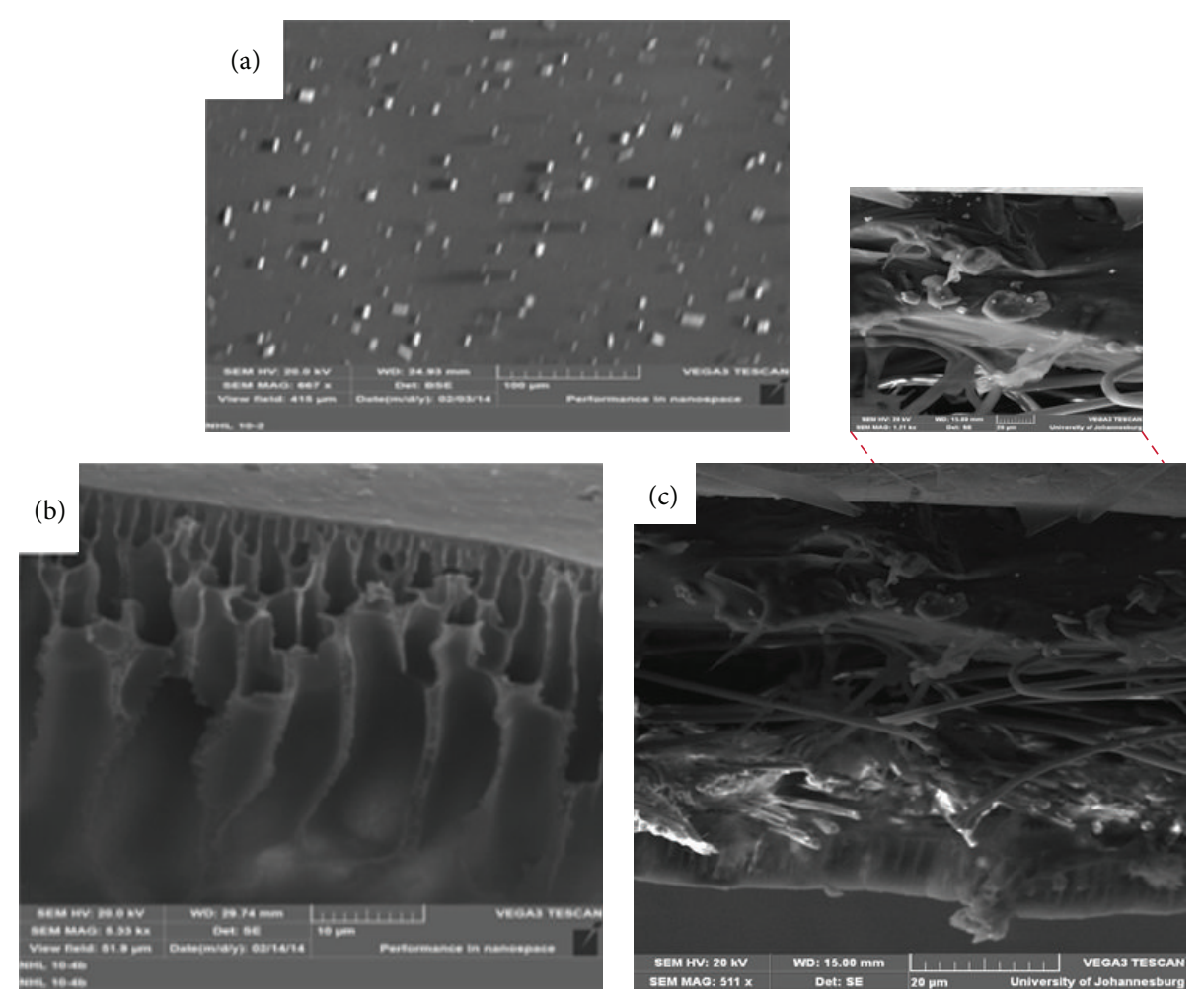

FIGURE 11: SEM micrographs of the $\mathrm{CCA} / \mathrm{TiO}_{2}$ mixed matrix membranes: (a) surface morphology, (b) cross section, and (c) nanoparticles within the polymer matrix [111, 112].

superior film-forming ability, strong thermal and chemical stability, and acidic and alkaline resistance, and hence have been widely used in many applications $[318,319]$. These membranes have good mechanical and anticompaction properties. However, like any other membranes, PS membranes have limitations to be used in water-treatment processes because they easily get fouled, have a low permeate flux, and are hydrophobic in nature $[310,311,320]$, hence the need to modify their properties.

Current research in membrane technology development is focussed on the improvement of antifouling and hydrophilicity properties while maintaining or improving their throughput characteristics [310, 311, 319, 321]. This can be attained by either bulk or surface modification which changes the chemical structure of the membranes. Also, inorganic nanoparticles can be incorporated through the membrane matrix or on the surface [309]. Although this phenomenon is still under debate, it is widely accepted that the thermodynamic state and kinetic properties of the system and how they vary during processing govern the structure formation pathway of the membrane. Also, physical parameters like the temperature, the composition of the casting solution, the composition of the nonsolvent bath, and the surrounding atmosphere play a pivotal role in determining the synthetic pathway as well as the final membrane structure [322, 323]. Incorporating inorganic nanomaterials into polymeric membranes has been found to improve the chemical stability, the thermal stability, the permeation, and the mechanical as well as the antifouling resistance of membranes [313, 318, 321, 324].
For such purposes, nanoparticles like $\mathrm{TiO}_{2}, \mathrm{Al}_{2} \mathrm{O}_{3}, \mathrm{ZrO}_{2}, \mathrm{Cu}$, $\mathrm{Ag}$, and $\mathrm{SiO}_{2}$ have been utilised in the past [309, 311, 318, 325].

Recently CCA-supported free $\mathrm{TiO}_{2}\left(\mathrm{CCA} / \mathrm{TiO}_{2} / \mathrm{PSf}\right)$ and $\mathrm{Pd}$-doped titania (CCA/Pd-TiO $/ 2$ PSf) nanoparticles have been embedded within a polysulfone matrix to synthesise mixed matrix membranes [111, 112]. In these studies, both the $\mathrm{CCA} / \mathrm{TiO}_{2} / \mathrm{PSf}$ and the $\left(\mathrm{CCA} / \mathrm{TiO}_{2} / \mathrm{PSf}\right)$ membranes were found to be highly photoactive for the discolouration of Rhodamine B under visible-light irradiation. The CCAsupported nanoparticles were distributed both within and on the surface of the membranes (Figure 11). These studies revealed that only a minimal amount of the nanoparticles can be incorporated within the polymer matrix without compromising the mechanical properties. Increasing the amount of the nanoparticles to about $0.5 \%$ resulted in weakening of the mechanical properties of the nanoparticles. The presence of the nanoparticles also enhanced the permeate flux as well as the fouling behaviour of the PSf membranes. This is thus a great step that eliminates not only the problems associated with posttreatment and aggregation but also fouling of the membranes and thus provides a better alternative in finding means to deal with water-treatment problems.

\section{Conclusion}

From the literature discussed, the health risks associated with the presence of pollutants in water due to the failure of conventional water-treatment technologies to effectively remove organic and inorganic pollutants have been highlighted. It 
has been revealed that $\mathrm{TiO}_{2}$ nanoparticles have demonstrated the ability to completely degrade organic pollutants in an aqueous medium resulting in the formation of innocuous products and thus have tremendous potential to be used in water-treatment processes. Reformative processes to shift the absorption edge of titania to the visible-light region have been discussed. Supporting the $\mathrm{TiO}_{2}$ on CCA supports has proven to drastically enhance the dispersion of the nanoparticles, reduce electron-hole pair recombination, and increase the surface area resulting in an increased photocatalytic activity. Also, CCA supports were found to play a major role in shifting the absorption edge of titania towards visible-light irradiation. Also, the LbL self-assembly of the metal-iondoped $\mathrm{TiO}_{2}$ on glass substrates overcame the problems associated with the need for the application of costly posttreatment processes needed when using suspended $\mathrm{TiO}_{2}$. The embedding of the titania nanoparticles within the a polymer matrix has proved to be the recent pivotal advancement in the application of titania nanoparticles for environmental remediation processes.

Overall, this review brings to attention the advancements of titania nanoparticles in their use for water-treatment processes. These advancements thus serve as techniques that can be used in conjunction with the present water-treatment technologies to alleviate the problems associated with pollutants in drinking water systems. Also, since titania can degrade organic pollutants while simultaneously oxidising heavy metal species, it serves as a cheap dual process that can be further explored to realize the potential of $\mathrm{TiO}_{2}$ in water-treatment processes. Furthermore, titania provides a cheaper alternative that can be used in conjunction with the already existing water-treatment technologies, especially membranes. Also the use of titania based systems is a better alternative for the use since it harnesses the green solar energy and thus reduces the environmental waste due to the use of chemicals. The ability of $\mathrm{TiO}_{2}$ nanoparticles to completely deal with organic pollutants without producing recalcitrant by-products has thus opened new research avenues to be pursued.

\section{Conflict of Interests}

The authors declare that there is no conflict of interests regarding the publication of this paper.

\section{Acknowledgment}

The authors are grateful to the Department of Applied Chemistry, University of Johannesburg, South Africa, for constantly supporting our research program on nanomaterials, especially their financial support.

\section{References}

[1] K. Murray, L. Slabbert, and B. Moloi, "Needs assessment and development framework for a tested implementation plan for the initialisation and execution of a National Toxicants Monitoring Programme (NTMP)," Final Report, Department of Water Affairs and Forestry (DWAF), Pretoria, South Africa, 2003.
[2] T. Pradeep and Anshup, "Noble metal nanoparticles for water purification: a critical review," Thin Solid Films, vol. 517, no. 24, pp. 6441-6478, 2009.

[3] M. Sun, D. Li, Y. Chen et al., "Synthesis and photocatalytic activity of calcium antimony oxide hydroxide for the degradation of dyes in water," Journal of Physical Chemistry C, vol. 113, no. 31, pp. 13825-13831, 2009.

[4] X. Wang, Z. Gai, B. Yu et al., "Degradation of carbazole by microbial cells immobilized in magnetic gellan gum gel beads," Applied and Environmental Microbiology, vol. 73, no. 20, pp. 6421-6428, 2007.

[5] S. Hong and M. Elimelech, "Chemical and physical aspects of natural organic matter (NOM) fouling of nanofiltration membranes," Journal of Membrane Science, vol. 132, no. 2, pp. 159-181, 1997.

[6] T. S. Natarajan, M. Thomas, K. Natarajan, H. C. Bajaj, and R. J. Tayade, "Study on UV-LED/TiO 2 process for degradation of Rhodamine B dye," Chemical Engineering Journal, vol. 169, no. 1-3, pp. 126-134, 2011.

[7] N. Savage and M. S. Diallo, "Nanomaterials and water purification: opportunities and challenges," Journal of Nanoparticle Research, vol. 7, no. 4-5, pp. 331-342, 2005.

[8] K. Kabra, R. Chaudhary, and R. L. Sawhney, “Treatment of hazardous organic and inorganic compounds through aqueousphase photocatalysis: a review," Industrial and Engineering Chemistry Research, vol. 43, no. 24, pp. 7683-7696, 2004.

[9] P. Romero-Gómez, V. Rico, J. P. Espinós, A. R. González-Elipe, R. G. Palgrave, and R. G. Egdell, "Nitridation of nanocrystalline $\mathrm{TiO}_{2}$ thin films by treatment with ammonia," Thin Solid Films, vol. 519, no. 11, pp. 3587-3595, 2011.

[10] Z. J. Bo, G. Maochu, W. J. Li, L. Z. Min, Z. Ming, and Y. Chen, "Effect of metal doping into $\mathrm{Ce}_{0.5} \mathrm{Zr}_{0.5} \mathrm{O}_{2}$ on photocatalytic activity of $\mathrm{TiO}_{2} / \mathrm{Ce}_{0.45} \mathrm{Zr}_{0.45} \mathrm{M}_{0.1} \mathrm{O}_{X}(\mathrm{M}=\mathrm{Y}, \mathrm{La}, \mathrm{Mn})$," Journal of Hazardous Materials, vol. 143, no. 1-2, pp. 516-521, 2007.

[11] I. Dror, D. Baram, and B. Berkowitz, "Use of nanosized catalysts for transformation of chloro-organic pollutants," Environmental Science and Technology, vol. 39, no. 5, pp. 1283-1290, 2005.

[12] D. N. Priya, J. M. Modak, and A. M. Raichur, "LbL fabricated poly(styrene sulfonate) $/ \mathrm{TiO}_{2}$ multilayer thin films for environmental applications," ACS Applied Materials \& Interfaces, vol. 1, no. 11, pp. 2684-2693, 2009.

[13] H. Choi, E. Stathatos, and D. D. Dionysiou, "Photocatalytic $\mathrm{TiO}_{2}$ films and membranes for the development of efficient wastewater treatment and reuse systems," Desalination, vol. 202, no. 1-3, pp. 199-206, 2007.

[14] G. V. Lowry and K. M. Johnson, "Congener-specific dechlorination of dissolved PCBs by microscale and nanoscale zerovalent iron in a water/methanol solution," Environmental Science and Technology, vol. 38, no. 19, pp. 5208-5216, 2004.

[15] W. Nam, J. H. Park, and G. Y. Han, "Enhanced photocatalytic oxidation properties in $\mathrm{Pt}_{-} \mathrm{TiO}_{2}$ thin films by grounding," Korean Journal of Chemical Engineering, vol. 26, no. 2, pp. 392397, 2009.

[16] P. Wang, T. Zhou, R. Wang, and T.-T. Lim, "Carbon-sensitized and nitrogen-doped $\mathrm{TiO}_{2}$ for photocatalytic degradation of sulfanilamide under visible-light irradiation," Water Research, vol. 45, no. 16, pp. 5015-5026, 2011.

[17] A. Faroon and J. Olson, Toxilogical Profile for Polychlorinated Biphenyls (PCBs), Agency for Toxic Substances and Disease Registry, US Department of Health and Human Security, 2000. 
[18] M. R. Hoffmann, S. T. Martin, W. Choi, and D. W. Bahnemann, "Environmental applications of semiconductor photocatalysis," Chemical Reviews, vol. 95, no. 1, pp. 69-96, 1995.

[19] T. I. Nkambule, R. W. Krause, B. B. Mamba, and J. Haarhoff, "Removal of natural organic matter from water using ionexchange resins and cyclodextrin polyurethanes," Physics and Chemistry of the Earth, vol. 34, no. 13-16, pp. 812-818, 2009.

[20] J. Chen, B. Gu, E. J. LeBoeuf, H. Pan, and S. Dai, "Spectroscopic characterization of the structural and functional properties of natural organic matter fractions," Chemosphere, vol. 48, no. 1 , pp. 59-68, 2002.

[21] H. C. Hong, M. H. Wong, A. Mazumder, and Y. Liang, "Trophic state, natural organic matter content, and disinfection byproduct formation potential of six drinking water reservoirs in the Pearl River Delta, China," Journal of Hydrology, vol. 359, no. 1-2, pp. 164-173, 2008.

[22] A. Matilainen, E. T. Gjessing, T. Lahtinen, L. Hed, A. Bhatnagar, and M. Sillanpää, "An overview of the methods used in the characterisation of natural organic matter (NOM) in relation to drinking water treatment," Chemosphere, vol. 83 , no. 11, pp. 1431-1442, 2011.

[23] B. Gu, J. Schmitt, Z. Chen, L. Liang, and J. F. McCarthy, "Adsorption and desorption of natural organic matter on iron oxide: mechanisms and models," Environmental Science and Technology, vol. 28, no. 1, pp. 38-46, 1994.

[24] V. Kanokkantapong, T. F. Marhaba, P. Pavasant, and B. Panyapinyophol, "Characterization of haloacetic acid precursors in source water," Journal of Environmental Management, vol. 80, no. 3, pp. 214-221, 2006.

[25] S. Mattaraj, C. Jarusutthirak, and R. Jiraratananon, "A combined osmotic pressure and cake filtration model for crossflow nanofiltration of natural organic matter," Journal of Membrane Science, vol. 322, no. 2, pp. 475-483, 2008.

[26] T. I. Nkambule, R. W. M. Krause, J. Haarhoff, and B. B. Mamba, "Treatability and characterization of natural organic matter (NOM) in South African waters using newly developed methods," Physics and Chemistry of the Earth, vol. 36, no. 14-15, pp. 1159-1166, 2011.

[27] S. McDonald, A. G. Bishop, P. D. Prenzler, and K. Robards, "Analytical chemistry of freshwater humic substances," Analytica Chimica Acta, vol. 527, no. 2, pp. 105-124, 2004.

[28] J. Kim, Z. Cai, and M. M. Benjamin, "Effects of adsorbents on membrane fouling by natural organic matter," Journal of Membrane Science, vol. 310, no. 1-2, pp. 356-364, 2008.

[29] H. Zhang, J. Qu, H. Liu, and X. Zhao, "Characterization of isolated fractions of dissolved organic matter from sewage treatment plant and the related disinfection by-products formation potential," Journal of Hazardous Materials, vol. 164, no. 2-3, pp. 1433-1438, 2009.

[30] C. M. M. Bougeard, E. H. Goslan, B. Jefferson, and S. A. Parsons, "Comparison of the disinfection by-product formation potential of treated waters exposed to chlorine and monochloramine," Water Research, vol. 44, no. 3, pp. 729-740, 2010.

[31] A. Kanan and T. Karanfil, "Formation of disinfection by-products in indoor swimming pool water: the contribution from filling water natural organic matter and swimmer body fluids," Water Research, vol. 45, no. 2, pp. 926-932, 2011.

[32] T. Bond, J. Huang, M. R. Templeton, and N. Graham, "Occurrence and control of nitrogenous disinfection by-products in drinking water-a review," Water Research, vol. 45, no. 15, pp. 4341-4354, 2011.
[33] B. Chen, W. Lee, P. K. Westerhoff, S. W. Krasner, and P. Herckes, "Solar photolysis kinetics of disinfection byproducts," Water Research, vol. 44, no. 11, pp. 3401-3409, 2010.

[34] H. Zhang, J. Qu, H. Liu, and D. Wei, "Characterization of dissolved organic matter fractions and its relationship with the disinfection by-product formation," Journal of Environmental Sciences, vol. 21, no. 1, pp. 54-61, 2009.

[35] I. Kristiana, C. Joll, and A. Heitz, "Powdered activated carbon coupled with enhanced coagulation for natural organic matter removal and disinfection by-product control: application in a western Australian water treatment plant," Chemosphere, vol. 83, no. 5, pp. 661-667, 2011.

[36] R. Shen and S. A. Andrews, "Demonstration of 20 pharmaceuticals and personal care products (PPCPs) as nitrosamine precursors during chloramine disinfection," Water Research, vol. 45, no. 2, pp. 944-952, 2011.

[37] S. H. Mhlongo, B. B. Mamba, and R. W. Krause, "Monitoring the prevalence of nitrosamines in South African waters and their removal using cyclodextrin polyurethanes," Physics and Chemistry of the Earth, Parts A/B/C, vol. 34, no. 13-16, pp. 819824, 2009.

[38] J. Nawrocki and P. Andrzejewski, "Nitrosamines and water," Journal of Hazardous Materials, vol. 189, no. 1-2, pp. 1-18, 2011.

[39] V. V. B. Rao and S. R. M. Rao, "Adsorption studies on treatment of textile dyeing industrial effluent by flyash," Chemical Engineering Journal, vol. 116, no. 1, pp. 77-84, 2006.

[40] S. N. Husaini, J. H. Zaidi, F. Malik, and M. Arif, "Application of nuclear track membrane for the reduction of pollutants in the industrial effluent," Radiation Measurements, vol. 43, no. 1, pp. S607-S611, 2008.

[41] X.-H. Ou, C.-H. Wu, and S.-L. Lo, "Photodegradation of 4chlorophenol by UV/photocatalysts: the effect of the interparticle electron transfer process," Reaction Kinetics and Catalysis Letters, vol. 88, no. 1, pp. 89-95, 2006.

[42] S. M. Ali, S. Z. Sabae, M. Fayez, M. Monib, and N. A. Hegazi, "The influence of agro-industrial effluents on River Nile pollution," Journal of Advanced Research, vol. 2, no. 1, pp. 85-95, 2011.

[43] B. Sancey, G. Trunfio, J. Charles et al., "Heavy metal removal from industrial effluents by sorption on cross-linked starch: chemical study and impact on water toxicity," Journal of Environmental Management, vol. 92, no. 3, pp. 765-772, 2011.

[44] K.-H. Kim and S.-K. Ihm, "Heterogeneous catalytic wet air oxidation of refractory organic pollutants in industrial wastewaters: a review," Journal of Hazardous Materials, vol. 186, no. 1, pp. 16-34, 2011.

[45] B. Hajem, H. Hamzaoui, and A. M'nif, "Chemical interaction between industrial acid effluents and the hydrous medium," Desalination, vol. 206, no. 1-3, pp. 154-162, 2007.

[46] L.-C. Chiang, J.-E. Chang, and S.-C. Tseng, "Electrochemical oxidation pretreatment of refractory organic pollutants," Water Science and Technology, vol. 36, no. 2-3, pp. 123-130, 1997.

[47] S. Ghasemi, S. Rahimnejad, S. R. Setayesh, S. Rohani, and M. R. Gholami, "Transition metal ions effect on the properties and photocatalytic activity of nanocrystalline $\mathrm{TiO}_{2}$ prepared in an ionic liquid," Journal of Hazardous Materials, vol. 172, no. 2-3, pp. 1573-1578, 2009.

[48] A. Kaur, S. Vats, S. Rekhi et al., "Physico-chemical analysis of the industrial effluents and their impact on the soil microflora," Procedia Environmental Sciences, vol. 2, pp. 595-599, 2010.

[49] B. Kayan, B. Gözmen, M. Demirel, and A. M. Gizir, "Degradation of acid red 97 dye in aqueous medium using wet oxidation 
and electro-Fenton techniques," Journal of Hazardous Materials, vol. 177, no. 1-3, pp. 95-102, 2010.

[50] L. Lei, Q. Dai, M. Zhou, and X. Zhang, "Decolorization of cationic red X-GRL by wet air oxidation: performance optimization and degradation mechanism," Physics and Chemistry of the Earth, Parts A/B/C, vol. 68, no. 13-16, pp. 1135-1142, 2007.

[51] H. Y. He, W. X. Dong, and G. H. Zhang, "Photodegradation of aqueous methyl orange on $\mathrm{MnTiO}_{3}$ powder at different initial pH," Research on Chemical Intermediates, vol. 36, no. 9, pp. 9951001, 2010.

[52] K. Yu, S. Yang, H. He, C. Sun, C. Gu, and Y. Ju, "Visible light-driven photocatalytic degradation of rhodamine $\mathrm{B}$ over $\mathrm{NaBiO}_{3}$ : Pathways and mechanism," Journal of Physical Chemistry A, vol. 113, no. 37, pp. 10024-10032, 2009.

[53] A. Murat, A. Meltem, S. Funda, K. Nadir, A. Ertugrul, and S. Hikmet, "A novel approach to the hydrothermal synthesis of anatase titania nanoparticles and the photocatalytic degradation of rhodamine B,' Turkish Journal of Chemistry, vol. 30, pp. 333-343, 2006.

[54] N. C. Respicio and J. Heitz, "Comparative toxicity of rhodamine B and rhodamine 6G to the house fly (Musca domestica L.)," Bulletin of Environmental Contamination and Toxicology, vol. 27, no. 2, pp. 274-281, 1981.

[55] T. Masciangioli and W.-X. Zhang, "Environmental technologies at the nanoscale," Environmental Science and Technology, vol. 37, no. 5, pp. 102-108, 2003.

[56] S. Suárez, N. Arconada, Y. Castro et al., "Photocatalytic degradation of TCE in dry and wet air conditions with $\mathrm{TiO}_{2}$ porous thin films," Applied Catalysis B: Environmental, vol. 108-109, pp. 14-21, 2011.

[57] Y. Cao, H. Tan, T. Shi, T. Shi, T. Tang, and J. Li, "Preparation of Ag-doped $\mathrm{TiO}_{2}$ nanoparticles for photocatalytic degradation of acetamiprid in water," Journal of Chemical Technology and Biotechnology, vol. 83, no. 4, pp. 546-552, 2008.

[58] J. Sá and J. A. Anderson, "FTIR study of aqueous nitrate reduction over $\mathrm{Pd} / \mathrm{TiO}_{2}$," Applied Catalysis B: Environmental, vol. 77, no. 3-4, pp. 409-417, 2008.

[59] C.-M. Hung, "Catalytic wet oxidation of ammonia solution: activity of the nanoscale platinum-palladium-rhodium composite oxide catalyst," Journal of Hazardous Materials, vol. 163, no. 1, pp. 180-186, 2009.

[60] Z. Wu and M. Zhou, "Partial degradation of phenol by advanced electrochemical oxidation process," Environmental Science and Technology, vol. 35, no. 13, pp. 2698-2703, 2001.

[61] J. Mucha and R. Zarzycki, "Analysis of wet oxidation process after initial thermohydrolysis of excess sewage sludge," Water Research, vol. 42, no. 12, pp. 3025-3032, 2008.

[62] A. W. Zularisam, A. F. Ismail, and R. Salim, "Behaviours of natural organic matter in membrane filtration for surface water treatment-a review," Desalination, vol. 194, no. 1-3, pp. 211-231, 2006.

[63] M. Anpo, "Utilization of $\mathrm{TiO}_{2}$ photocatalysts in green chemistry," Pure and Applied Chemistry, vol. 72, no. 7, pp. 1265-1270, 2000.

[64] J.-Y. Li, W.-H. Ma, P.-X. Lei, and J.-C. Zhao, "Detection of intermediates in the $\mathrm{TiO}_{2}$-assisted photodegradation of Rhodamine B under visible light irradiation," Journal of Environmental Sciences, vol. 19, no. 7, pp. 892-896, 2007.

[65] K. Sunada, Y. Kikuchi, K. Hashimoto, and A. Fujishima, "Bactericidal and detoxification effects of $\mathrm{TiO}_{2}$ thin film photocatalysts," Environmental Science and Technology, vol. 32, no. 5, pp. 726-728, 1998.
[66] A. Bhattacharyya, S. Kawi, and M. B. Ray, "Photocatalytic degradation of orange II by $\mathrm{TiO}_{2}$ catalysts supported on adsorbents," Catalysis Today, vol. 98, no. 3, pp. 431-439, 2004.

[67] V. Mirkhani, S. Tangestaninejad, M. Moghadam, M. H. Habibi, and A. R. Vartooni, "Photodegradation of aromatic amines by $\mathrm{Ag}-\mathrm{TiO}_{2}$ photocatalyst," Journal of the Iranian Chemical Society, vol. 6, no. 4, pp. 800-807, 2009.

[68] P. E. Savage, "Organic chemical reactions in supercritical water," Chemical Reviews, vol. 99, no. 2-3, pp. 603-621, 1999.

[69] H. E. Barner, C. Y. Huang, T. Johnson, G. Jacobs, M. A. Martch, and W. R. Killilea, "Supercritical water oxidation: an emerging technology," Journal of Hazardous Materials, vol. 31, no. 1, pp. $1-17,1992$.

[70] V. Marulanda and G. Bolaños, "Supercritical water oxidation of a heavily PCB-contaminated mineral transformer oil: Laboratory-scale data and economic assessment," Journal of Supercritical Fluids, vol. 54, no. 2, pp. 258-265, 2010.

[71] S.-H. Son, J.-H. Lee, and C.-H. Lee, "Corrosion phenomena of alloys by subcritical and supercritical water oxidation of 2chlorophenol," Journal of Supercritical Fluids, vol. 44, no. 3, pp. 370-378, 2008.

[72] T. Fujii, R. Hayashi, S.-I. Kawasaki, A. Suzuki, and Y. Oshima, "Water density effects on methanol oxidation in supercritical water at high pressure up to $100 \mathrm{MPa}$," Journal of Supercritical Fluids, vol. 58, no. 1, pp. 142-149, 2011.

[73] P. A. Marrone and G. T. Hong, "Corrosion control methods in supercritical water oxidation and gasification processes," Journal of Supercritical Fluids, vol. 51, no. 2, pp. 83-103, 2009.

[74] R. Hayashi, M. Onishi, M. Sugiyama, S. Koda, and Y. Oshima, "Kinetic analysis on alcohol concentration and mixture effect in supercritical water oxidation of methanol and ethanol by elementary reaction model," The Journal of Supercritical Fluids, vol. 40, no. 1, pp. 74-83, 2007.

[75] F. Stüber, J. Font, A. Fortuny, C. Bengoa, A. Eftaxias, and A. Fabregat, "Carbon materials and catalytic wet air oxidation of organic pollutants in wastewater," Topics in Catalysis, vol. 33, no. 1-4, pp. 3-50, 2005.

[76] N. Li, C. Descorme, and M. Besson, "Catalytic wet air oxidation of chlorophenols over supported ruthenium catalysts," Journal of Hazardous Materials, vol. 146, no. 3, pp. 602-609, 2007.

[77] D. Prabhakaran, T. Kannadasan, and C. Ahmed Basha, "Mediated electrochemical oxidation process for destruction of TOC in a batch recirculation reactor," International Journal of ChemTech Research, vol. 1, no. 4, pp. 962-969, 2009.

[78] D. Nematollahi and L. Mohammadi-Behzad, "Electrochemical oxidation of catechol in the presence of some azacrown ethers and transition metal ions in acetonitrile," International Journal of Electrochemical Science, vol. 4, no. 11, pp. 1583-1592, 2009.

[79] L.-C. Chiang, J.-E. Chang, and T.-C. Wen, "Indirect oxidation effect in electrochemical oxidation treatment of landfill leachate," Water Research, vol. 29, no. 2, pp. 671-678, 1995.

[80] J. D. Rodgers, W. Jedral, and N. J. Bunce, "Electrochemical oxidation of chlorinated phenols," Environmental Science and Technology, vol. 33, no. 9, pp. 1453-1457, 1999.

[81] S. Jiao, S. Zheng, D. Yin, L. Wang, and L. Chen, "Aqueous photolysis of tetracycline and toxicity of photolytic products to luminescent bacteria," Chemosphere, vol. 73, no. 3, pp. 377-382, 2008.

[82] L. Fang, J. Huang, G. Yu, and X. Li, "Quantitative structureproperty relationship studies for direct photolysis rate constants and quantum yields of polybrominated diphenyl ethers in 
hexane and methanol," Ecotoxicology and Environmental Safety, vol. 72, no. 5, pp. 1587-1593, 2009.

[83] B. Abramović, D. Šojić, and V. Anderluh, "Visible-light-induced photocatalytic degradation of herbicide mecoprop in aqueous suspension of $\mathrm{TiO}_{2}$," Acta Chimica Slovenica, vol. 54, no. 3, pp. 558-564, 2007.

[84] E. Bae and W. Choi, "Highly enhanced photoreductive degradation of perchlorinated compounds on dye-sensitized metal/ $\mathrm{TiO}_{2}$ under visible light," Environmental Science \& Technology, vol. 37, no. 1, pp. 147-152, 2003.

[85] F. Zhang, J. Zhao, T. Shen, H. Hidaka, E. Pelizzetti, and N. Serpone, " $\mathrm{TiO}_{2}$-assisted photodegradation of dye pollutants. II. Adsorption and degradation kinetics of eosin in $\mathrm{TiO}_{2}$ dispersions under visible light irradiation," Applied Catalysis B: Environmental, vol. 15, no. 1-2, pp. 147-156, 1998.

[86] L. Zhang and T. J. Webster, "Nanotechnology and nanomaterials: promises for improved tissue regeneration," Nano Today, vol. 4, no. 1, pp. 66-80, 2009.

[87] B. F. G. Johnson, "Nanoparticles in catalysis," Topics in Catalysis, vol. 24, no. 1-4, pp. 147-159, 2003.

[88] X. Chen and S. S. Mao, "Titanium dioxide nanomaterials: Synthesis, properties, modifications and applications," Chemical Reviews, vol. 107, no. 7, pp. 2891-2959, 2007.

[89] Z. He, C. Sun, S. Yang, Y. Ding, H. He, and Z. Wang, "Photocatalytic degradation of rhodamine $\mathrm{B}$ by $\mathrm{Bi}_{2} \mathrm{WO}_{6}$ with electron accepting agent under microwave irradiation: mechanism and pathway," Journal of Hazardous Materials, vol. 162, no. 2-3, pp. 1477-1486, 2009.

[90] W. Dong and C. Zhu, "Optical properties of surface-modified $\mathrm{Bi}_{2} \mathrm{O}_{3}$ nanoparticles," Journal of Physics and Chemistry of Solids, vol. 64, no. 2, pp. 265-271, 2003.

[91] F. Meng, F. Lu, Z. Sun, and J. Lü, "A mechanism for enhanced photocatalytic activity of nano-size silver particle modified titanium dioxide thin films," Science China Technological Sciences, vol. 53, no. 11, pp. 3027-3032, 2010.

[92] A. Fujishima, T. N. Rao, and D. A. Tryk, "Titanium dioxide photocatalysis," Journal of Photochemistry and Photobiology C: Photochemistry Reviews, vol. 1, no. 1, pp. 1-21, 2000.

[93] M. Ni, M. K. H. Leung, D. Y. C. Leung, and K. Sumathy, "A review and recent developments in photocatalytic water-splitting using $\mathrm{TiO}_{2}$ for hydrogen production," Renewable and Sustainable Energy Reviews, vol. 11, no. 3, pp. 401-425, 2007.

[94] W. Tang, Q. Wang, X. Zeng, and X. Chen, "Photocatalytic degradation on Disperse Blue with modified nano- $\mathrm{TiO}_{2}$ film electrode," Journal of Solid State Electrochemistry, vol. 16, no. 4, pp. 1429-1445, 2012.

[95] U. Diebold, "The surface science of titanium dioxide," Surface Science Reports, vol. 48, no. 5-8, pp. 53-229, 2003.

[96] A. Kudo, R. Niishiro, A. Iwase, and H. Kato, "Effects of doping of metal cations on morphology, activity, and visible light response of photocatalysts," Chemical Physics, vol. 339, no. 1-3, pp. 104110, 2007.

[97] A. R. Malagutti, H. A. J. L. Mourão, J. R. Garbin, and C. Ribeiro, "Deposition of $\mathrm{TiO}_{2}$ and Ag: $\mathrm{TiO}_{2}$ thin films by the polymeric precursor method and their application in the photodegradation of textile dyes," Applied Catalysis B: Environmental, vol. 90, no. 1-2, pp. 205-212, 2009.

[98] K. M. Reddy, S. V. Manorama, and A. R. Reddy, "Bandgap studies on anatase titanium dioxide nanoparticles," Materials Chemistry and Physics, vol. 78, no. 1, pp. 239-245, 2003.
[99] R. Pode, "On the problem of open circuit voltage in metal phthalocyanine/C60 organic solar cells," Advanced Materials Letters, vol. 2, pp. 3-11, 2011.

[100] R. Ferrando, J. Jellinek, and R. L. Johnston, "Nanoalloys: from theory to applications of alloy clusters and nanoparticles," Chemical Reviews, vol. 108, no. 3, pp. 845-910, 2008.

[101] L. Shivalingappa, J. Sheng, and T. Fukami, "Photocatalytic effect in platinum doped titanium dioxide films," Vacuum, vol. 48, no. 5, pp. 413-416, 1997.

[102] C. Minero, G. Mariella, V. Maurino, D. Vione, and E. Pelizzetti, "Photocatalytic transformation of organic compounds in the presence of inorganic ions. 2. Competitive reactions of phenol and alcohols on a titanium dioxide-fluoride system," Langmuir, vol. 16, no. 23, pp. 8964-8972, 2000.

[103] C. Minero, G. Mariella, V. Maurino, and E. Pelizzetti, "Photocatalytic transformation of organic compounds in the presence of inorganic anions. 1. Hydroxyl-mediated and direct electrontransfer reactions of phenol on a titanium dioxide-fluoride system," Langmuir, vol. 16, no. 6, pp. 2632-2641, 2000.

[104] S. Wang, L. Ji, B. Wu, Q. Gong, Y. Zhu, and J. Liang, "Influence of surface treatment on preparing nanosized $\mathrm{TiO}_{2}$ supported on carbon nanotubes," Applied Surface Science, vol. 255, no. 5, pp. 3263-3266, 2008.

[105] P. Bouras, E. Stathatos, and P. Lianos, "Pure versus metalion-doped nanocrystalline titania for photocatalysis," Applied Catalysis B: Environmental, vol. 73, no. 1-2, pp. 51-59, 2007.

[106] M. M. Mahlambi, A. K. Mishra, S. B. Mishra, R. W. Krause, B. B. Mamba, and A. M. Raichur, "Effect of metal ions (Ag, Co, $\mathrm{Ni}$, and $\mathrm{Pd}$ ) on the visible light degradation of Rhodamine $\mathrm{B}$ by carbon-covered alumina-supported $\mathrm{TiO}_{2}$ in aqueous solutions," Industrial and Engineering Chemistry Research, vol. 52, no. 5, pp. 1783-1794, 2013.

[107] W. Weng, M. Ma, P. Du et al., "Superhydrophilic Fe doped titanium dioxide thin films prepared by a spray pyrolysis deposition," Surface and Coatings Technology, vol. 198, no. 1-3, pp. 340-344, 2005.

[108] A. Izquierdo, S. S. Ono, J.-C. Voegel, P. Schaaf, and G. Decher, "Dipping versus spraying: exploring the deposition conditions for speeding up layer-by-layer assembly," Langmuir, vol. 21, no. 16, pp. 7558-7567, 2005.

[109] G. Decher, "Fuzzy nanoassemblies: toward layered polymeric multicomposites," Science, vol. 277, no. 5330, pp. 1232-1237, 1997.

[110] M. M. Mahlambi, A. K. Mishra, S. B. Mishra, A. M. Raichur, B. B. Mamba, and R. W. Krause, "Layer-by-layer self-assembled metal-ion- (Ag-, Co-, Ni-, and Pd-) doped $\mathrm{TiO}_{2}$ nanoparticles: synthesis, characterisation, and visible light degradation of rhodamine B," Journal of Nanomaterials, vol. 2012, Article ID 302046, 12 pages, 2012.

[111] M. M. Mahlambi, O. T. Mahlangu, G. D. Vilakati, and B. B. Mamba, "Visible light photodegradation of rhodamine B dye by two forms of carbon-covered alumina supported $\mathrm{TiO}_{2} /$ polysulfone membranes," Industrial and Engineering Chemistry Research, vol. 53, no. 14, pp. 5709-5717, 2014.

[112] M. M. Mahlambi, G. D. Vilakati, and B. B. Mamba, "Synthesis, characterization, and visible light degradation of rhodamine $\mathrm{B}$ dye by carbon-covered alumina supported Pd$\mathrm{TiO}_{2} /$ polysulfone membranes," Separation Science and Technology, vol. 49, no. 14, pp. 2124-2134, 2014.

[113] A. N. Guz and Y. Y. Rushchitskii, "Nanomaterials: on the mechanics of nanomaterials," International Applied Mechanics, vol. 39, no. 11, pp. 1271-1293, 2003. 
[114] J. D. Mackenzie and E. P. Bescher, "Chemical routes in the synthesis of nanomaterials using the sol-gel process," Accounts of Chemical Research, vol. 40, no. 9, pp. 810-818, 2007.

[115] C. E. Allmond, A. T. Sellinger, K. Gogick, and J. M. FitzGerald, "Photo-chemical synthesis and deposition of noble metal nanoparticles," Applied Physics A, vol. 86, no. 4, pp. 477480, 2007.

[116] K. Ramanathan, D. Avnir, A. Modestov, and O. Lev, "Sol-gel derived ormosil-exfoliated graphite- $\mathrm{TiO}_{2}$ composite floating catalyst: photodeposition of copper," Chemistry of Materials, vol. 9, no. 11, pp. 2533-2540, 1997.

[117] J. Wang, R. Li, Z. Zhang et al., "Degradation of hazardous dyes in wastewater using nanometer mixed crystal $\mathrm{TiO}_{2}$ powders under visible light irradiation," Water, Air, and Soil Pollution, vol. 189, no. 1-4, pp. 225-237, 2008.

[118] D. Beydoun and R. Amal, "Implications of heat treatment on the properties of a magnetic iron oxide-titanium dioxide photocatalyst," Materials Science and Engineering B, vol. 94, no. 1, pp. 71-81, 2002.

[119] W. Ho, J. C. Yu, and S. Lee, "Synthesis of hierarchical nanoporous F-doped $\mathrm{TiO}_{2}$ spheres with visible light photocatalytic activity," Chemical Communications, no. 10, pp. 1115-1117, 2006.

[120] J. Yu and J. Zhang, "A simple template-free approach to $\mathrm{TiO}_{2}$ hollow spheres with enhanced photocatalytic activity," Dalton Transactions, vol. 39, no. 25, pp. 5860-5867, 2010.

[121] H. D. Jang, S.-K. Kim, and S.-J. Kim, "Effect of particle size and phase composition of titanium dioxide nanoparticles on the photocatalytic properties," Journal of Nanoparticle Research, vol. 3, no. 2-3, pp. 141-147, 2001.

[122] A. Pottier, C. Chanéac, E. Tronc, L. Mazerolles, and J.-P. Jolivet, "Synthesis of brookite $\mathrm{TiO}_{2}$ nanoparticles by thermolysis of $\mathrm{TiCl}_{4}$ in strongly acidic aqueous media," Journal of Materials Chemistry, vol. 11, no. 4, pp. 1116-1121, 2001.

[123] D.-S. Seo, J.-K. Lee, E.-G. Lee, and H. Kim, "Effect of aging agents on the formation of $\mathrm{TiO}_{2}$ nanocrystalline powder," Materials Letters, vol. 51, no. 2, pp. 115-119, 2001.

[124] M. Afuyoni, G. Nashed, and I. M. Nasser, " $\mathrm{TiO}_{2}$ doped with $\mathrm{SnO}_{2}$ and studing its structural and electrical properties," Energy Procedia, vol. 6, pp. 11-20, 2011.

[125] S. Nakade, M. Matsuda, S. Kambe et al., "Dependence of $\mathrm{TiO}_{2}$ nanoparticle preparation methods and annealing temperature on the efficiency of dye-sensitized solar cells," Journal of Physical Chemistry B, vol. 106, no. 39, pp. 10004-10010, 2002.

[126] M. Subramanian, S. Vijayalakshmi, S. Venkataraj, and R. Jayavel, "Effect of cobalt doping on the structural and optical properties of $\mathrm{TiO}_{2}$ films prepared by sol-gel process," Thin Solid Films, vol. 516, no. 12, pp. 3776-3782, 2008.

[127] J. Ovenstone, "Preparation of novel titania photocatalysts with high activity," Journal of Materials Science, vol. 36, no. 6, pp. 1325-1329, 2001.

[128] Y. Zhang, A. Weidenkaff, and A. Reller, "Mesoporous structure and phase transition of nanocrystalline $\mathrm{TiO}_{2}$," Materials Letters, vol. 54, no. 5-6, pp. 375-381, 2002.

[129] M. Behpour, S. M. Ghoreishi, and F. S. Razavi, "Photocatalytic activity of $\mathrm{TiO}_{2} / \mathrm{Ag}$ nanoparticles on degradation of water pollutions," Digest Journal of Nanomaterials and Biostructures, vol. 5, no. 2, pp. 467-475, 2010.

[130] J. Araña, J. M. Doña-Rodríguez, E. Tello Rendón et al., “TiO activation by using activated carbon as a support: part I. Surface characterisation and decantability study," Applied Catalysis B: Environmental, vol. 44, no. 2, pp. 161-172, 2003.
[131] P. C. Lansåker, J. Backholm, G. A. Niklasson, and C. G. Granqvist, " $\mathrm{TiO}_{2} / \mathrm{Au} / \mathrm{TiO}_{2}$ multilayer thin films: novel metalbased transparent conductors for electrochromic devices," Thin Solid Films, vol. 518, no. 4, pp. 1225-1229, 2009.

[132] M.-S. Wong, S.-W. Hsu, K. K. Rao, and C. P. Kumar, "Influence of crystallinity and carbon content on visible light photocatalysis of carbon doped titania thin films," Journal of Molecular Catalysis A: Chemical, vol. 279, no. 1, pp. 20-26, 2008.

[133] T. Peng, D. Zhao, K. Dai, W. Shi, and K. Hirao, "Synthesis of titanium dioxide nanoparticles with mesoporous anatase wall and high photocatalytic activity," Journal of Physical Chemistry $B$, vol. 109, no. 11, pp. 4947-4952, 2005.

[134] J. P. Vicente, T. Gacoin, P. Barboux, J.-P. Boilot, M. Rondet, and L. Guéneau, "Photocatalytic decomposition of fatty stains by $\mathrm{TiO}_{2}$ thin films," International Journal of Photoenergy, vol. 5, no. 2, pp. 95-98, 2003.

[135] P. Kiri, G. Hyett, and R. Binions, "Solid state thermochromic materials," Advanced Materials Letters, vol. 1, no. 2, pp. 86-105, 2010.

[136] M. I. Zaki, G. A. H. Mekhemer, N. E. Fouad, T. C. Jagadale, and S. B. Ogale, "Surface texture and specific adsorption sites of solgel synthesized anatase $\mathrm{TiO}_{2}$ nanoparticles," Materials Research Bulletin, vol. 45, no. 10, pp. 1470-1475, 2010.

[137] A. S. Barnard and P. Zapol, "Predicting the energetics, phase stability, and morphology evolution of faceted and spherical anatase nanocrystals," Journal of Physical Chemistry B, vol. 108, no. 48, pp. 18435-18440, 2004.

[138] J. Zhu, J. Zhang, F. Chen, K. Iino, and M. Anpo, "High activity $\mathrm{TiO}_{2}$ photocatalysts prepared by a modified sol-gel method: characterization and their photocatalytic activity for the degradation of XRG and X-GL," Topics in Catalysis, vol. 35, no. 3-4, pp. 261-268, 2005.

[139] J. A. Navío, G. Colón, M. Macías, C. Real, and M. I. Litter, "Iron-doped titania semiconductor powders prepared by a solgel method. Part I: synthesis and characterization," Applied Catalysis A: General, vol. 177, no. 1, pp. 111-120, 1999.

[140] V. Panić, A. Dekanski, S. Milonjić, R. Atanasoski, and B. Nikolić, "The influence of the aging time of $\mathrm{RuO}_{2}$ and $\mathrm{TiO}_{2}$ sols on the electrochemical properties and behavior for the chlorine evolution reaction of activated titanium anodes obtained by the sol-gel procedure," Electrochimica Acta, vol. 46, no. 2-3, pp. 415421, 2000.

[141] J. Zarzycki, "Past and present of sol-gel science and technology," Journal of Sol-Gel Science and Technology, vol. 8, no. 1-3, pp. 1722, 1997.

[142] A. Ahmad, J. Thiel, and S. I. Shah, "Structural effects of niobium and silver doping on titanium dioxide nanoparticles," Journal of Physics: Conference Series, vol. 61, no. 1, pp. 11-15, 2007.

[143] K.-R. Zhu, M.-S. Zhang, J.-M. Hong, and Z. Yin, "Size effect on phase transition sequence of $\mathrm{TiO}_{2}$ nanocrystal," Materials Science and Engineering A, vol. 403, no. 1-2, pp. 87-93, 2005.

[144] T. Sugimoto, K. Okada, and H. Itoh, "Synthesis of uniform spindle-type titania particles by the gel-sol method," Journal of Colloid and Interface Science, vol. 193, no. 1, pp. 140-143, 1997.

[145] T. Sugimoto, X. Zhou, and A. Muramatsu, "Synthesis of uniform anatase $\mathrm{TiO}_{2}$ nanoparticles by gel-sol method: 1. Solution chemistry of $\mathrm{Ti}(\mathrm{OH})_{n}^{(4-n)+}$ complexes," Journal of Colloid and Interface Science, vol. 252, pp. 339-346, 2002.

[146] T. Sugimoto, X. Zhou, and A. Muramatsu, "Synthesis of uniform anatase $\mathrm{TiO}_{2}$ nanoparticles by gel-sol method. 4. Shape control," Journal of Colloid and Interface Science, vol. 259, no. 1, pp. 53-61, 2003. 
[147] T. Sugimoto, X. Zhou, and A. Muramatsu, "Synthesis of uniform anatase $\mathrm{TiO}_{2}$ nanoparticles by gel-sol method: 3. Formation process and size control," Journal of Colloid and Interface Science, vol. 259, no. 1, pp. 43-52, 2003.

[148] W. Chen and W. Gao, "Sol-enhanced electroplating of nanostructured $\mathrm{Ni}-\mathrm{TiO}_{2}$ composite coatings-the effects of sol concentration on the mechanical and corrosion properties," Electrochimica Acta, vol. 55, no. 22, pp. 6865-6871, 2010.

[149] Y. Lei, L. D. Zhang, and J. C. Fan, "Fabrication, characterization and Raman study of $\mathrm{TiO}_{2}$ nanowire arrays prepared by anodic oxidative hydrolysis of $\mathrm{TiCl}_{3}$," Chemical Physics Letters, vol. 338, no. 4-6, pp. 231-236, 2001.

[150] X.-S. Zhou, L.-J. Li, Y.-H. Lin, and C.-W. Nan, "Characterization and properties of anatase $\mathrm{TiO}_{2}$ film prepared via colloidal sol method under low temperature," Journal of Electroceramics, vol. 21, no. 1-4, pp. 795-797, 2008.

[151] J. Zhu, J. Ren, Y. Huo, Z. Bian, and H. Li, "Nanocrystalline $\mathrm{Fe} / \mathrm{TiO}_{2}$ visible photocatalyst with a mesoporous structure prepared via a nonhydrolytic sol-gel route," Journal of Physical Chemistry C, vol. 111, no. 51, pp. 18965-18969, 2007.

[152] G. Guo, J. K. Whitesell, and M. A. Fox, "Synthesis of $\mathrm{TiO}_{2}$ photocatalysts in supercritical $\mathrm{CO}_{2}$ via a non-hydrolytic route," Journal of Physical Chemistry B, vol. 109, no. 40, pp. 18781-18785, 2005.

[153] Y.-W. Jun, M. F. Casula, J.-H. Sim, S. Y. Kim, J. Cheon, and A. P. Alivisatos, "Surfactant-assisted elimination of a high energy facet as a means of controlling the shapes of $\mathrm{TiO}_{2}$ nanocrystals," Journal of the American Chemical Society, vol. 125, no. 51, pp. 15981-15985, 2003.

[154] T. J. Trentler, T. E. Denler, J. F. Bertone, A. Agrawal, and V. L. Colvin, "Synthesis of $\mathrm{TiO}_{2}$ nanocrystals by nonhydrolytic solution-based reactions," Journal of the American Chemical Society, vol. 121, no. 7, pp. 1613-1614, 1999.

[155] B. Koo, J. Park, Y. Kim, S.-H. Choi, Y.-E. Sung, and T. Hyeon, "Simultaneous phase- and size-controlled synthesis of $\mathrm{TiO}_{2}$ nanorods via non-hydrolytic sol-gel reaction of syringe pump delivered precursors," Journal of Physical Chemistry B, vol. 110, no. 48, pp. 24318-24323, 2006.

[156] A. López, D. Acosta, A. I. Martínez, and J. Santiago, "Nanostructured low crystallized titanium dioxide thin films with good photocatalytic activity," Powder Technology, vol. 202, no. 1-3, pp. 111-117, 2010.

[157] J. Liu, Y. Zhao, L. Shi et al., "Solvothermal synthesis of crystalline phase and shape controlled $\mathrm{Sn}^{4+}$-Doped $\mathrm{TiO}_{2}$ nanocrystals: Effects of reaction solvent," ACS Applied Materials and Interfaces, vol. 3, no. 4, pp. 1261-1268, 2011.

[158] J. Liao, L. Shi, S. Yuan, Y. Zhao, and J. Fang, "Solvothermal synthesis of $\mathrm{TiO}_{2}$ nanocrystal colloids from peroxotitanate complex solution and their photocatalytic activities," Journal of Physical Chemistry C, vol. 113, no. 43, pp. 18778-18783, 2009.

[159] W. Q. Fang, J. Z. Zhou, J. Liu et al., "Hierarchical structures of single-crystalline anatase $\mathrm{TiO} 2$ nanosheets dominated by 001 facets," Chemistry, vol. 17, no. 5, pp. 1423-1427, 2011.

[160] X. Wang, J. Zhuang, Q. Peng, and Y. Li, "A general strategy for nanocrystal synthesis," Nature, vol. 437, no. 7055, pp. 121-124, 2005.

[161] X.-L. Li, Q. Peng, J.-X. Yi, X. Wang, and Y. Li, "Near monodisperse $\mathrm{TiO}_{2}$ nanoparticles and nanorods," Chemistry-A European Journal, vol. 12, no. 8, pp. 2383-2391, 2006.

[162] J. Xu, J.-P. Ge, and Y.-D. Li, "Solvothermal synthesis of monodisperse PbSe nanocrystals," The Journal of Physical Chemistry B, vol. 110, no. 6, pp. 2497-2501, 2006.
[163] K. S. Yeung and Y. W. Lam, "A simple chemical vapour deposition method for depositing thin $\mathrm{TiO}_{2}$ films," Thin Solid Films, vol. 109, no. 2, pp. 169-178, 1983.

[164] H. Yoshitake, T. Sugihara, and T. Tatsumi, "Preparation of wormhole-like mesoporous $\mathrm{TiO}_{2}$ with an extremely large surface area and stabilization of its surface by chemical vapor deposition," Chemistry of Materials, vol. 14, no. 3, pp. 1023-1029, 2002.

[165] H. Nizard, M. L. Kosinova, N. I. Fainer, Y. M. Rumyantsev, B. M. Ayupov, and Y. V. Shubin, "Deposition of titanium dioxide from TTIP by plasma enhanced and remote plasma enhanced chemical vapor deposition," Surface and Coatings Technology, vol. 202, no. 17, pp. 4076-4085, 2008.

[166] Y. Guo, X.-W. Zhang, W.-H. Weng, and G.-R. Han, "Structure and properties of nitrogen-doped titanium dioxide thin films grown by atmospheric pressure chemical vapor deposition," Thin Solid Films, vol. 515, no. 18, pp. 7117-7121, 2007.

[167] P. G. Karlsson, J. H. Richter, M. P. Andersson et al., “ $\mathrm{TiO}_{2}$ chemical vapor deposition on $\mathrm{Si}(111)$ in ultrahigh vacuum: transition from interfacial phase to crystalline phase in the reaction limited regime," Surface Science, vol. 605, no. 13-14, pp. 11471156, 2011.

[168] W.-Y. Ahn, S. A. Sheeley, T. Rajh, and D. M. Cropek, "Photocatalytic reduction of 4-nitrophenol with arginine-modified titanium dioxide nanoparticles," Applied Catalysis B: Environmental, vol. 74, no. 1-2, pp. 103-110, 2007.

[169] B. Neppolian, H. Yamashita, Y. Okada, H. Nishijima, and M. Anpo, "Preparation of unique $\mathrm{TiO}_{2}$ nano-particle photocatalysts by a multi-gelation method for control of the physicochemical parameters and reactivity," Catalysis Letters, vol. 105, no. 1-2, pp. 111-117, 2005.

[170] H. Liu, W. Yang, Y. Ma et al., "Synthesis and characterization of titania prepared by using a photoassisted sol-gel method," Langmuir, vol. 19, no. 7, pp. 3001-3005, 2003.

[171] Y. Bessekhouad, D. Robert, and J. V. Weber, "Synthesis of photocatalytic $\mathrm{TiO}_{2}$ nanoparticles: optimization of the preparation conditions," Journal of Photochemistry and Photobiology A: Chemistry, vol. 157, no. 1, pp. 47-53, 2003.

[172] G. Tian, H. Fu, L. Jing, and C. Tian, "Synthesis and photocatalytic activity of stable nanocrystalline $\mathrm{TiO}_{2}$ with high crystallinity and large surface area," Journal of Hazardous Materials, vol. 161, no. 2-3, pp. 1122-1130, 2009.

[173] A. Daßler, A. Feltz, J. Jung, W. Ludwig, and E. Kaisersberger, "Characterization of rutile and anatase powders by thermal analysis," Journal of Thermal Analysis, vol. 33, no. 3, pp. 803-809, 1988.

[174] W. Fu, H. Yang, M. Li, M. Li, N. Yang, and G. Zou, "Anatase $\mathrm{TiO}_{2}$ nanolayer coating on cobalt ferrite nanoparticles for magnetic photocatalyst," Materials Letters, vol. 59, no. 27, pp. 3530-3534, 2005.

[175] N. Chitose, S. Ueta, S. Seino, and T. A. Yamamoto, "Radiolysis of aqueous phenol solutions with nanoparticles. 1. Phenol degradation and TOC removal in solutions containing $\mathrm{TiO}_{2}$ induced by UV, $\gamma$-ray and electron beams," Chemosphere, vol. 50, no. 8, pp. 1007-1013, 2003.

[176] X. Li, R. Xiong, and G. Wei, "S-N co-doped $\mathrm{TiO}_{2}$ photocatalysts with visible-light activity prepared by sol-gel method," Catalysis Letters, vol. 125, no. 1-2, pp. 104-109, 2008.

[177] K. Mori, K. Maki, S. Kawasaki, S. Yuan, and H. Yamashita, "Hydrothermal synthesis of $\mathrm{TiO}_{2}$ photocatalysts in the presence of $\mathrm{NH}_{4} \mathrm{~F}$ and their application for degradation of organic 
compounds," Chemical Engineering Science, vol. 63, no. 20, pp. 5066-5070, 2008.

[178] M.-C. Wang, H.-J. Lin, C.-H. Wang, and H.-C. Wu, "Effects of annealing temperature on the photocatalytic activity of $\mathrm{N}$ doped $\mathrm{TiO}_{2}$ thin films," Ceramics International, vol. 38 , no. 1 , pp. 195-200, 2012.

[179] D.-S. Bae, K.-S. Han, and J. H. Adair, "Synthesis of $\mathrm{Cu} / \mathrm{SiO}_{2}$ nanosize particles by a reverse micelle and sol-gel processing," Journal of Materials Science Letters, vol. 21, no. 1, pp. 53-54, 2002.

[180] S.-W. Wei, B. Peng, L.-Y. Chai, Y.-C. Liu, and Z.-Y. Li, "Preparation of doping titania antibacterial powder by ultrasonic spray pyrolysis," Transactions of Nonferrous Metals Society of China, vol. 18, no. 5, pp. 1145-1150, 2008.

[181] C.-C. Chan, C.-C. Chang, W.-C. Hsu, S.-K. Wang, and J. Lin, "Photocatalytic activities of Pd-loaded mesoporous $\mathrm{TiO}_{2}$ thin films," Chemical Engineering Journal, vol. 152, no. 2-3, pp. $492-$ 497, 2009.

[182] M. Hamadanian, A. Reisi-Vanani, and A. Majedi, "Sol-gel preparation and characterization of $\mathrm{Co} / \mathrm{TiO}_{2}$ nanoparticles: application to the degradation of methyl orange," Journal of the Iranian Chemical Society, vol. 7, no. 1, pp. S52-S58, 2010.

[183] S. Klosek and D. Raftery, "Visible light driven V-doped $\mathrm{TiO}_{2}$ photocatalyst and its photooxidation of ethanol," Journal of Physical Chemistry B, vol. 105, no. 14, pp. 2815-2819, 2002.

[184] G. N. Kryukova, G. A. Zenkovets, A. A. Shutilov et al., "Structural peculiarities of $\mathrm{TiO}_{2}$ and $\mathrm{Pt} / \mathrm{TiO}_{2}$ catalysts for the photocatalytic oxidation of aqueous solution of acid orange 7 dye upon ultraviolet light," Applied Catalysis B: Environmental, vol. 71, no. 3-4, pp. 169-176, 2007.

[185] R. Mechiakh, N. B. Sedrine, and R. Chtourou, "Sol-gel synthesis, characterization and optical properties of mercury-doped $\mathrm{TiO}_{2}$ thin films deposited on ITO glass substrates," Applied Surface Science, vol. 257, no. 21, pp. 9103-9109, 2011.

[186] D. Jing, Y. Zhang, and L. Guo, "Study on the synthesis of $\mathrm{Ni}$ doped mesoporous $\mathrm{TiO}_{2}$ and its photocatalytic activity for hydrogen evolution in aqueous methanol solution," Chemical Physics Letters, vol. 415, no. 1-3, pp. 74-78, 2005.

[187] J. Nair, P. Nair, F. Mizukami, Y. Oosawa, and T. Okubo, "Microstructure and phase transformation behavior of doped nanostructured titania," Materials Research Bulletin, vol. 34, no. 8, pp. 1275-1290, 1999.

[188] S. S. Samal, P. Jeyaraman, and V. Vishwakarma, "Sonochemical coating of $\mathrm{Ag}-\mathrm{TiO}_{2}$ nanoparticles on textile fabrics for stain repellency and self-cleaning-the Indian scenario: a review," Journal of Minerals and Materials Characterization and Engineering, vol. 9, no. 6, pp. 519-525, 2010.

[189] M. Takahashi, K. Mita, H. Toyuki, and M. Kume, "Pt-TiO 2 thin films on glass substrates as efficient photocatalysts," Journal of Materials Science, vol. 24, no. 1, pp. 243-246, 1989.

[190] A. Towata, Y. Uwamino, M. Sando, K. Iseda, and H. Taoda, "Synthesis of titania photocatalysts dispersed with nickel nanosized particles," Nanostructured Materials, vol. 10, no. 6, pp. 10331042, 1998.

[191] T. Umebayashi, T. Yamaki, H. Itoh, and K. Asai, "Analysis of electronic structures of $3 \mathrm{~d}$ transition metal-doped $\mathrm{TiO}_{2}$ based on band calculations," Journal of Physics and Chemistry of Solids, vol. 63, no. 10, pp. 1909-1920, 2002.

[192] N. Serpone, D. Lawless, J. Disdier, and J.-M. Herrmann, "Spectroscopic, photoconductivity, and photocatalytic studies of $\mathrm{TiO}_{2}$ colloids. Naked and with the lattice doped with $\mathrm{Cr}^{3+}, \mathrm{Fe}^{3+}$, and $\mathrm{V}^{5+}$ cations," Langmuir, vol. 10, no. 3, pp. 643-652, 1994.
[193] E. Stathatos, T. Petrova, and P. Lianos, "Study of the efficiency of visible-light photocatalytic degradation of basic blue adsorbed on pure and doped mesoporous titania films," Langmuir, vol. 17, no. 16, pp. 5025-5030, 2001.

[194] M. Stir, R. Nicula, and E. Burkel, "Pressure-temperature phase diagrams of pure and Ag-doped nanocrystalline $\mathrm{TiO}_{2}$ photocatalysts," Journal of the European Ceramic Society, vol. 26, no. 9, pp. 1547-1553, 2006.

[195] Y. Ao, J. Xu, D. Fu, and C. Yuan, "Preparation of Ag-doped mesoporous titania and its enhanced photocatalytic activity under UV light irradiation," Journal of Physics and Chemistry of Solids, vol. 69, no. 11, pp. 2660-2664, 2008.

[196] C. Burda, Y. Lou, X. Chen, A. C. S. Samia, J. Stout, and J. L. Gole, "Enhanced nitrogen doping in $\mathrm{TiO}_{2}$ nanoparticles," Nano Letters, vol. 3, no. 8, pp. 1049-1051, 2003.

[197] S. S. Srinivasan, J. Wade, E. K. Stefanakos, and Y. Goswami, "Synergistic effects of sulfation and co-doping on the visible light photocatalysis of $\mathrm{TiO}_{2}$," Journal of Alloys and Compounds, vol. 424, no. 1-2, pp. 322-326, 2006.

[198] L. Lin, W. Lin, Y. X. Zhu et al., "Uniform carbon-covered titania and its photocatalytic property," Journal of Molecular Catalysis A: Chemical, vol. 236, no. 1-2, pp. 46-53, 2005.

[199] Y. Ao, J. Xu, D. Fu, and C. Yuan, "Synthesis of C,N,S-tridoped mesoporous titania with enhanced visible light-induced photocatalytic activity," Microporous and Mesoporous Materials, vol. 122, no. 1-3, pp. 1-6, 2009.

[200] J.-A. He, R. Mosurkal, L. A. Samuelson, L. Li, and J. Kumar, "Dye-sensitized solar cell fabricated by electrostatic layer-bylayer assembly of amphoteric $\mathrm{TiO}_{2}$ nanoparticles," Langmuir, vol. 19, no. 6, pp. 2169-2174, 2003.

[201] M. Sorescu and T. Xu, "The effect of ball-milling on the thermal behavior of anatase-doped hematite ceramic system," Journal of Thermal Analysis and Calorimetry, vol. 103, no. 2, pp. 479-484, 2011.

[202] A. A. Ismail, I. A. Ibrahim, M. S. Ahmed, R. M. Mohamed, and H. El-Shall, "Sol-gel synthesis of titania-silica photocatalyst for cyanide photodegradation," Journal of Photochemistry and Photobiology A: Chemistry, vol. 163, no. 3, pp. 445-451, 2004.

[203] D. Beydoun, R. Amal, G. Low, and S. McEvoy, "Occurrence and prevention of photodissolution at the phase junction of magnetite and titanium dioxide," Journal of Molecular Catalysis A: Chemical, vol. 180, no. 1-2, pp. 193-200, 2002.

[204] J. C. Yu, J. Lin, and R. W. M. Kwok, "Enhanced photocatalytic activity of $\mathrm{Ti}_{1-\mathrm{x}} \mathrm{V}_{\mathrm{x}} \mathrm{O}_{2}$ solid solution on the degradation of acetone," Journal of Photochemistry and Photobiology A: Chemistry, vol. 111, no. 1-3, pp. 199-203, 1997.

[205] D. Han, Y. Li, and W. Jia, "Preparation and characterization of molecularly imprinted $\mathrm{SiO}_{2}-\mathrm{TiO}_{2}$ and photo-catalysis for 2, 4dichlorophenol," Advanced Materials Letters, vol. 1, no. 3, pp. 188-192, 2010.

[206] A. Ulgen and W. F. Hoelderich, "Conversion of glycerol to acrolein in the presence of $\mathrm{WO}_{3} / \mathrm{TiO}_{2}$ catalysts," Applied Catalysis A: General, vol. 400, no. 1-2, pp. 34-38, 2011.

[207] K. T. Ranjit, H. Cohen, I. Willner, S. Bossmann, and A. M. Braun, "Lanthanide oxide-doped titanium dioxide: effective photocatalysts for the degradation of organic pollutants," Journal of Materials Science, vol. 34, no. 21, pp. 5273-5280, 1999.

[208] L. Chen, X. Pang, G. Yu, and J. Zhang, "In-situ coating of MWNTs with sol-gel $\mathrm{TiO}_{2}$ nanoparticles," Advanced Materials Letters, vol. 1, no. 1, pp. 75-78, 2010. 
[209] L. H. Huang, C. Sun, and Y. L. Liu, "Pt/N-codoped $\mathrm{TiO}_{2}$ nanotubes and its photocatalytic activity under visible light," Applied Surface Science, vol. 253, no. 17, pp. 7029-7035, 2007.

[210] J. Matos, J. Laine, and J.-M. Herrmann, "Synergy effect in the photocatalytic degradation of phenol on a suspended mixture of titania and activated carbon," Applied Catalysis B: Environmental, vol. 18, no. 3-4, pp. 281-291, 1998.

[211] M. A. Nawi, A. H. Jawad, S. Sabar, and W. S. W. Ngah, "Immobilized bilayer $\mathrm{TiO}_{2}$ /chitosan system for the removal of phenol under irradiation by a 45 watt compact fluorescent lamp," Desalination, vol. 280, no. 1-3, pp. 288-296, 2011.

[212] B. Tryba, A. W. Morawski, and M. A. Inagaki, "A new route for preparation of $\mathrm{TiO}_{2}$-mounted activated carbon," Applied Catalysis B: Environmental, vol. 46, no. 1, pp. 203-208, 2003.

[213] T. Tsumura, N. Kojitani, H. Umemura, M. Toyoda, and M. Inagaki, "Composites between photoactive anatase-type $\mathrm{TiO}_{2}$ and adsorptive carbon," Applied Surface Science, vol. 196, no. 14, pp. 429-436, 2002.

[214] J. Yu, X. Zhao, and Q. Zhao, "Effect of film thickness on the grain size and photocatalytic activity of the sol-gel derived nanometer $\mathrm{TiO}_{2}$ thin films," Journal of Materials Science Letters, vol. 19, no. 12, pp. 1015-1017, 2000.

[215] W. Yuan, J. Ji, J. Fu, and J. Shen, "A facile method to construct hybrid multilayered films as a strong and multifunctional antibacterial coating," Journal of Biomedical Materials Research-Part B: Applied Biomaterials, vol. 85, no. 2, pp. 556$563,2008$.

[216] Y. Lai, H. Zhuang, K. Xie et al., "Fabrication of uniform $\mathrm{Ag} / \mathrm{TiO}_{2}$ nanotube array structures with enhanced photoelectrochemical performance," New Journal of Chemistry, vol. 34, no. 7, pp. 13351340, 2010.

[217] S. Li, I. N. Germanenko, and M. S. El-Shall, "Nanoparticles from the vapor phase: synthesis and characterization of $\mathrm{Si}, \mathrm{Ge}, \mathrm{MoO}_{3}$, and $\mathrm{WO}_{3}$ nanocrystals," Journal of Cluster Science, vol. 10, no. 4, pp. 533-547, 1999.

[218] J. Zhao, X. Wang, Y. Kang, X. Xu, and Y. Li, "Photoelectrochemical ativities of $\mathrm{W}$-doped titania nanotube arrays fabricated by anodization," IEEE Photonics Technology Letters, vol. 20, no. 14, pp. 1213-1215, 2008.

[219] M. Epifani, A. Helwig, J. Arbiol et al., “TiO2 thin films from titanium butoxide: synthesis, Pt addition, structural stability, microelectronic processing and gas-sensing properties," Sensors and Actuators B: Chemical, vol. 130, no. 2, pp. 599-608, 2008.

[220] Y. Li, X. Yu, and Q. Yang, "Fabrication of $\mathrm{TiO}_{2}$ nanotube thin films and their gas sensing properties," Journal of Sensors, vol. 2009, Article ID 402174, 19 pages, 2009.

[221] A. Serra, M. Re, M. Palmisano et al., "Assembly of hybrid silvertitania thin films for gas sensors," Sensors and Actuators B: Chemical, vol. 145, no. 2, pp. 794-799, 2010.

[222] M. H. Yaacob, A. Z. Sadek, K. Latham, K. Kalantar-Zadeh, and W. Wlodarski, "Optical $\mathrm{H}_{2}$ sensing performance of anodized nanoporous $\mathrm{TiO}_{2}$ thin films," Procedia Chemistry, vol. 1, pp. 951954, 2009.

[223] D. Chen and A. K. Ray, "Removal of toxic metal ions from wastewater by semiconductor photocatalysis," Chemical Engineering Science, vol. 56, no. 4, pp. 1561-1570, 2001.

[224] D. G. Shchukin, E. A. Ustinovich, D. V. Sviridov, and A. I. Kulak, "Titanium and iron oxide-based magnetic photocatalysts for oxidation of organic compounds and sulfur dioxide," High Energy Chemistry, vol. 38, no. 3, pp. 167-173, 2004.
[225] D.-E. Gu, B.-C. Yang, and Y.-D. Hu, "A novel method for preparing V-doped titanium dioxide thin film photocatalysts with high photocatalytic activity under visible light irradiation," Catalysis Letters, vol. 118, no. 3-4, pp. 254-259, 2007.

[226] X. Hou, X. Wu, and A. Liu, "Studies on photocatalytic activity of $\mathrm{Ag} / \mathrm{TiO}_{2}$ films," Frontiers of Chemistry in China, vol. 1, no. 4, pp. 402-407, 2006.

[227] B. Zhao and Y.-W. Chen, "Ag/TiO ${ }_{2}$ sol prepared by a sol-gel method and its photocatalytic activity," Journal of Physics and Chemistry of Solids, vol. 72, no. 11, pp. 1312-1318, 2011.

[228] M. C. Kao, H. Z. Chen, S. L. Young, C. Y. Kung, C. C. Lin, and Z. Y. Hong, "Microstructure and optical properties of tantalum modified $\mathrm{TiO}_{2}$ thin films prepared by the sol-gel process," Journal of Superconductivity and Novel Magnetism, vol. 23, no. 5, pp. 843-845, 2010.

[229] A. Bai, W. Liang, G. Zheng, and J. Xue, "Preparation and enhanced daylight-induced photo-catalytic activity of transparent C-doped $\mathrm{TiO}_{2}$ thin films," The Journal of Wuhan University of Technology-Material Science Edition, vol. 25, pp. 738-742, 2010.

[230] L. Ge, M. Xu, and H. Fang, "Synthesis and characterization of the $\mathrm{Pd} / \mathrm{InVO}_{4}-\mathrm{TiO}_{2}$ co-doped thin films with visible light photocatalytic activities," Applied Surface Science, vol. 253, no. 4, pp. 2257-2263, 2006.

[231] J. Yu, J. C. Yu, B. Cheng, and X. Zhao, "Photocatalytic activity and characterization of the sol-gel derived $\mathrm{Pb}$-doped $\mathrm{TiO}_{2}$ thin films," Journal of Sol-Gel Science and Technology, vol. 24, no. 1, pp. 39-48, 2002.

[232] N. S. Begum, H. M. F. Ahmed, and K. R. Gunashekar, "Effects of $\mathrm{Ni}$ doping on photocatalytic activity of $\mathrm{TiO}_{2}$ thin films prepared by liquid phase deposition technique," Bulletin of Materials Science, vol. 31, no. 5, pp. 747-751, 2008.

[233] F. Meng, X. Song, and Z. Sun, "Photocatalytic activity of $\mathrm{TiO}_{2}$ thin films deposited by RF magnetron sputtering," Vacuum, vol. 83, no. 9, pp. 1147-1151, 2009.

[234] C. Zhang, R. Chen, J. Zhou, J. Cheng, and Q. Xia, "Synthesis of $\mathrm{TiO}_{2}$ films on glass slides by the sol-gel method and their photocatalytic activity," Rare Metals, vol. 28, no. 4, pp. 378-384, 2009.

[235] Z. He, Z. Yu, H. Miao, G. Tan, and Y. Liu, "Preparation of $\mathrm{TiO}_{2}$ thin film by the LPD method on functionalized organic selfassembled monolayers," Science in China, Series E: Technological Sciences, vol. 52, no. 1, pp. 137-140, 2009.

[236] G. A. Battiston, R. Gerbasi, M. Porchia, and A. Marigo, "Influence of substrate on structural properties of $\mathrm{TiO}_{2}$ thin films obtained via MOCVD," Thin Solid Films, vol. 239, no. 2, pp. 186-191, 1994.

[237] F. Ren, K. He, Y. Ling, and J. Feng, "Novel fabrication of netlike and flake-like Fe doped $\mathrm{TiO}_{2}$ thin films," Applied Surface Science, vol. 257, no. 22, pp. 9621-9625, 2011.

[238] M. Zheng, Y. Shu, J. Sun, and T. Zhang, "Carbon-covered alumina: a superior support of noble metal-like catalysts for hydrazine decomposition," Catalysis Letters, vol. 121, no. 1-2, pp. 90-96, 2008.

[239] V. Shashikala, V. Siva Kumar, A. H. Padmasri et al., "Advantages of nano-silver-carbon covered alumina catalyst prepared by electro-chemical method for drinking water purification," Journal of Molecular Catalysis A: Chemical, vol. 268, no. 1-2, pp. 95-100, 2007.

[240] D. R. Uhlmann, G. Teowee, and J. Boulton, "The future of solgel science and technology," Journal of Sol-Gel Science and Technology, vol. 8, no. 1-3, pp. 1083-1091, 1997. 
[241] J.-X. Wang, L.-X. Wen, Z.-H. Wang, M. Wang, L. Shao, and J.F. Chen, "Facile synthesis of hollow silica nanotubes and their application as supports for immobilization of silver nanoparticles," Scripta Materialia, vol. 51, no. 11, pp. 1035-1039, 2004.

[242] T. I. Halkides, D. I. Kondarides, and X. E. Verykios, "Catalytic reduction of $\mathrm{NO}$ by $\mathrm{C}_{3} \mathrm{H}_{6}$ over $\mathrm{Rh} / \mathrm{TiO}_{2}$ catalysts effect of $\mathrm{W}^{6+}$ cation doping of $\mathrm{TiO}_{2}$ on morphological characteristics and catalytic performance," Applied Catalysis B: Environmental, vol. 41, no. 4, pp. 415-426, 2003.

[243] N. L. V. Carreño, I. T. S. Garcia, L. S. S. M. Carreño et al., "Synthesis of titania/carbon nanocomposites by polymeric precursor method," Journal of Physics and Chemistry of Solids, vol. 69, no. 8, pp. 1897-1904, 2008.

[244] D. Dumitriu, A. R. Bally, C. Ballif et al., "Photocatalytic degradation of phenol by $\mathrm{TiO}_{2}$ thin films prepared by sputtering," Applied Catalysis B: Environmental, vol. 25, no. 2-3, pp. 83-92, 2000.

[245] M. Vondrova, T. Klimczuk, V. L. Miller et al., "Supported superparamagnetic Pd/Co alloy nanoparticles prepared from a silica/cyanogel co-gel," Chemistry of Materials, vol. 17, no. 25, pp. 6216-6218, 2005.

[246] P. M. Boorman, K. Chong, R. A. Kydd, and J. M. Lewis, "A comparison of alumina, carbon, and carbon-covered alumina as supports for Ni-Mo-F additives: carbon deposition and model compound reaction studies," Journal of Catalysis, vol. 128, no. 2, pp. 537-550, 1991.

[247] J. P. R. Vissers, F. P. M. Mercx, S. M. A. M. Bouwens, V. H. J. de Beer, and R. Prins, "Carbon-covered alumina as a support for sulfide catalysts," Journal of Catalysis, vol. 114, no. 2, pp. 291-302, 1988.

[248] P. M. Boorman and K. Chong, "Preparation of carbon-covered alumina using fluorohydrocarbons. A new acidic support material," Applied Catalysis A, General, vol. 95, no. 2, pp. 197-210, 1993.

[249] L. Lin, W. Lin, Y. X. Zhu et al., "Uniformly carbon-covered alumina and its surface characteristics," Langmuir, vol. 21, no. 11, pp. 5040-5046, 2005.

[250] M. Błachnio, P. Staszczuk, G. Grodzicka, L. Lin, and Y. X. Zhu, "Adsorption and porosity properties of carbon-covered alumina surfaces," Journal of Thermal Analysis and Calorimetry, vol. 88, no. 2, pp. 601-606, 2007.

[251] P. M. Boorman, R. A. Kydd, T. S. Sorensen, K. Chong, J. M. Lewis, and W. S. Bell, "A comparison of alumina, carbon and carbon-covered alumina as supports for NiMoF additives: gas oil hydroprocessing studies," Fuel, vol. 71, no. 1, pp. 87-93, 1992.

[252] P. M. Boorman and K. Chong, "A comparative gas oil hydroprocessing study of alumina, carbon, and carbon-covered alumina supported nickel-molybdenum catalysts: effect of quinoline, thiophene, and vanadium spiking," Energy \& Fuels, vol. 6, no. 3, pp. 300-307, 1992.

[253] L. Lin, W. Lin, P. Wang, Y.-X. Zhu, B.-Y. Zhao, and Y.-C. Xie, "Uniform carbon-covered alumina synthesized by pyrolysis of sucrose $/ \gamma-\mathrm{Al}_{2} \mathrm{O}_{3}$," Acta Physico. Chimica Sinica, vol. 20, no. 10, pp. 1179-1181, 2004.

[254] L. F. Sharanda, Y. V. Plyuto, I. V. Babich et al., "Synthesis and characterisation of hybrid carbon-alumina support," Applied Surface Science, vol. 252, no. 24, pp. 8549-8556, 2006.

[255] P. Jana and V. Ganesan, "The production of a carbon-coated alumina foam," Carbon, vol. 49, no. 10, pp. 3292-3298, 2011.

[256] K. S. R. Rao, P. K. Rao, S. K. Masthan, L. Kaluschnaya, and V. B. Shur, "New type of carbon coated alumina supports for the preparation of highly ctive ruthenium catalysts for ammonia synthesis," Applied Catalysis, vol. 62, no. 1, pp. L19-L22, 1990.

[257] Y. Zhu, X. Pan, and Y. Xie, "Dispersion of sucrose on the surface of alumina," Acta Physico-Chimica Sinica, vol. 15, no. 9, pp. 830-833, 1999.

[258] S. K. Maity, L. Flores, J. Ancheyta, and H. Fukuyama, "Carbonmodified alumina and alumina-carbon-supported hydrotreating catalysts," Industrial and Engineering Chemistry Research, vol. 48, no. 3, pp. 1190-1195, 2009.

[259] D. B. Murphy, R. W. Carroll, and J. E. Klonowski, "Analysis of products of high-temperature pyrolysis of various hydrocarbons," Carbon, vol. 35, no. 12, pp. 1819-1823, 1997.

[260] C. Paek, A. V. McCormick, and P. W. Carr, "Preparation and evaluation of carbon coated alumina as a high surface area packing material for high performance liquid chromatography," Journal of Chromatography A, vol. 1217, no. 42, pp. 6475-6483, 2010.

[261] L. F. Sharanda, Y. V. Plyuto, I. V. Babich, Y. A. Babich, and J. A. Moulijn, "Preparation of carbon-coated alumina by pyrolysis of adsorbed acetylacetone," Mendeleev Communications, vol. 9, no. 3, pp. 95-96, 1999.

[262] S. K. Masthan, P. S. S. Prasad, K. S. R. Rao, and P. K. Rao, "Hysteresis during ammonia synthesis over promoted ruthenium catalysts supported on carbon-covered alumina," Journal of Molecular Catalysis, vol. 67, no. 2, pp. L1-L5, 1991.

[263] M. M. Mahlambi, A. K. Mishra, S. B. Mishra, R. W. Krause, B. B. Mamba, and A. M. Raichur, "Synthesis and characterization of carbon-covered alumina (CCA) supported $\mathrm{TiO}_{2}$ nanocatalysts with enhanced visible light photodegradation of Rhodamine B," Journal of Nanoparticle Research, vol. 14, article 790, 2012.

[264] J. Medina-Valtierra, J. García-Servín, C. Frausto-Reyes, and S. Calixto, "The photocatalytic application and regeneration of anatase thin films with embedded commercial $\mathrm{TiO}_{2}$ particles deposited on glass microrods," Applied Surface Science, vol. 252, no. 10, pp. 3600-3608, 2006.

[265] S.-Y. Lin, Y.-C. Chen, C.-M. Wang, and C.-C. Liu, "Effect of heat treatment on electrochromic properties of $\mathrm{TiO}_{2}$ thin films," Journal of Solid State Electrochemistry, vol. 12, no. 11, pp. 14811486, 2008.

[266] D. J. Kim, D. S. Kim, S. Cho, S. W. Kim, S. H. Lee, and J. C. Kim, "Measurement of thermal conductivity of $\mathrm{TiO}_{2}$ thin films using $3 \omega$ method," International Journal of Thermophysics, vol. 25, no. 1, pp. 281-289, 2004.

[267] B. R. Sankapal, M. C. Lux-Steiner, and A. Ennaoui, "Synthesis and characterization of anatase- $\mathrm{TiO}_{2}$ thin films," Applied Surface Science, vol. 239, no. 2, pp. 165-170, 2005.

[268] C. Sarantopoulos, A. N. Gleizes, and F. Maury, "Chemical vapor deposition and characterization of nitrogen doped $\mathrm{TiO}_{2}$ thin films on glass substrates," Thin Solid Films, vol. 518, no. 4, pp. 1299-1303, 2009.

[269] L. Sedláková, M. Horáková, P. Hájková, A. Kolouch, J. Karásek, and P. Špatenka, "Photocatalytic properties of titanium oxidebased films deposited by PECVD," Journal of Superhard Materials, vol. 29, no. 3, pp. 162-165, 2007.

[270] C. R. Kleijn, R. Dorsman, K. J. Kuijlaars, M. Okkerse, and H. van Santen, "Multi-scale modeling of chemical vapor deposition processes for thin film technology," Journal of Crystal Growth, vol. 303, no. 1, pp. 362-380, 2007.

[271] H. Y. Ha, S. W. Nam, T. H. Lim, I.-H. Oh, and S.-A. Hong, "Properties of the $\mathrm{TiO}_{2}$ membranes prepared by CVD of titanium tetraisopropoxide," Journal of Membrane Science, vol. 111, no. 1, pp. 81-92, 1996. 
[272] V. G. Bessergenev, I. V. Khmelinskii, R. J. F. Pereira, V. V. Krisuk, A. E. Turgambaeva, and I. K. Igumenov, "Preparation of $\mathrm{TiO}_{2}$ films by CVD method and its electrical, structural and optical properties," Vacuum, vol. 64, no. 3-4, pp. 275-279, 2002.

[273] K. Kamata, K. Maruyama, S. Amano, and H. Fukazawa, "Rapid formation of $\mathrm{TiO}_{2}$ films by a conventional CVD method," Journal of Materials Science Letters, vol. 9, no. 3, pp. 316-319, 1990.

[274] N. S. Begum, H. M. Farveez Ahmed, and O. M. Hussain, "Characterization and photocatalytic activity of boron-doped $\mathrm{TiO}_{2}$ thin films prepared by liquid phase deposition technique," Bulletin of Materials Science, vol. 31, no. 5, pp. 741-745, 2008.

[275] S.-Q. Sun, B. Sun, W. Zhang, and D. Wang, "Preparation and antibacterial activity of $\mathrm{Ag}-\mathrm{TiO}_{2}$ composite film by liquid phase deposition (LPD) method," Bulletin of Materials Science, vol. 31, no. 1, pp. 61-66, 2008.

[276] M. N. Ghazzal, N. Barthen, and N. Chaoui, "Photodegradation kinetics of stearic acid on UV-irradiated titania thin film separately followed by optical microscopy and Fourier transform infrared spectroscopy," Applied Catalysis B: Environmental, vol. 103, no. 1-2, pp. 85-90, 2011.

[277] B. J. Brasjen, A. W. V. Cuijk, and A. A. Darhuber, "Dip-coating of chemically patterned surfaces," Chemical Engineering and Processing, vol. 50, no. 5-6, pp. 565-568, 2011.

[278] N. Negishi, K. Takeuchi, and T. Ibusuki, "Surface structure of the $\mathrm{TiO}_{2}$ thin film photocatalyst," Journal of Materials Science, vol. 33, no. 24, pp. 5789-5794, 1998.

[279] R. Bayón, G. San Vicente, C. Maffiotte, and Á. Morales, “Characterization of copper-manganese-oxide thin films deposited by dip-coating," Solar Energy Materials and Solar Cells, vol. 92, no. 10, pp. 1211-1216, 2008.

[280] Z. Wang, K. Sun, S. Shen, N. Zhang, J. Qiao, and P. Xu, "Preparation of YSZ thin films for intermediate temperature solid oxide fuel cells by dip-coating method," Journal of Membrane Science, vol. 320, no. 1-2, pp. 500-504, 2008.

[281] A. Nakaruk and C. C. Sorrell, "Conceptual model for spray pyrolysis mechanism: fabrication and annealing of titania thin films," Journal of Coatings Technology Research, vol. 7, no. 5, pp. 665-676, 2010.

[282] M. Okuya, K. Nakade, and S. Kaneko, "Porous $\mathrm{TiO}_{2}$ thin films synthesized by a spray pyrolysis deposition (SPD) technique and their application to dye-sensitized solar cells," Solar Energy Materials and Solar Cells, vol. 70, no. 4, pp. 425-435, 2002.

[283] M. Okuya, K. Shiozaki, N. Horikawa et al., "Porous $\mathrm{TiO}_{2}$ thin films prepared by spray pyrolysis deposition (SPD) technique and their application to UV sensors," Solid State Ionics, vol. 172, no. 1-4, pp. 527-531, 2004.

[284] B.-H. Kim, J.-Y. Lee, Y.-H. Choa, M. Higuchi, and N. Mizutani, "Preparation of $\mathrm{TiO}_{2}$ thin film by liquid sprayed mist CVD method," Materials Science and Engineering: B, vol. 107, no. 3, pp. 289-294, 2004.

[285] D. R. Acosta, A. I. Martinez, A. A. Lopez, and C. R. Magana, "Titanium dioxide thin films: the effect of the preparation method in their photocatalytic properties," Microscopy, vol. 228, pp. 183-188, 2005.

[286] L. Castañeda, A. Maldonado, and M. de la L. Olvera, "Sensing properties of chemically sprayed $\mathrm{TiO} 2$ thin films using $\mathrm{Ni}$, Ir, and Rh as catalysts," Sensors and Actuators B: Chemical, vol. 133, no. 2, pp. 687-693, 2008.

[287] R. S. Sonawane and M. K. Dongare, "Sol-gel synthesis of $\mathrm{Au} / \mathrm{TiO}_{2}$ thin films for photocatalytic degradation of phenol in sunlight," Journal of Molecular Catalysis A: Chemical, vol. 243, no. 1, pp. 68-76, 2006.

[288] L. Sun, T. An, S. Wan et al., "Effect of synthesis conditions on photocatalytic activities of nanoparticulate $\mathrm{TiO}_{2}$ thin films," Separation and Purification Technology, vol. 68, no. 1, pp. 83-89, 2009.

[289] M. Vishwas, S. K. Sharma, K. N. Rao, S. Mohan, K. V. A. Gowda, and R. P. S. Chakradhar, "Influence of surfactant and annealing temperature on optical properties of sol-gel derived nanocrystalline $\mathrm{TiO}_{2}$ thin films," Spectrochimica Acta Part A: Molecular and Biomolecular Spectroscopy, vol. 75, no. 3, pp. 1073-1077, 2010.

[290] R. Zanoni, G. Righini, A. Montenero et al., "XPS analysis of sol-gel processed doped and undoped $\mathrm{TiO}_{2}$ films for sensors," Surface and Interface Analysis, vol. 22, no. 1, pp. 376-379, 1994.

[291] Y. Guo, W. Geng, and J. Sun, "Layer-by-layer deposition of polyelectrolyte-polyelectrolyte complexes for multilayer film fabrication," Langmuir, vol. 25, no. 2, pp. 1004-1010, 2009.

[292] G. Decher, J. D. Hong, and J. Schmitt, "Buildup of ultrathin multilayer films by a self-assembly process: III. Consecutively alternating adsorption of anionic and cationic polyelectrolytes on charged surfaces," Thin Solid Films, vol. 210-211, no. 2, pp. 831-835, 1992.

[293] T.-H. Kim and B.-H. Sohn, "Photocatalytic thin films containing $\mathrm{TiO}_{2}$ nanoparticles by the layer-by-layer self-assembling method," Applied Surface Science, vol. 201, no. 1-4, pp. 109-114, 2002.

[294] H. Ai, S. A. Jones, and Y. M. Lvov, "Biomedical applications of electrostatic layer-by-layer nano-assembly of polymers, enzymes, and nanoparticles," Cell Biochemistry and Biophysics, vol. 39, no. 1, pp. 23-43, 2003.

[295] J. B. Schlenoff and S. T. Dubas, "Mechanism of polyelectrolyte multilayer growth: charge overcompensation and distribution," Macromolecules, vol. 34, no. 3, pp. 592-598, 2001.

[296] T. Sasaki, Y. Ebina, T. Tanaka, M. Harada, M. Watanabe, and G. Decher, "Layer-by-layer assembly of titania nanosheet/ polycation composite films," Chemistry of Materials, vol. 13, no. 12, pp. 4661-4667, 2001.

[297] B. Schoeler, G. Kumaraswamy, and F. Caruso, "Investigation of the influence of polyelectrolyte charge density on the growth of multilayer thin films prepared by the layer-by-layer technique," Macromolecules, vol. 35, no. 3, pp. 889-897, 2002.

[298] M. M. De Villiers, D. P. Otto, S. J. Strydom, and Y. M. Lvov, "Introduction to nanocoatings produced by layer-by-layer (LbL) self-assembly," Advanced Drug Delivery Reviews, vol. 63, no. 9, pp. 701-715, 2011.

[299] G. Decher, B. Lehr, K. Lowack, Y. Lvov, and J. Schmitt, "New nanocomposite films for biosensors: layer-by-layer adsorbed films of polyelectrolytes, proteins or DNA," Biosensors and Bioelectronics, vol. 9, no. 9-10, pp. 677-684, 1994.

[300] N. I. Kovtyukhova, B. R. Martin, J. K. N. Mbindyo, T. E. Mallouk, M. Cabassi, and T. S. Mayer, "Layer-by-layer self-assembly strategy for template synthesis of nanoscale devices," Materials Science and Engineering C, vol. 19, no. 1-2, pp. 255-262, 2002.

[301] Y. Liu, Y. Wang, and R. O. Claus, "Layer-by-layer ionic selfassembly of $\mathrm{Au}$ colloids into multilayer thin-films with bulk metal conductivity," Chemical Physics Letters, vol. 298, no. 4-6, pp. 315-319, 1998.

[302] K. Ariga, J. P. Hill, and Q. Ji, "Layer-by-layer assembly as a versatile bottom-up nanofabrication technique for exploratory research and realistic application," Physical Chemistry Chemical Physics, vol. 9, no. 19, pp. 2319-2340, 2007. 
[303] A. A. Antipov, G. B. Sukhorukov, E. Donath, and H. Möhwald, "Sustained release properties of polyelectrolyte multilayer capsules," Journal of Physical Chemistry B, vol. 105, no. 12, pp. 22812284, 2001.

[304] F. Wang, J. Feng, and C. Gao, "Manipulating the properties of coacervated polyelectrolyte microcapsules by chemical crosslinking," Colloid and Polymer Science, vol. 286, no. 8-9, pp. 951957, 2008

[305] S. Anandhakumar and A. M. Raichur, "A facile route to synthesize silver nanoparticles in polyelectrolyte capsules," Colloids and Surfaces B: Biointerfaces, vol. 84, no. 2, pp. 379-383, 2011.

[306] S. Anandhakumar, M. Debapriya, V. Nagaraja, and A. M. Raichur, "Polyelectrolyte microcapsules for sustained delivery of water-soluble drugs," Materials Science and Engineering C, vol. 31, no. 2, pp. 342-349, 2011.

[307] S. Anandhakumar, V. Nagaraja, and A. M. Raichur, "Reversible polyelectrolyte capsules as carriers for protein delivery," Colloids and Surfaces B: Biointerfaces, vol. 78, no. 2, pp. 266-274, 2010.

[308] N. A. Kotov, I. Dekany, and J. H. Fendler, "Layer-by-layer selfassembly of polyelectrolyte-semiconductor nanoparticle composite films," Journal of Physical Chemistry, vol. 99, no. 35, pp. 13065-13069, 1995.

[309] A. Mollahosseini, A. Rahimpour, M. Jahamshahi, M. Peyravi, and M. Khavarpour, "The effect of silver nanoparticle size on performance and antibacteriality of polysulfone ultrafiltration membrane," Desalination, vol. 306, pp. 41-50, 2012.

[310] D. Y. Koseoglu-Imer, B. Kose, M. Altinbas, and I. Koyuncu, "The production of polysulfone (PS) membrane with silver nanoparticles (AgNP): physical properties, filtration performances, and biofouling resistances of membranes," Journal of Membrane Science, vol. 428, pp. 620-628, 2013.

[311] Z. Fan, Z. Wang, N. Sun, J. Wang, and S. Wang, "Performance improvement of polysulfone ultrafiltration membrane by blending with polyaniline nanofibers," Journal of Membrane Science, vol. 320 , no. 1-2, pp. 363-371, 2008.

[312] E. Saljoughi and S. M. Mousavi, "Preparation and characterization of novel polysulfone nanofiltration membranes for removal of cadmium from contaminated water," Separation and Purification Technology, vol. 90, pp. 22-30, 2012.

[313] R. J. Wang, Y. Chen, H. M. Xie, G. Q. Kai, Z. Y. Wang, and J. Pan, "Polysaccharide separation mechanism in polysulfone- $\mathrm{Fe}_{3} \mathrm{O}_{4}$ magnetic composite membranes," Chinese Science Bulletin, vol. 56, no. 18, pp. 1951-1956, 2011.

[314] N. A. A. Hamid, A. F. Ismail, T. Matsuura et al., "Morphological and separation performance study of polysulfone/titanium dioxide $\left(\mathrm{PSF} / \mathrm{TiO}_{2}\right)$ ultrafiltration membranes for humic acid removal," Desalination, vol. 273, no. 1, pp. 85-92, 2011.

[315] N. Y. Abu-Thabit, S. A. Ali, and S. M. J. Zaidi, "New highly phosphonated polysulfone membranes for PEM fuel cells," Journal of Membrane Science, vol. 360, no. 1-2, pp. 26-33, 2010.

[316] S. Ramaswamy, C. Gopalakrishnan, N. S. Kumar, A. Littleflower, and M. Ponnavaikko, "Fabrication of Ni nanodots templated by nanoporous polysulfone membrane: structural and magnetic properties," Applied Physics A: Materials Science and Processing, vol. 98, no. 3, pp. 481-485, 2010.

[317] Y. Devrim, S. Erkan, N. Baç, and I. Eroğlu, "Preparation and characterization of sulfonated polysulfone/titanium dioxide composite membranes for proton exchange membrane fuel cells," International Journal of Hydrogen Energy, vol. 34, no. 8, pp. 3467-3475, 2009.

[318] Y. Yang, H. Zhang, P. Wang, Q. Zheng, and J. Li, "The influence of nano-sized $\mathrm{TiO}_{2}$ fillers on the morphologies and properties of PSF UF membrane," Journal of Membrane Science, vol. 288, no. 1-2, pp. 231-238, 2007.

[319] M. Padaki, A. M. Isloor, A. F. Ismail, and M. S. Abdullah, "Synthesis, characterization and desalination study of novel PSAB and mPSAB blend membranes with Polysulfone (PSf)," Desalination, vol. 295, pp. 35-42, 2012.

[320] N. Ghaemi, S. S. Madaeni, A. Alizadeh et al., "Fabrication and modification of polysulfone nanofiltration membrane using organic acids: morphology, characterization and performance in removal of xenobiotics," Separation and Purification Technology, vol. 96, pp. 214-228, 2012.

[321] S. Rajesh, S. Senthilkumar, A. Jayalakshmi, M. T. Nirmala, A. F. Ismail, and D. Mohan, "Preparation and performance evaluation of poly (amide-imide) and $\mathrm{TiO}_{2}$ nanoparticles impregnated polysulfone nanofiltration membranes in the removal of humic substances," Colloids and Surfaces A: Physicochemical and Engineering Aspects, vol. 418, pp. 92-104, 2013.

[322] M. J. Eckelman, M. S. Mauter, J. A. Isaacs, and M. Elimelech, "New perspectives on nanomaterial aquatic ecotoxicity: production impacts exceed direct exposure impacts for carbon nanotoubes," Environmental Science and Technology, vol. 46, no. 5, pp. 2902-2910, 2012.

[323] A. Tiraferri, N. Y. Yip, W. A. Phillip, J. D. Schiffman, and M. Elimelech, "Relating performance of thin-film composite forward osmosis membranes to support layer formation and structure," Journal of Membrane Science, vol. 367, no. 1-2, pp. 340-352, 2011.

[324] S. Liang, Y. Kang, A. Tiraferri, E. P. Giannelis, X. Huang, and M. Elimelech, "Highly hydrophilic polyvinylidene fluoride (PVDF) ultrafiltration membranes via postfabrication grafting of surface-tailored silica nanoparticles," ACS Applied Materials and Interfaces, vol. 5, no. 14, pp. 6694-6703, 2013.

[325] M. S. Mauter, Y. Wang, K. C. Okemgbo, C. O. Osuji, E. P. Giannelis, and M. Elimelech, "Antifouling ultrafiltration membranes via post-fabrication grafting of biocidal nanomaterials," ACS Applied Materials and Interfaces, vol. 3, no. 8, pp. 2861-2868, 2011. 

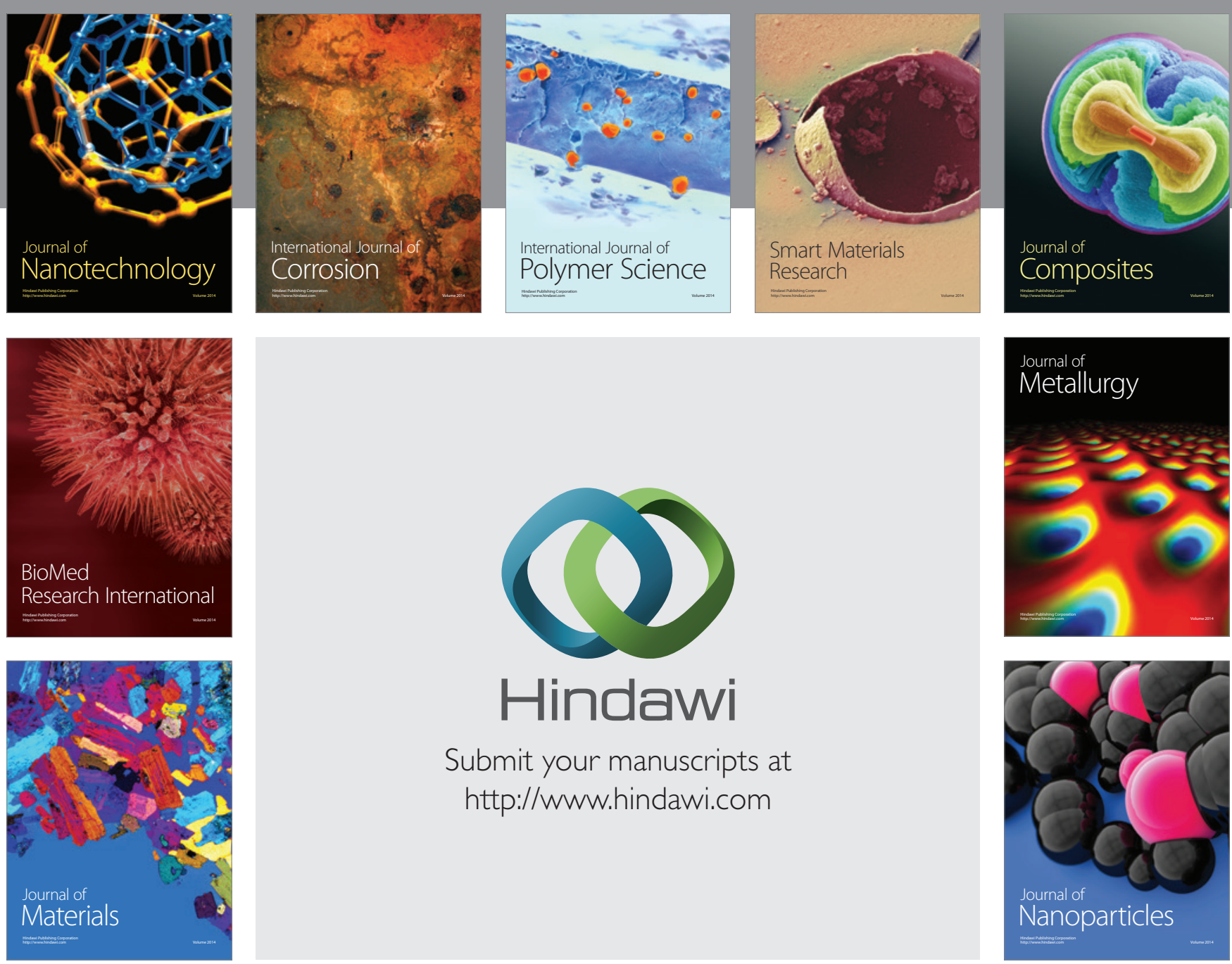

Submit your manuscripts at http://www.hindawi.com
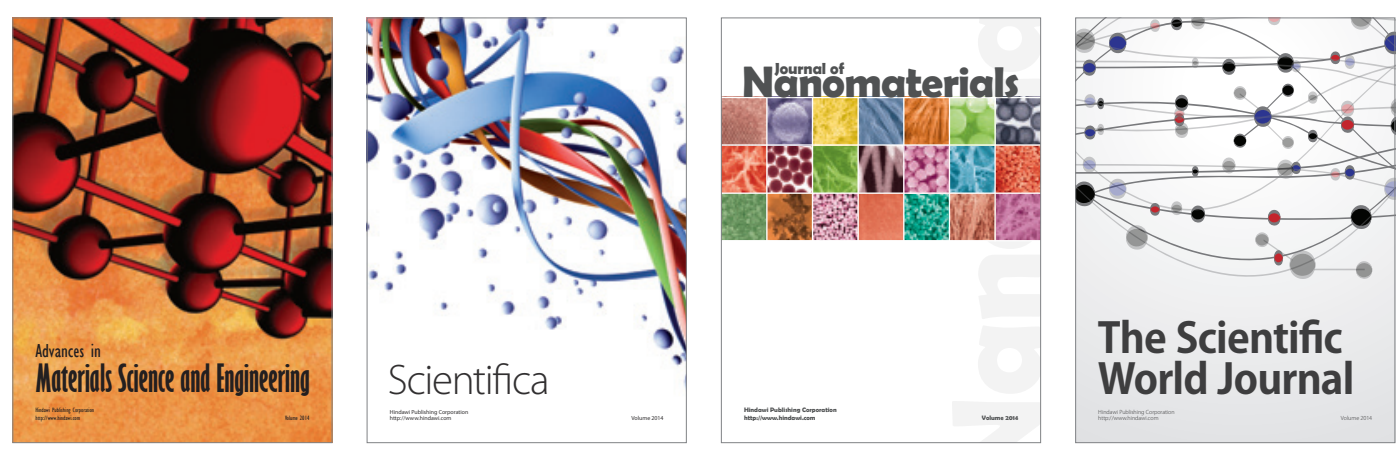

\section{The Scientific World Journal}
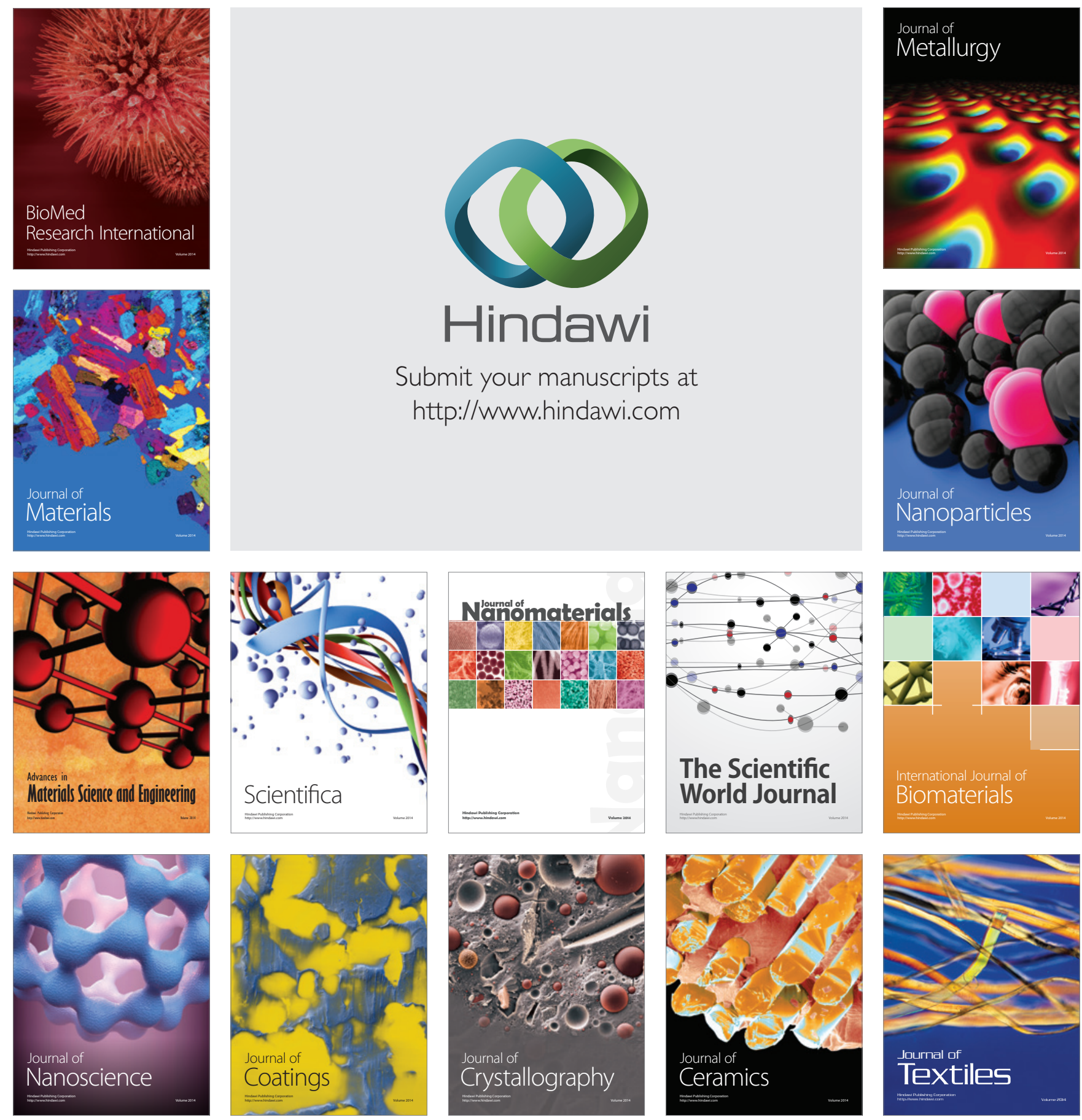